\title{
4-exo-dig Cyclocarbopalladation, discovery and application in the synthesis of complex polycyclic molecules
}

\author{
Gaëlle Blond and Jean Suffert \\ Université de Strasbourg, CNRS, LIT UMR 7200, F-67000 Strasbourg, France \\ Corresponding authors e-mail: jean.suffert@unistra.fr, gaelle.blond@unistra.fr
}

\section{Preface}

The 4-exo-dig cyclocarbopalladations has been efficiently used to produce molecular complexity in a straightforward manner. Strained 1,2-cyclobutanediols are rapidly obtained, usually under microwave irradiation, in high yields. In many cases, the cyclocarbopalladation cascade reaction is associated with a 6 or $8 \pi$ electrocyclic reactions. Polycyclic skeletons of unnatural or natural products can be prepared in few steps from simple starting material. Very strained aromatic polycycles, taxanes framework, cyclooctatrienes, cyclooctatetraenes, fenestranes and fenestrenes have been obtained following in all cases as a first step a 4-exo-dig cyclocarbopalladation reaction.

\section{Introduction}

The potential of palladium-catalyzed process in organic synthesis has not yet been fully explored. For more than 25 years the investigation of new methodologies for the preparation of complex molecules has been extensively pursued for the development of short, highly efficient, atom- and step-economic pathways. For this purpose, catalytic systems using noble metals are tools of choice and many examples are now available in this context using palladium, rhodium, ruthenium, platinium and others from the transition element class. The usefulness of strategies based on palladium cyclization cascades has been demonstrated in the past leading to polycyclic frameworks in regio- and stereoselective manner. ${ }^{1}$ The formation of new polycyclic systems is an important challenge in organic synthesis and cyclocarbopalladation is often the key step for the preparation of rings of different size.

One of the most efficient cyclization processes that have been used in the literature concerns the intramolecular attack of an organopalladium activated species on a tethered triple bond. Most of the time, an initial 5-exo-dig, 6-exo-dig, or 7-exo-dig cyclocarbopalladation is involved followed by a terminating cross-coupling reaction with various organometallic reagents. ${ }^{2}$ Significant studies for almost 20 years in our laboratory were and are directed at the development of cyclocarbopalladation to design and elaborate complex polycyclic molecules from simple starting material. In this context, we report herein our investigations in the study of cascade reactions involving 4-exo-dig cyclocarbopalladations, its discovery and its power in the synthesis of targets that are difficult to obtain by more classical ways. 


\section{Discovery of the 4-exo-dig cyclocarbopalladation in the first synthesis of cyclobutenediol and application to the synthesis of strained polycyclic compounds.}

\subsection{The 4-exo-dig / $6 \pi$ electrocyclization}

The power of the intramolecular cyclization in order to prepare cyclic and polycyclic scaffolds is well documented in the literature for decades and is often use in the total synthesis of natural or unnatural compounds. ${ }^{3}$ The formation of five, six or larger rings has been reported using classical methods, cyclization of charged atoms, radical cyclization and more recently using noble metal catalyzed reactions. In this context palladium is a metal of choice for the synthesis of polycyclic derivatives. Usually the processes using this metal are extremely efficient and deliver easily five or six membered ring structures through a 5-exo, 6-exo trig or dig cyclization following the Baldwin rules. The reaction involved in this type of cyclization is a syn-Heck type addition on a double or triple bond.

The cyclocarbopalladation process was described for the first time in 1988 by Grigg ${ }^{4}$ shortly followed by Negishi. ${ }^{5}$ This reaction afforded stereodefined exocyclic alkenes. 5-, 6-, or 7-exodig cyclocarbopalladations have been performed with success. The reaction can be ended by a terminating cross coupling reaction either with a hydride source, an alkene, $\mathrm{CO}$, or various organometallic reagents (aluminum, zirconium, boron, zinc, or tin derivatives) (Scheme 1).

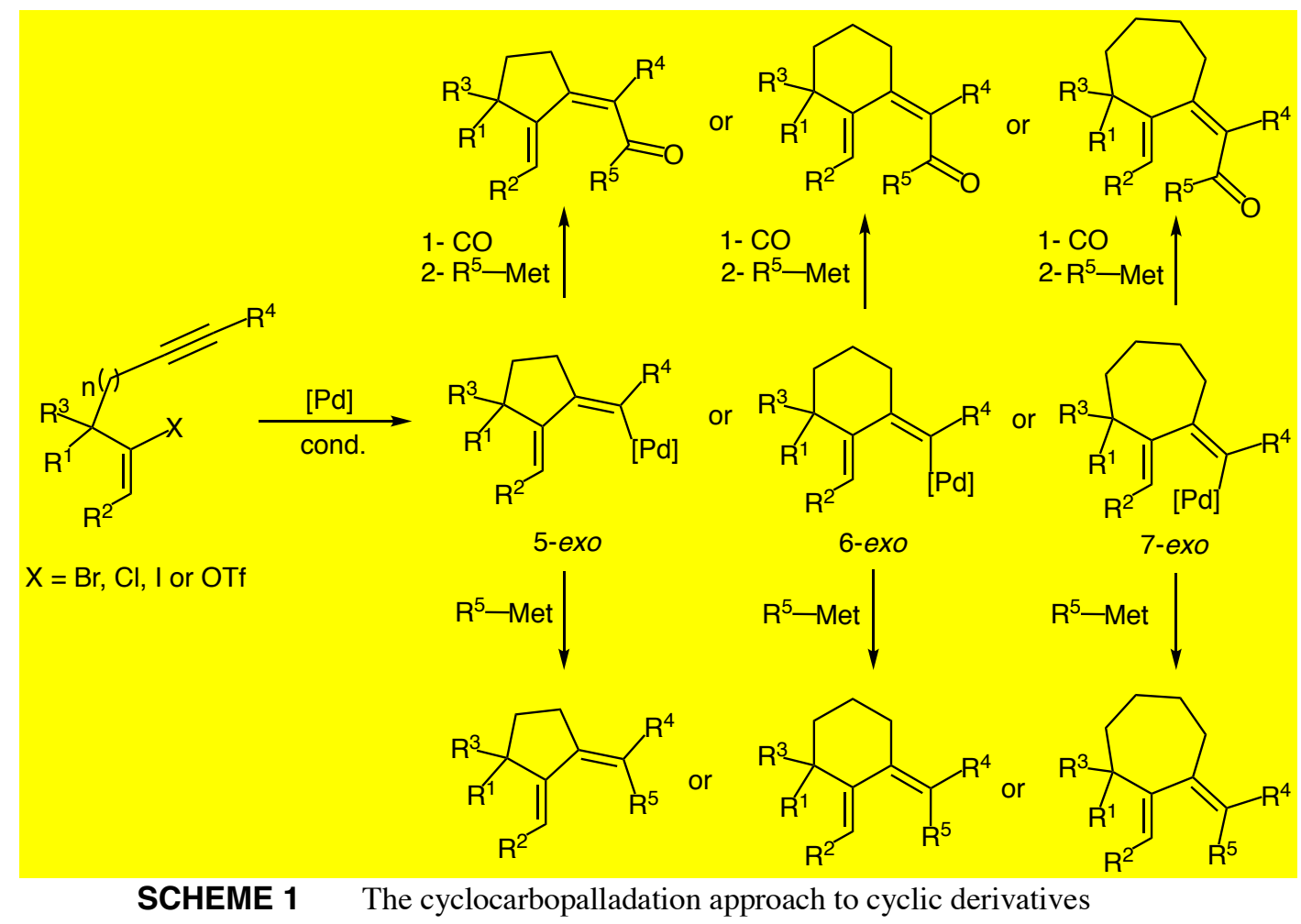

In the beginning of the 2000 we were particularly interested in the study of a new type of carbopalladation reactions following an unlikely 4-exo-dig reaction that is not supported by the classical Baldwin rules (Scheme 2). But in this case the use of palladium in this approach could potentially force the process to occur. 


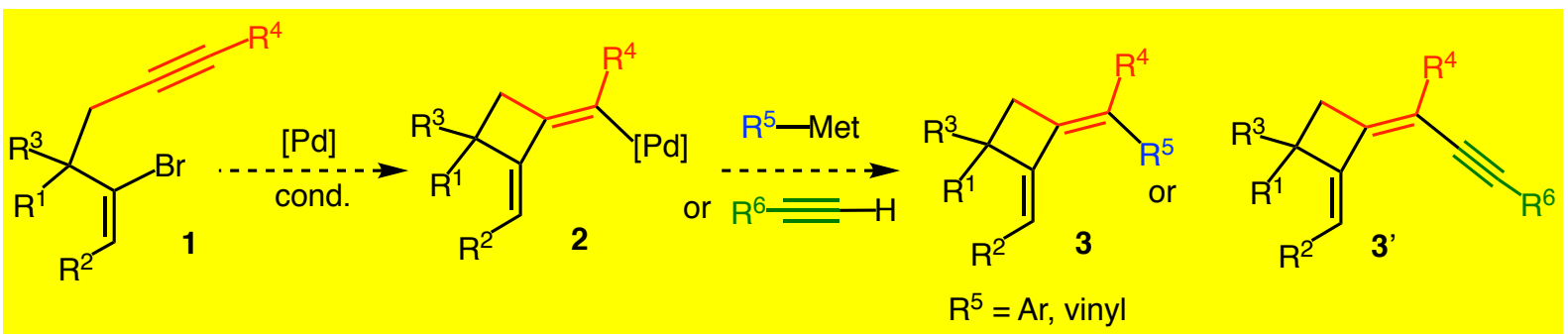

SCHEME 2 The 4-exo-dig cyclocarbopalladation

The approach of the molecule $\mathbf{3}$ or $\mathbf{3}$ ' was based on the simple idea that the vinylbromide $\mathbf{1}$ bearing a properly positioned triple bond, should smoothly cyclized under palladium catalysis through a 4-exo-dig cyclocarbopalladation to give the palladium derivative 2 . The former should react with an organometallic specie or a terminal alkyne to eventually give a substituted cyclobutane $\mathbf{3}$ or $\mathbf{3}$ ' bearing two exocyclic double bonds. A very important fact can be point out, the two double bonds are conjugated that must be crucial for further reactivities.

This process has never been studied in the past and should give useful compounds that can be transformed or decorated in further reactions. Our goal was first to design a convenient molecule that can efficiently undergo the 4-exo-dig cyclocarbopalladation avoiding the possibility of a direct cross coupling reaction. Our initial idea was to force the side chain bearing the reactive triple bond to be located in face of the palladium atom inserted into the C-Br bond. In this manner the palladium was very close to the triple bond and thus is perfectly settled to form a new carbon-carbon bond leading to a four unsaturated membered ring structure. In this direction, we decided to start with the unsaturated bromoketone 5 that is easily prepared in large scale from enone $\mathbf{4 a} / \mathbf{4 b}$. Addition of a properly doubly protected propargylic lithium derivative gave a mixture of anti and syn-diol $\mathbf{6 a / 6} \mathbf{b}$ and $\mathbf{7 a / 7 \mathbf { b }}$ in a ratio average around 70/30. These two diastereomers can be easily separated by chromatography after treatment of the crude by $p$ $\mathrm{TsOH}$ in $\mathrm{MeOH}$ to remove the protecting group on the propargylic alcohol (Scheme 3).

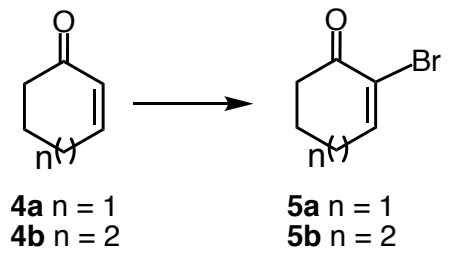

$4 a n=1$
$4 b n=2$

$5 \mathrm{~b} n=2$
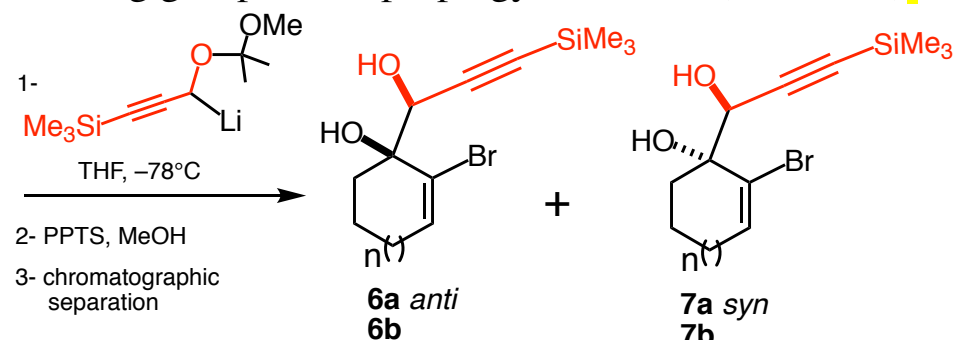

7 a syn

$7 \mathrm{~b}$

SCHEME 3 The synthesis of anti- and syn-diols

With $\mathbf{6 a}$ in hand, we though that the possible formation of a hydrogen bond between the proximal $\mathrm{OH}$ should favor a favorable conformation of the molecule during the insertion of the palladium on the $\mathrm{C}-\mathrm{Br}$ bond and it subsequent insertion on the proximal triple bond through a 4-exo-dig cyclocarbopalladtion. In this direction, 6a was treated with $\operatorname{Pd}\left(\mathrm{PPh}_{3}\right)_{4}$ and tributhylvinyl stannane 8 in benzene at $90^{\circ} \mathrm{C}$ for $6 \mathrm{~h}$. Despite the consumption of all starting material, to our surprise, no trace of the expected bicyclic product 9 was observed under these conditions but a different compound was the only product isolated. After extensive NMR experiments, the structure of the final product 10 was elucidated (Scheme 4). During this process, a tricyclic compound was formed. After the cross coupling reaction between the palladium intermediate and the vinylstannane a spontaneous $6 \pi$-electrocyclization of the formed triene occurred at $90{ }^{\circ} \mathrm{C}$ giving rise to a very strained product $\mathbf{1 0}$ including a cyclobutene ring shared by two other cycles. The low stability of $\mathbf{1 0}$ probably explains the low yield observed (32\%). When the starting material $\mathbf{6 b}$ including a seven membered ring was subjected 
to the same reaction conditions an identical product 11 was isolated in a better yield (62\%). No traces of the direct Stille coupling product 12 between the starting vinyl bromide $\mathbf{6 a}$ and the vinylstannane 8 was observed in both cases. ${ }^{6}$

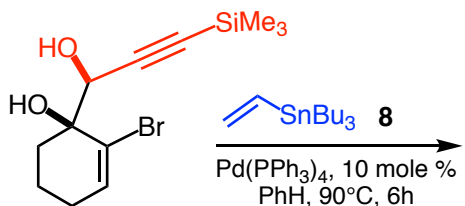

$6 a$

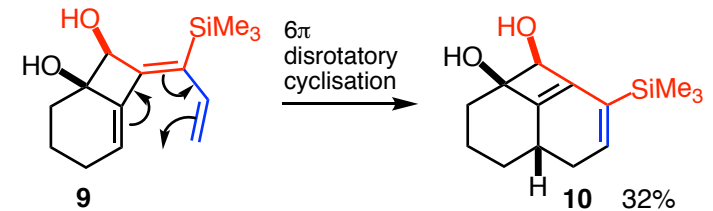<smiles>C=CC1=CCCCC1(O)[C@H](O)C#CCC</smiles>

11

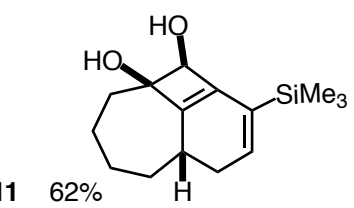

SCHEME 4 The 4-exo-dig followed by a $6 \pi$-electrocyclization

If the trans-bis(tributylstannyl)ethylene $\mathbf{1 3}$ was used instead the vinylstannane $\mathbf{8}$ under the same conditions, new products $\mathbf{1 8 \mathbf { a }}$ and $\mathbf{1 8 b}$ were formed that doesn't include the cyclobutane moiety. The proposed mechanism for the formation of $18 \mathbf{a}$ or $18 \mathbf{b}$ is shown in Scheme 5 . A $6 \pi$-electron disrotatory electrocyclization results in the strained tricyclic diol 15. The anti-stereochemistry between the proton 6 and the tributylstannyl group is fixed by the electrocyclization process. Intermediate 15 undergoes a concerted elimination of $\mathrm{SnBu}_{3}$ and ring opening of the cyclobutenediol leading to the enol 16. The formation of the conjugated diene $\mathbf{1 7}$ is then followed after prototropy by an intramolecular attack of the alcoholate on the ketone from the concave face to form the last stereocenter, resulting in the hemiketal $\mathbf{1 8}$ in respectively $62 \%$ for $\mathrm{n}=1$ and $24 \%$ for $\mathrm{n}=2$.

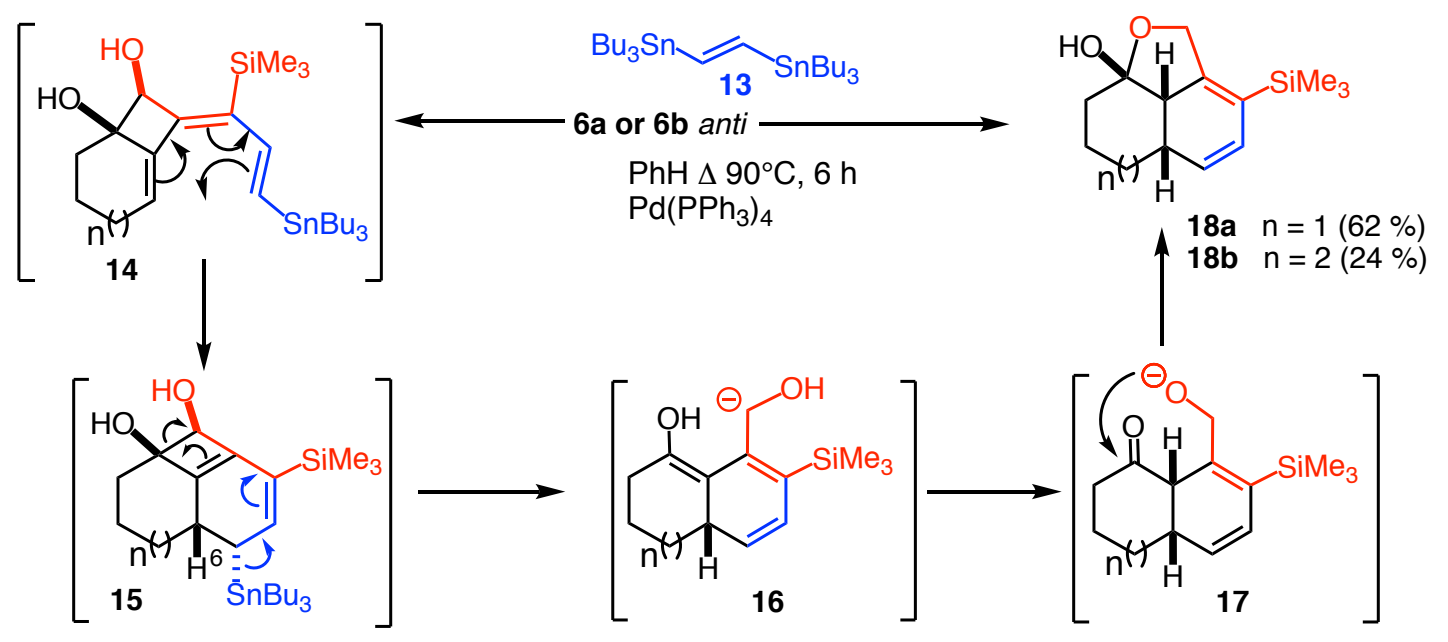

SCHEME 5 Mechanism of the formation of $\mathbf{1 8 a}$ or $\mathbf{1 8 b}$

The presence of the diol functionality in $\mathbf{6 a}$ was crucial for the exclusive 4-exo-dig reaction to proceed. When one replaced the homopropargylic $\mathrm{OH}$ by a hydrogen in $\mathbf{1 9}$, we observed the formation of two products under identical experimental conditions. A mixture of the 4-exo-dig and the direct cross-coupling products was obtained in low yield (23\%) with a ratio of 65:35 respectively for 20:21 (Scheme 6). 


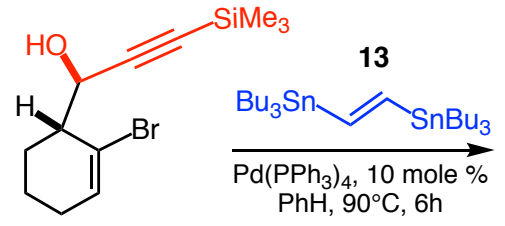

19

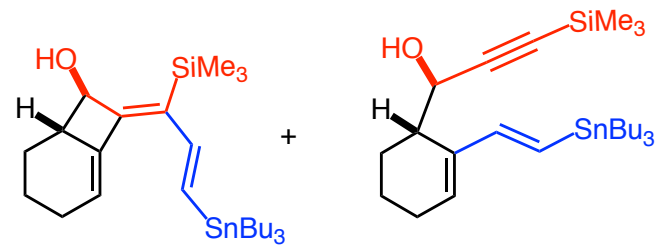

20:21 $=65: 35$

SCHEME 6 Reactivity of the propargylic alcohol 19

In this particular case, no rearranged product was observed by a possible elimination of the tributylstannyl moiety. The structure of $\mathbf{1 1}$ as well as $\mathbf{1 8 \mathbf { a }}$ was confirmed by X-Ray diffraction analysis as shown on figure 1 .

11
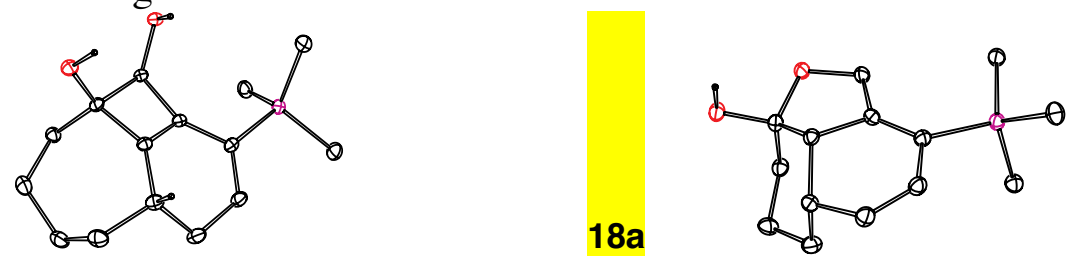

FIGURE $1 \quad$ X-Ray diffraction analysis of strained tricyclic products 11 and $\mathbf{1 8 a}$

With these primary results in hand, we decided to study the scope and limitation of this unique cyclization that has been described for the first time. First, syn-diols $\mathbf{7 a}$ and $\mathbf{7 b}$ were also tested under the classical reaction conditions.

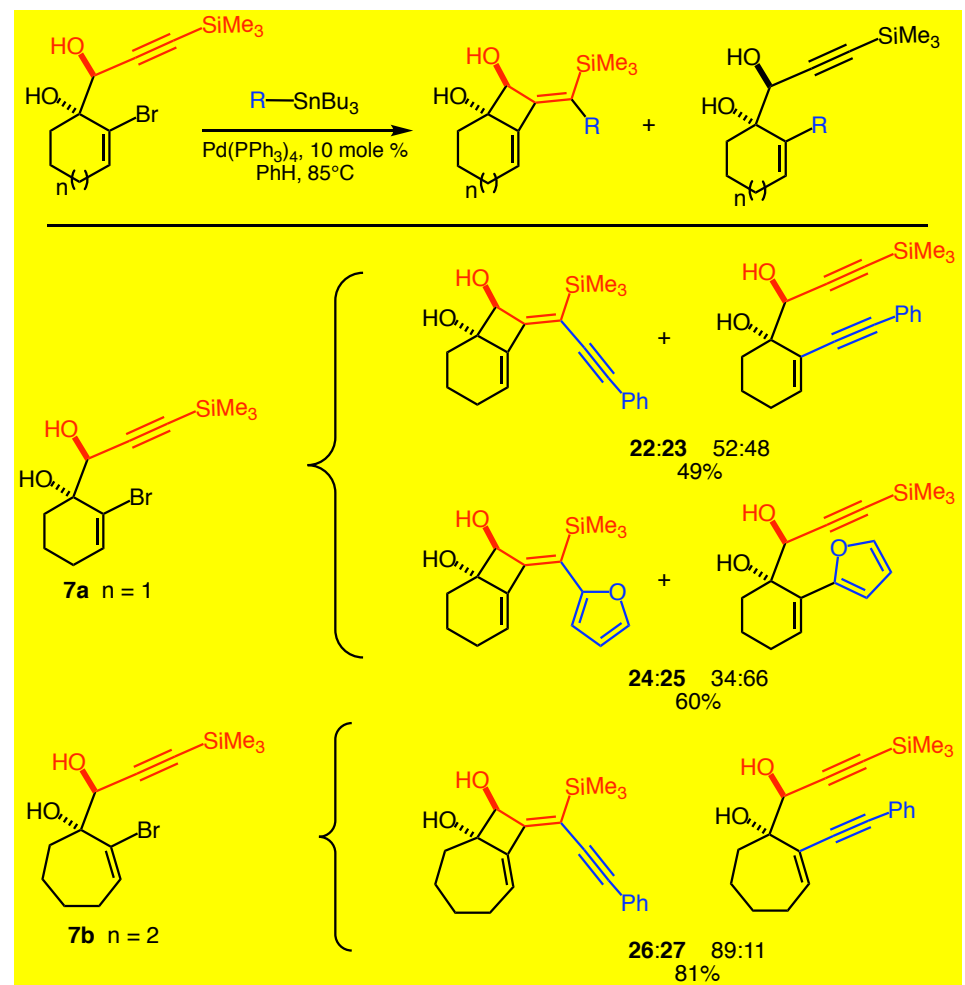

SCHEME 7 The 4-exo-cyclocarbopalladation on the syn-diols

In the majority of the cases studied, we obtained a mixture of the 4-exo-dig and the direct Stille cross-coupling products again showing the importance of the relative stereochemistry of the diol function. This fact supported our hypothesis that a possible hydrogen bond was formed forcing the two reactive sites to be close to each other and giving the 4-exo-dig cyclization 
exclusively. Therefore the anti-diol favors the cyclocarbopalladation process, whereas the syndiol conducts to a mixture of both products.

TABLE 1 Scope and limitations of the 4-exo-dig cyclocarbopalladation

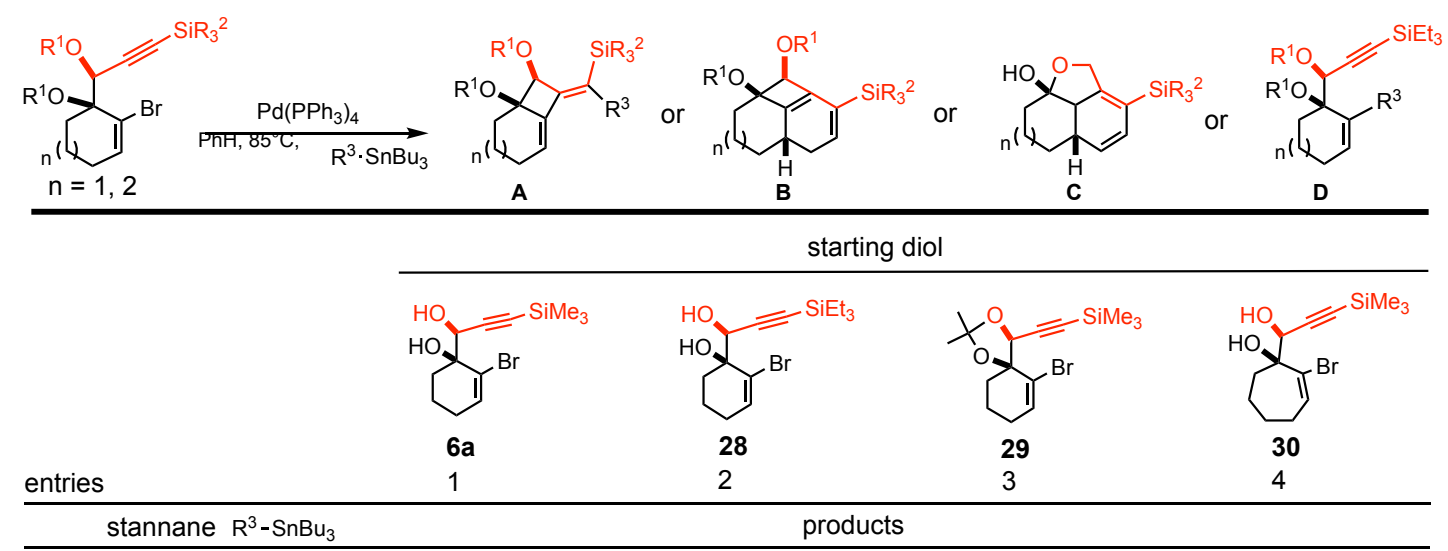

a

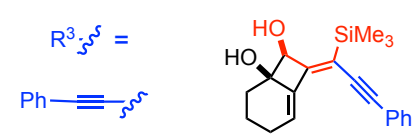

31

b $\quad 10-5$

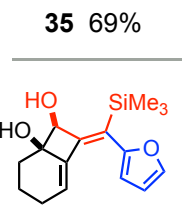

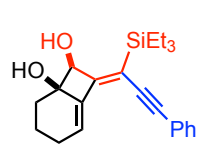

$3652 \%$

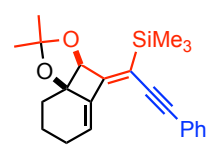

$3753 \%$

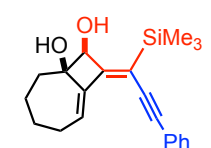

$3861 \%$
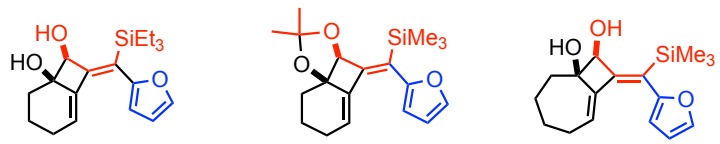

32

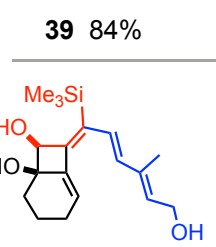

$40^{a} 30 \%$

$4183 \%$

$4270 \%$<smiles>CC=CC(C)=CCO</smiles>

33

$4312 \%$
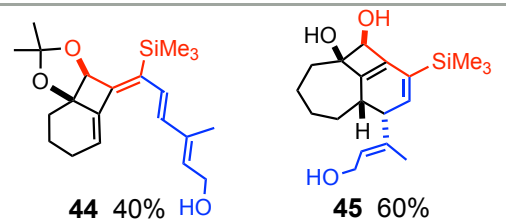

complex
mixture

$4440 \%$

$4560 \%$
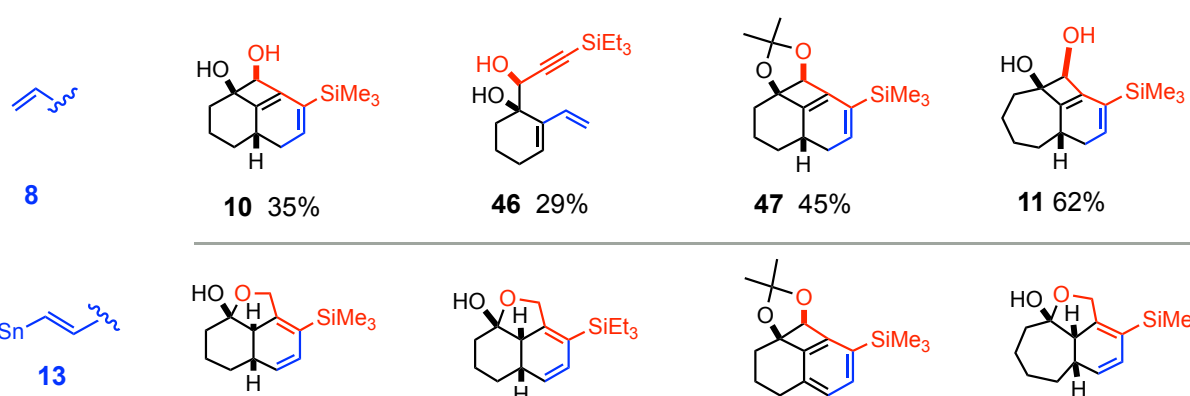

$4629 \%$

$4745 \%$

$1162 \%$

e $\mathrm{Bu}_{3} \mathrm{Sn} \overbrace{}^{z_{2}}$

13

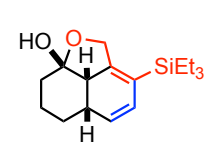

$4862 \%$

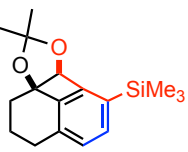

$4921 \%$

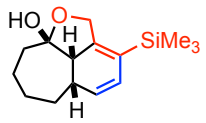

18a $62 \%$

complex
mixture

18b $24 \%$

$\mathrm{f} \mathrm{\gamma}^{2}$

34

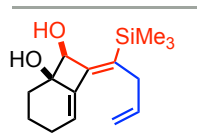

$5056 \%$

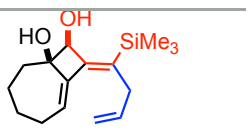

$5171 \%$

A systematic study was envisaged starting with four different vinylbromides (entries 1-4, Table 1) and six different stannanes (Entries a-f, Table 1). During these investigations, four different products can be obtained (Products A-D). Without going in details on Table 1, one can observed that, in general, the 4-exo-dig cyclization was observed in most of the cases with yields ranging 
from 12 to $84 \%$. The use of the simple vinylstannane 8 as a coupling partner (Entry d), gave, after formation of the cyclobutane ring and a $6 \pi$-electrocyclization, the unusual strained tricyclic systems 10, 46, 47 and 11. In some cases (with 6a, 28 and 30), the cyclobutene ring formed after a $6 \pi$-electrocyclization, rearranged to finally furnish the hemiacetal derivatives (Entry e, products 18a, 48, 18b). The protection of the diol moiety didn't affect deeply the yields of the products (Entries $3 \mathrm{a}$ to $3 \mathrm{e}$ ). ${ }^{7}$

The use of the syn-diol as starting material gave in general a mixture of the 4-exo-dig and Stille direct cross coupling products in the few cases studied. It is only on the 7 membered vinylbromide starting compound that we obtained only the 4-exo-exo-dig product. The cyclocarbopalladation can be easily scale up by increasing the reaction by 10 fold without relevant yield loss.

The importance of the ring size and the presence or absence of the diol function as well as the nature of the substituent on the triple bond have been studied. The starting compound shows the best yield and exclusive formation of the 4-exo-dig product when it contains a 6 membered ring, an anti-1,2- diol and a $\mathrm{SiMe}_{3}$ substituent on the alkyne. ${ }^{8}$

We have extended this methodology to the synthesis of cyclobutane diols bearing a dienynes functionality, obtained in very good yields. The introduction of the triple bond was performed using the alkyne stannylated reagent under microwave irradiation at $130{ }^{\circ} \mathrm{C}$. The yields of 53an were between 71 to $86 \%$. Identically when a stannylated furan or thiophene were used, the cyclobutanediols 54 and 55 were obtained in acceptable yields respectively $63 \%$ and $46 \%$.

When the reaction was done in presence of the trans-bis(tributylstannyl)ethylene, a further $6 \pi$ electrocyclization occurred giving rise to the bicyclic cyclohexadienes 57a-d. Yields are better if the diol are protected as a dioxolane. ${ }^{9}$

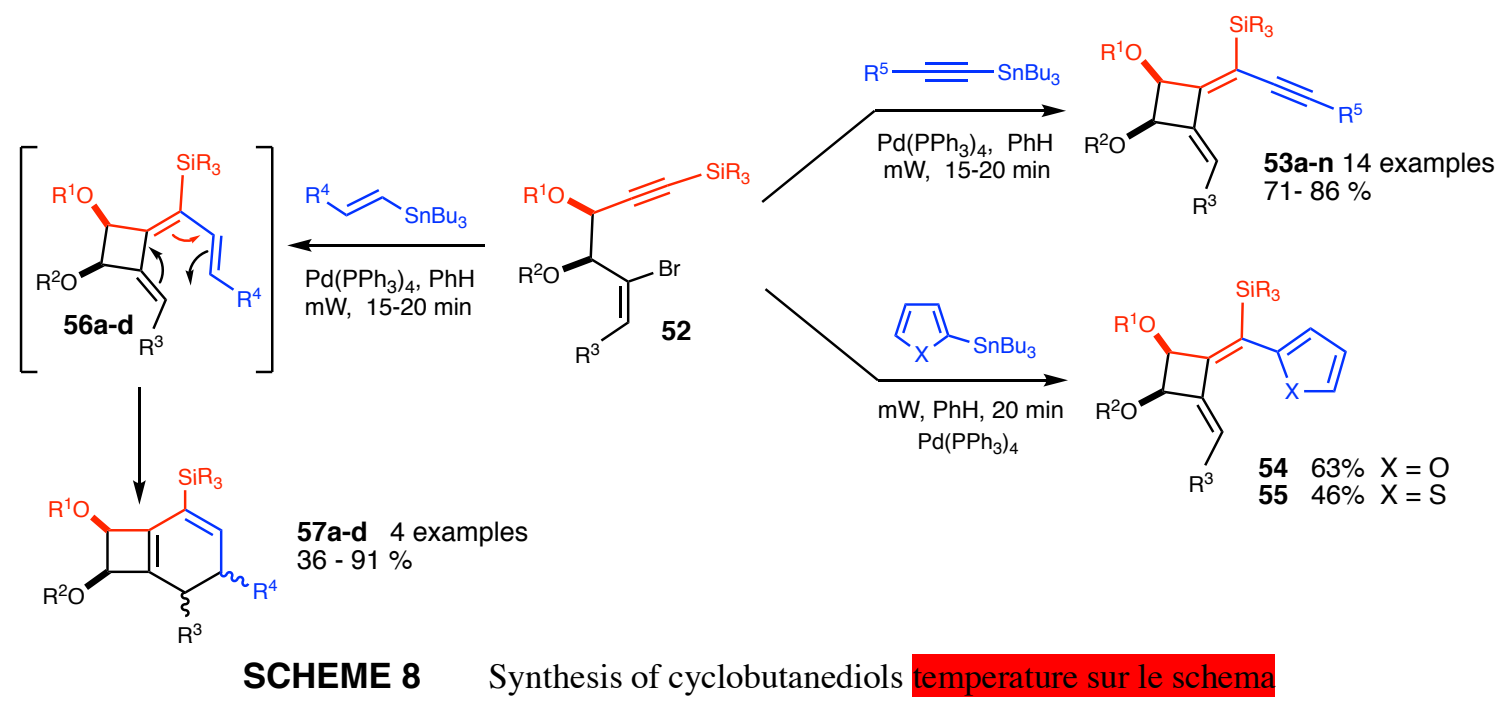

This study was followed by an extensive use of the 4-exo-dig cyclocarbopalladation for the synthesis of much more complex molecules always through efficient cascade reactions. Our next objective was the use of an $8 \pi$-electrocyclization for the synthesis of polycyclic scaffolds including a cyclooctatriene moiety. ${ }^{10}$

\subsection{Cascade 4-exo-dig / 8 $\pi$-electrocyclization}

The $6 \pi$-electrocyclization has been used for a powerful synthesis of some very strained tricyclic scaffolds as it has been demonstrated above. The conditions used, $90{ }^{\circ} \mathrm{C}, \mathrm{Pd}\left(\mathrm{PPh}_{3}\right)_{4}$ in benzene 
gave exclusively the 4-exo-dig cyclocarbopalladation followed by an electrocyclic closure of the triene formed when the starting compound was properly decorated.

Next, we turned our attention to the synthesis of molecules containing a 8-membered ring structure following the same kind of approach than before. If one is able to build a derivative containing four contiguous conjugated double bonds with the required configuration, we have the possibility to produce a cyclooctatriene through a $8 \pi$-electrocyclization process. This substructure is commonly represented in the natural products family. Over 100 compounds shared a cyclooctane moiety. But due to the high degree of ring strain, unfavorable entropic and enthalpic factors and trans-annular interactions, their preparation is often difficult. Therefore the metallocatalyzed route using transition metal like the palladium remains a good solution to this end. The basic tri and tetracyclic structures of ophiobolin A (58) ${ }^{10}$ and aleurodiscal (59) $)^{11}$ contain respectively a 5,8,5-tricyclic and 5,6,8,5-tetracyclic core and were chosen to illustrate this methodology.

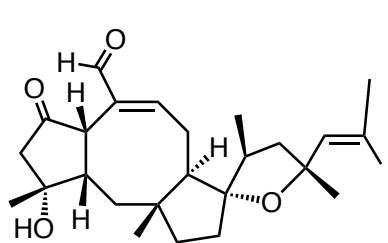

58

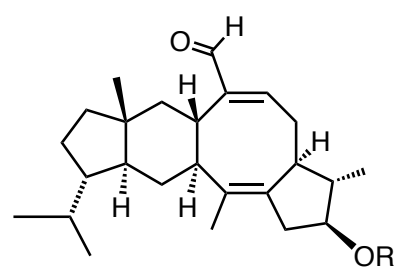

59

FIGURE 2 The structure of ophioboline A and aleurodiscal

Thus, we decided to use the stannylated diene 61-65 (X $=\mathrm{CCO}_{2} \mathrm{Et}, \mathrm{C}\left(\mathrm{CH}_{2} \mathrm{OH}\right)_{2}$, $\mathrm{C}\left(\mathrm{CH}_{2} \mathrm{OC}\left(\mathrm{CH}_{3}\right)_{2} \mathrm{OCH}_{2}\right)$, NTs, $\left.\mathrm{O}\right)$ that can be easily prepared in large scale by a straightforward method developed by Lautens et al. ${ }^{12}$

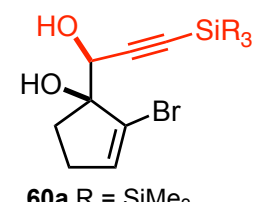

60a R = $\mathrm{SiMe}_{3}$ 60b $\mathrm{R}=\mathrm{SiEt}_{3}$<smiles>OC(C#C[SiH3])C1(O)CCCC=C1Br</smiles>

6a $\mathrm{R}=\mathrm{SiMe}_{3}$ $28 \mathrm{R}=\mathrm{SiEt}_{3}$

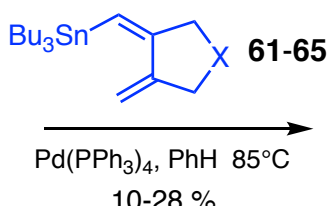

$10-28 \%$
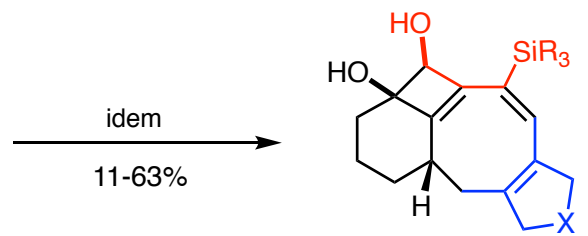

66-73<smiles></smiles>

and

74-85
$\mathrm{X}=\mathrm{C}\left(\mathrm{CO}_{2} \mathrm{Me}\right)_{2}, \mathrm{C}\left(\mathrm{CH}_{2} \mathrm{OH}\right)_{2}$ $\mathrm{O}, \mathrm{NTs}$,

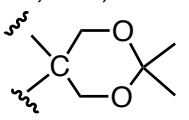

$\mathrm{R}_{3}=$ Me or Et

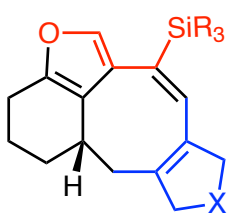

SCHEME 9 Synthesis of cyclooctatrienes through a 4-exo-dig cyclocarbopalladation

It is important to note that in this particular case the use of the 5-membered vinyl bromide 60a or 60b allows the 4-exo-dig cyclocarbopalladation because it is followed by an $8 \pi$ electrocyclization reaction. In the case of a possible $6 \pi$-electrocyclization the formation of a $5,4,6$ tricyclic product was not permitted due to the large strain contained in this system. The reaction of $60 \mathbf{a}, \mathbf{b}, \mathbf{6 a}$ and 28 with the stannylated dienes 61-65 gave in one-pot operation the corresponding 5,8,5 66-73 and 6,4,8,5 or 6,5,8,5 74-85 polycycles with low to moderate yields (11 to $63 \%$ ). All these compounds were formed as a single diastereomer. The modest yields observed are compensated by the structural complexity of the final products obtained and the limited number of steps in the reaction sequence. 
On Scheme 10, we presents the proposed mechanism for the preparation of the substructure of the polycyclic scaffold present in the ophioboline natural product family. The starting compound 60a was reacted with the stannylated diene 61 in the presence of $\operatorname{Pd}\left(\mathrm{PPh}_{3}\right)_{4}$, at $85^{\circ} \mathrm{C}$ in benzene. After the initial insertion of palladium (0) into the $\mathrm{C}-\mathrm{Br}$ bond and syn-4-exo-dig addition on the proximal triple bond the tetraene $\mathbf{8 6}$ was formed but cannot be isolated. Under the reaction conditions it immediately underwent a conrotatory $8 \pi$-electrocyclization that furnish the tetracyclic system $\mathbf{8 7}$. This unstable compound is very strained and gave after a $4 \pi$ electrocyclic opening the bis(enol) 88. This molecule was able to give 2 different products 89/90 in a ratio 3:1 following two routes. Compound 90 was simply formed through the bis(enol)/ketoaldehyde equilibrium and the keto allylic alcohol 89 by the 1,5-hydrogen shift of the bis(enol) as shown on scheme $10 .{ }^{13}$

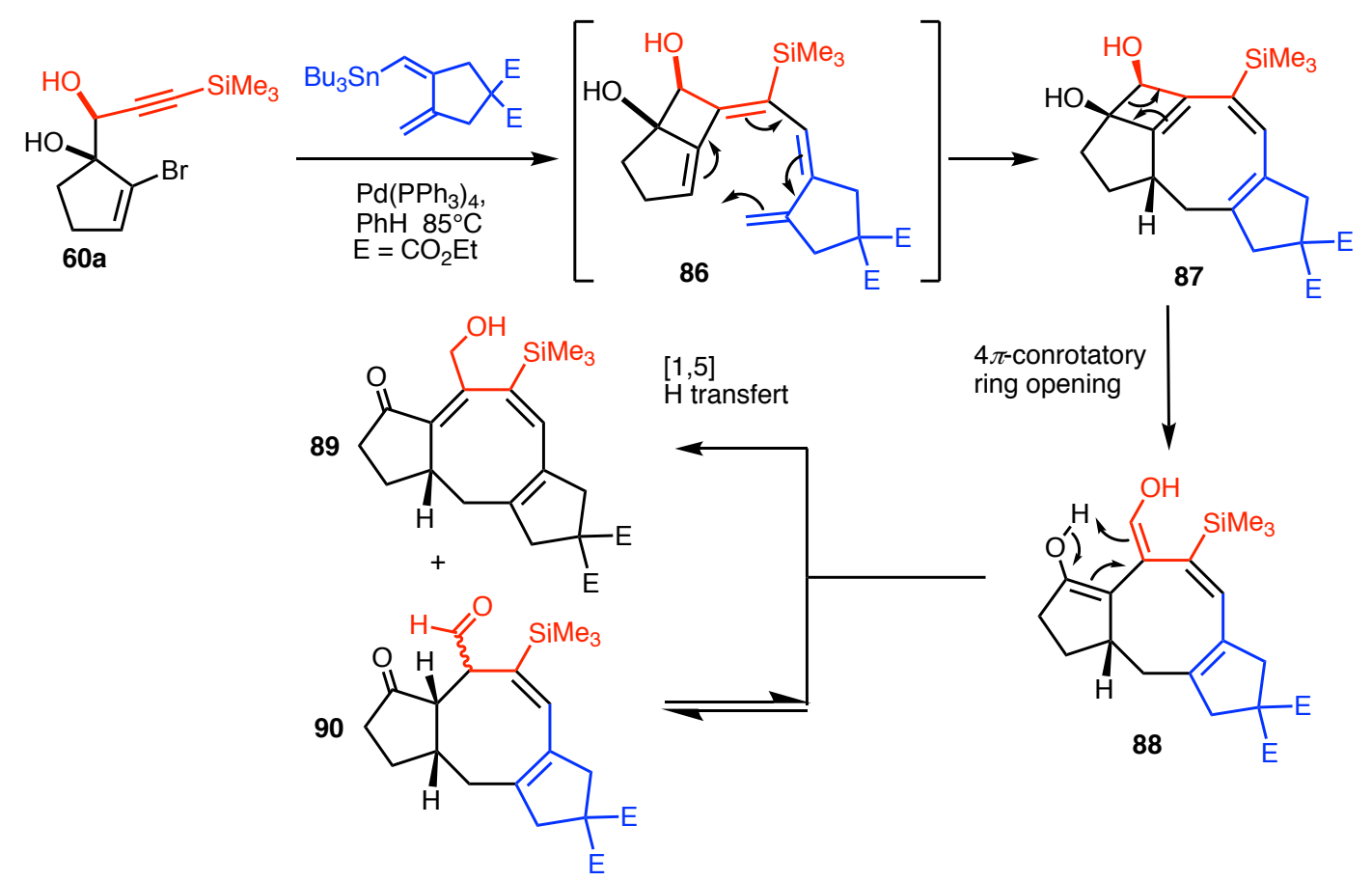

SCHEME 10 Mechanism of the 4-exo-dig/8 $\pi$-electrocyclization/ring opening cascade

The strategy developed and described above was based on a cascade reaction consisting of a 4exo-dig cyclocarbopalladation, Stille cross-coupling reaction, and conrotatory $8 \pi$ electrocyclization. To date, only rare examples of this pericyclic reaction for the direct formation of eight-membered rings have been described. Thus, we have shown that its potential as an efficient route to stable cyclooctatrienes should be considered.

\subsection{The 4-exo-dig cyclocarbopalladation in the synthesis of strained aromatic derivatives}

During the search and investigations to propose a new way to produce cyclooctatrienes derivatives we were pleased to discover a new route and family of new strained tricyclic scaffolds through a very efficient cascade reaction involving a 4-exo-dig carbopalladation as a starting trigger. The proposed strategy for the synthesis of cyclooctatrienes was based on a three different ways that are described in scheme 11. The starting vinylbromide bearing two triple bond or eventually another third triple or double bond on the tether should have reacted 
intermolecularly with a vinylstannane (path 1) or intramolecularly (path 2 and 3) to give the desired final product through an $8 \pi$ electrocyclization (path 4 ).

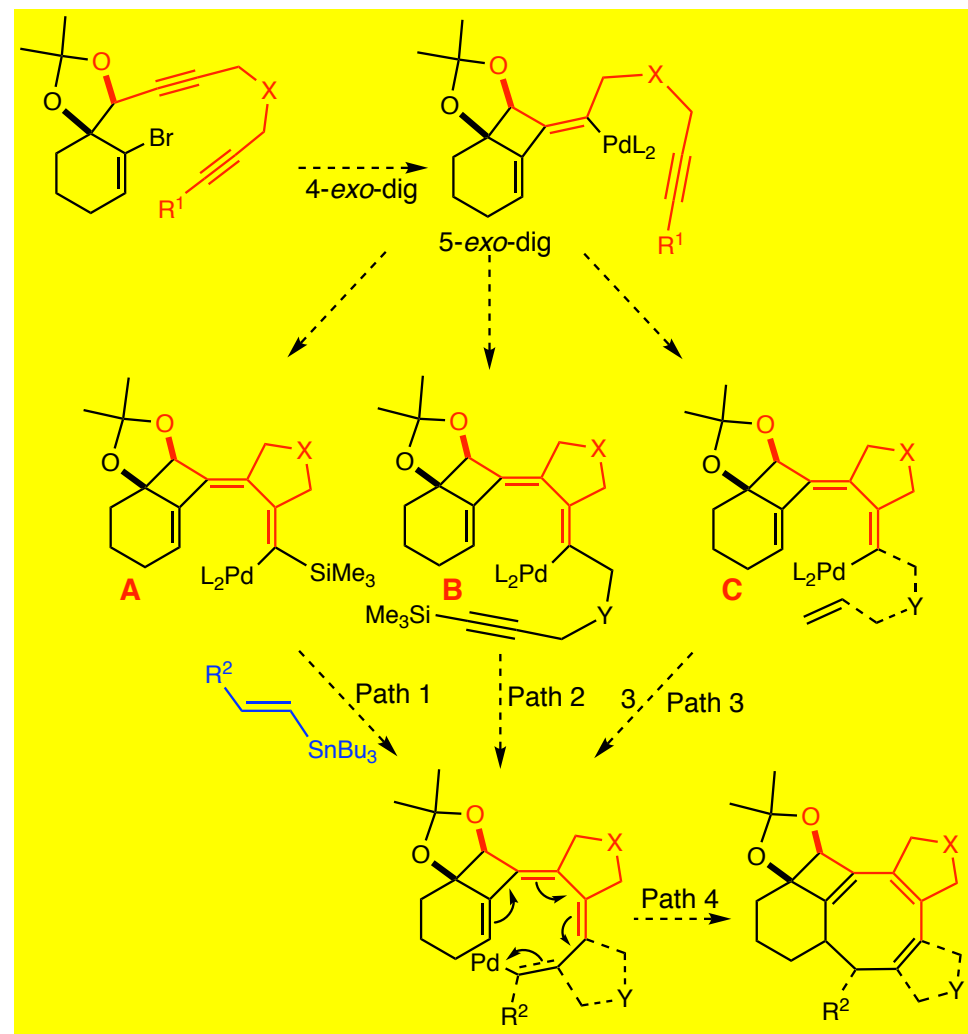

SCHEME 11 Strategies proposed for the synthesis of cyclooctatrienes

None of these paths have taken place. Instead, we observed the only and exclusive formation of strained aromatic polycyclic products. No incorporation of the vinylstannane moiety, following path 1 , took place but, at first, this stannane was crucial to obtain an efficient reaction. For example, increasing the number of vinylstannane equivalent from 0 to 5 equivalents increased the yield of compound $\mathbf{9 4 b}$ from 12 to $86 \%$. This observation clearly showed that the vinylstannane was serving as either a base or reducing agent in this transformation (vide infra). Therefore the vinyltributylstannane was replaced with an organic base (see Table in Scheme 12). Diisopropylamine in large excess was the base of choice for the best experimental conditions.

The most probable mechanism is described in Scheme 12. Due to kinetic reasons the transmetallation of palladium with the vinyltributylstannane is not fast enough before the $6 \pi$ electrocyclization that is really easy under the reaction conditions. Indeed, instead of realizing the Stille cross coupling (path 1), or the second 5-exo-dig (path 2), or 5-exo-trig (path 3) (Scheme 11), a concerted disrotatory $6 \pi$ electrocyclization on the palladated triene 92a,b occurred (Scheme 12). The hydrogen and the palladium are in a cis-configuration in 93a,b allowing a syn dehydropalladation elimination and giving the final strained aromatic derivatives 94a,b (path a and b). 


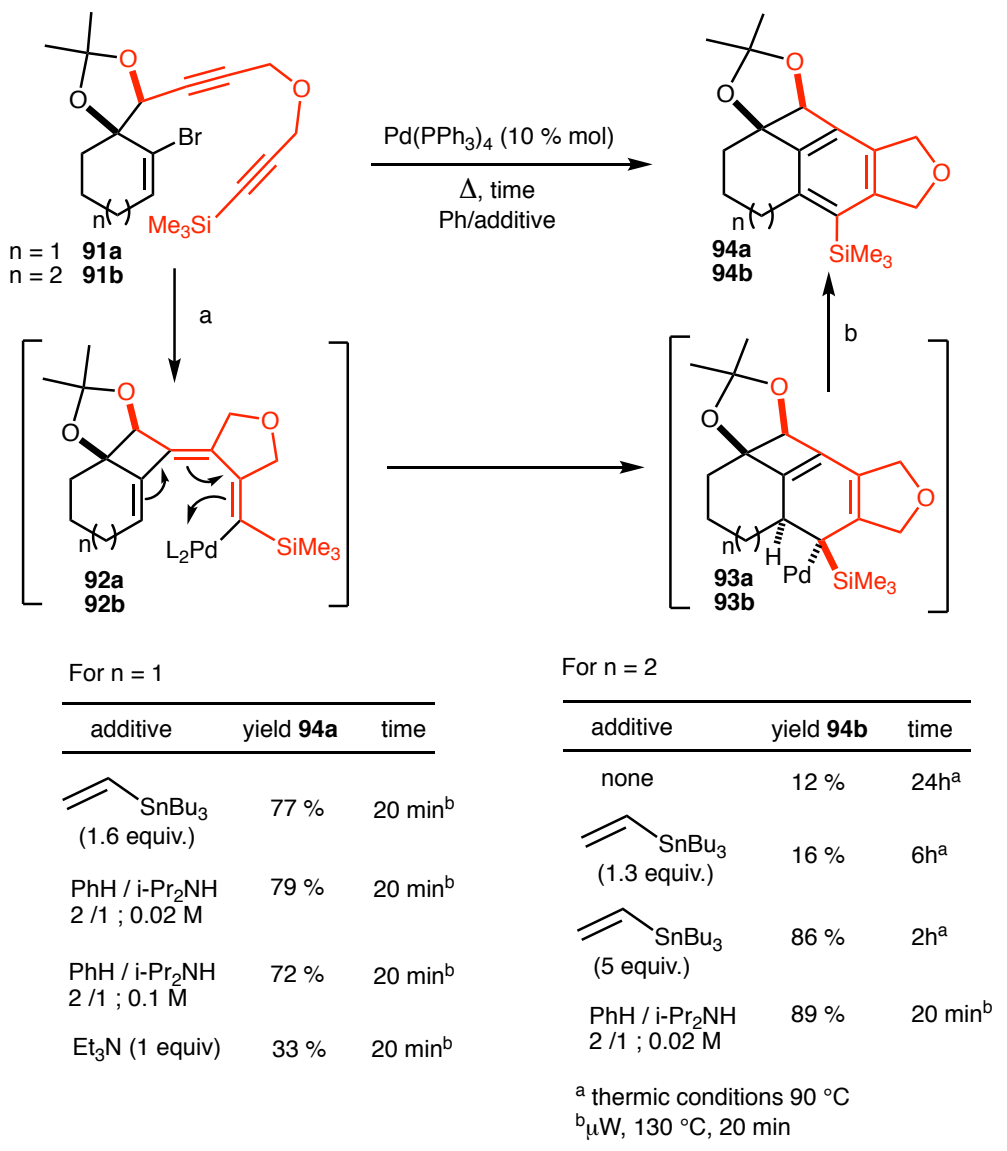

SCHEME 12 Synthesis of strained aromatic derivatives

We were able to synthesized a number of compounds of this type including different heteroatoms, substituents, size cycle, in good to very good yields (50 to $92 \%$, see Figure 3). Even when the terminal triple bond on 91a or $\mathbf{b}$ was substituted by a tether containing an extra triple or double bond in place of the $\mathrm{SiMe}_{3}$ group, we obtained the same type of aromatic derivatives but in relatively low yields (traces to $47 \%$ ). 

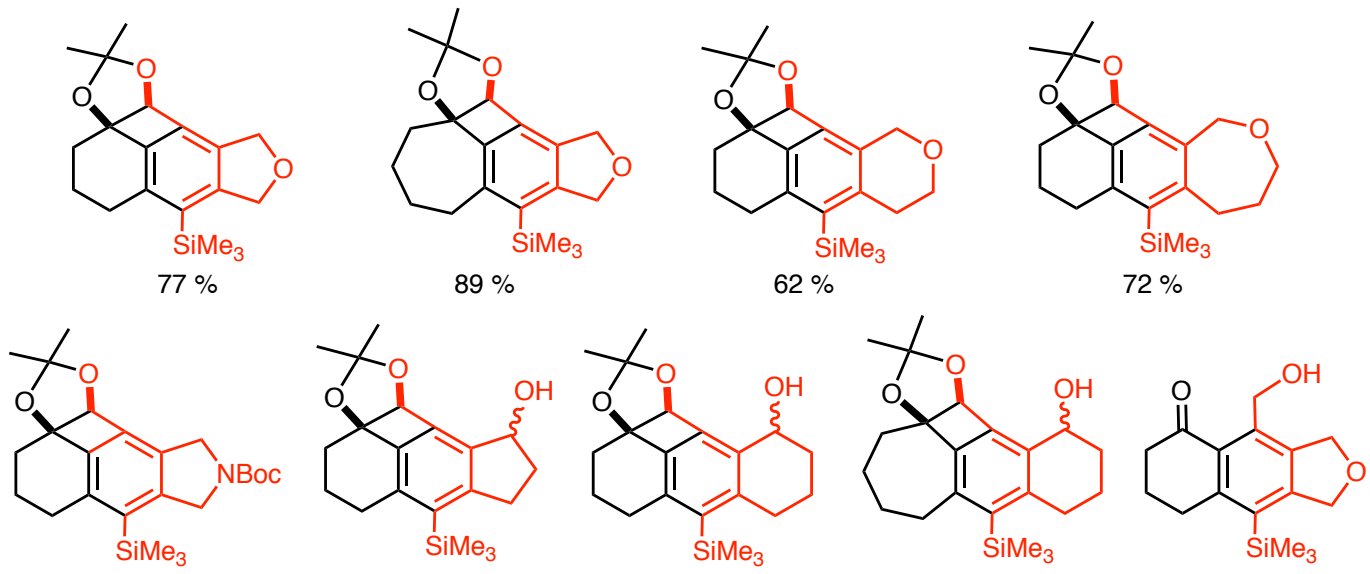

$50 \%$

$68 \% 50 / 50$

$92 \% 52 / 48$

$88 \% \quad 59 / 41$

$46 \%$
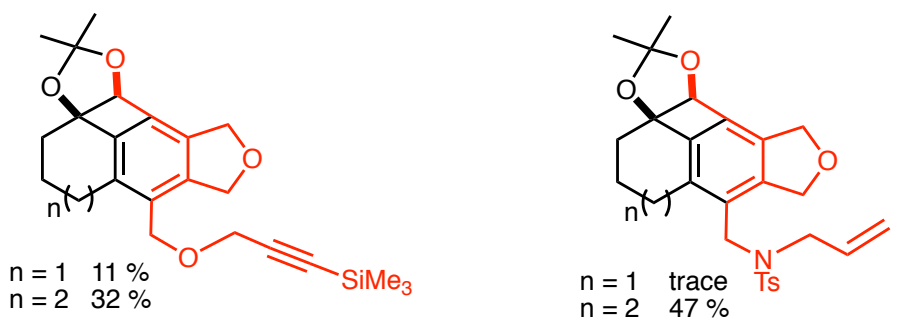

FIGURE 3

Synthesis of strained aromatic polycycles through a 4-exo-dig cyclocarbopalladation

All this compounds are quite stable and can be purified without any difficulties. We never succeeded in the preparation of single crystal of any type of this strained compounds since it was very interesting to study the X-Ray crystallographic structure of one product and particularly the nature of the tight bond between the aromatic and the dioxolane function.

\subsection{4-exo-dig followed by ring expansion in the synthesis of taxane skeleton}

The discovery of the taxol 95, an anticancer drug, highlighted the synthetic and biological interest of such complex polycycles. Still today, the access of the polycyclic systems of the taxane family is of great interest and several important contributions have been proposed these last decades in order to efficiently synthesized new taxanes particularly those that would overcome resistance of the taxol itself. In our laboratory, we were particularly interested in the synthesis of the ABC core scaffold (Scheme 13) present in the natural product, which could be decorated to achieve activity comparable or superior to taxol. The idea to access to the $6,8,6$ sub-structure of the taxane came from our discovery on the synthesis of strained aromatic polycycles that has been performed through a cascade reaction involving the 4-exo-dig cyclocarbopalladation. In that work, we were able to prepare these compounds following the route described in Scheme 12. The starting compound included a chain ending by a terminal substituted triple bond. In place of the triple bond, if we use a terminal double bond substituted or not, we could envisaged to produce 96 from 98 by a cascade reaction including a 4-exo-dig cyclization, a 6 -exo-trig cyclization, a $\beta$-HPd elimination and eventually a $6 \pi$ electrocyclization. This reaction sequence should produce the tetracyclic derivative 97 bearing a central cyclohexadiene. If one could selectively cleave selectively the 4 membered ring double bond it is possible to obtain the tricyclic compound $\mathbf{9 6}$ nicely decorated by three different ketones. 

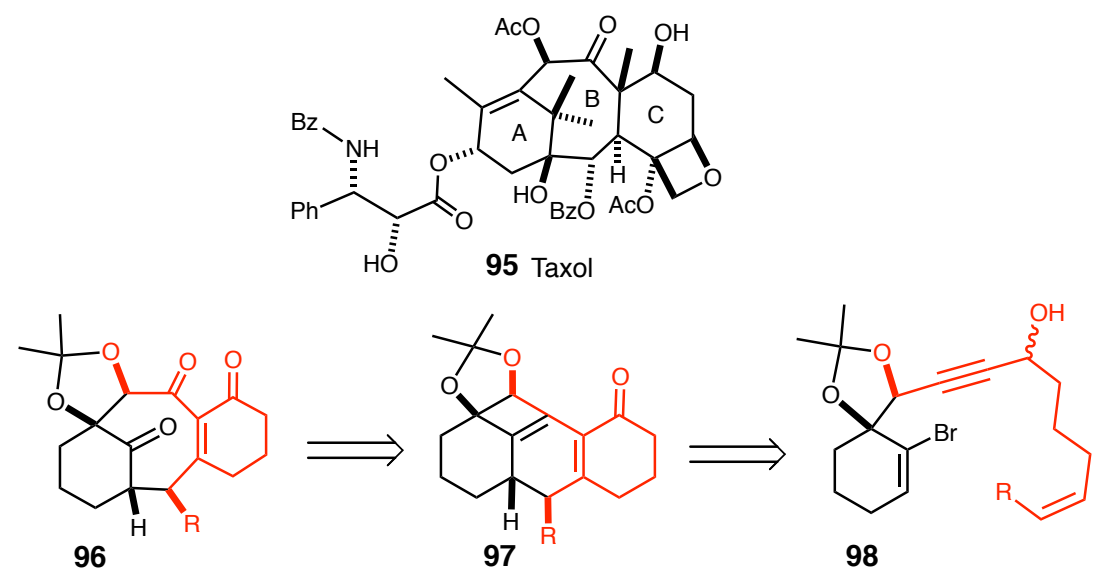

SCHEME 13 Retrosynthetic approach of the taxane core structure of taxol

The starting compounds 98a-i were prepared in 60 to $90 \%$ yields in 5 steps sequence from 2bromo-cyclohex-2-one 5a. The configuration of the double bond can be $E$ or $Z$ and sometime was a mixture of the $E$ and $Z$ configuration depending of the nature of the $\mathrm{R}$ group. Several compounds of type 98a-i were treated under palladium catalysis and microwave irradiation. In all cases, the cascade occurred following the mechanism depicted in Scheme 14. When the R group was an aromatic, in some cases we observed the formation of a mixture of the cis and trans tetracyclic derivatives. For example, starting with a 100:0 phenyl substituted Z-double bond, we obtained at the end of the cascade a 83:17 mixture of the cis:trans products in $62 \%$ yield. This observation was explained as a result of a possible anti-hydride elimination in 100ai to give 103a-i before the $6 \pi$-electrocyclization in order to avoid the strong stereoelectronic interactions between the aromatic moiety and the cyclohexene.

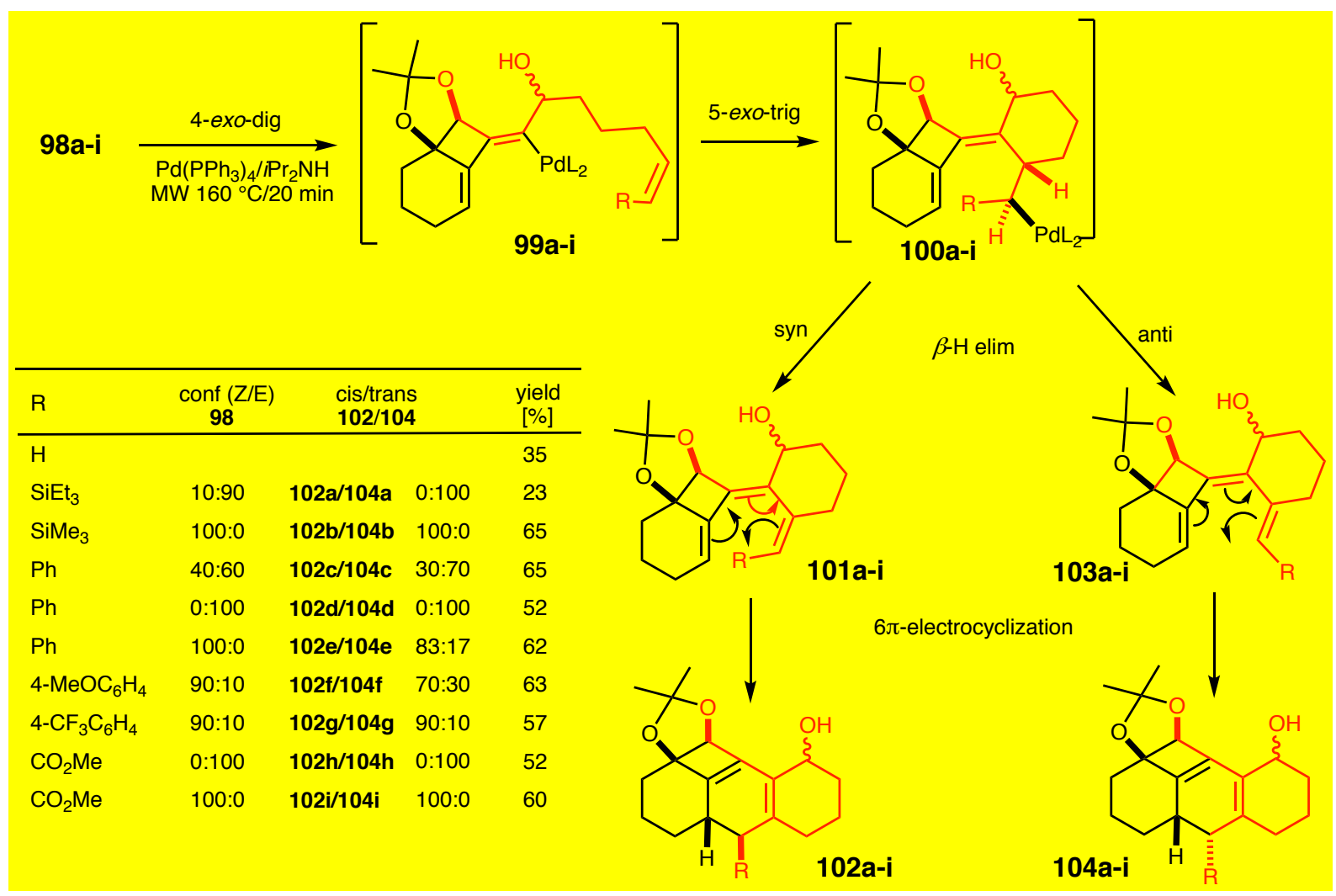

SCHEME 14 Proposed mechanism for the synthesis of tetracyclic derivatives 
When the $\mathrm{R}$ group was different from an aromatic moiety, the reaction was completely diastereoselective. A $Z$ configuration of the double bond giving only the cis product, an $E$ one giving only the trans one. The structure of one of the product $102 \mathrm{~g}$ was confirmed by X-Ray structure analysis (Figure 4).

With 102a-i in hand, the next step was to increase the reactivity of the cyclobutenic double bond versus the allylic double bond towards an oxidative cleavage. To this end the allylic alcohol 102a-i was oxidized using Dess-Martin periodinane in $\mathrm{CH}_{2} \mathrm{Cl}_{2}$ at room temperature for $2 \mathrm{~h}$ producing 105a-i in good yields (68-90\%). After checking several oxidizing systems we decided to use the $\mathrm{RuCl}_{3}$ in presence of $\mathrm{NaIO}_{4}$ in a mixture $\mathrm{CCl}_{4} / \mathrm{CH}_{3} \mathrm{CN} / \mathrm{H}_{2} \mathrm{O}$. The cleavage of the more reactive cyclobutenic double bond was very fast at $0^{\circ} \mathrm{C}$ within $30 \mathrm{~min}$. Yields were acceptable, ranging from 40 to $62 \%$.
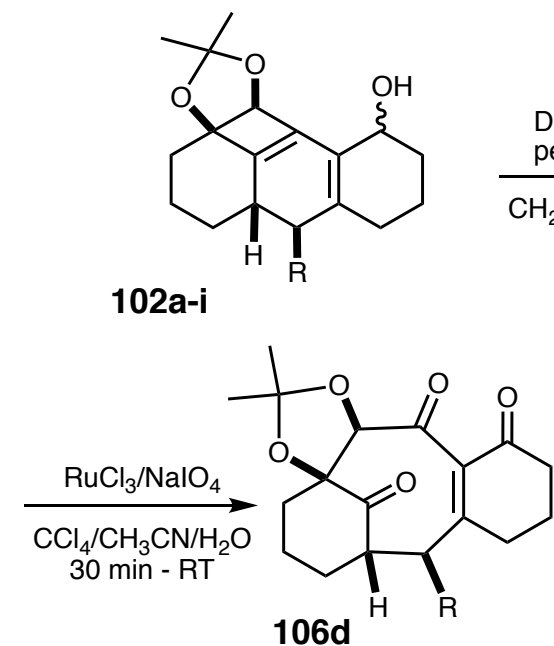

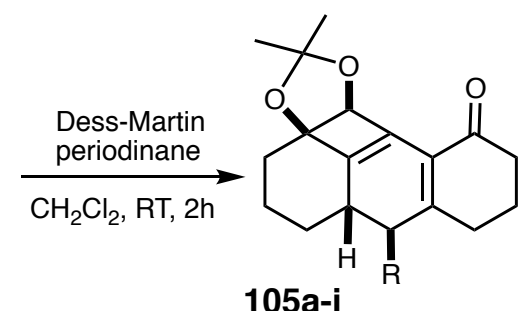

105a-i

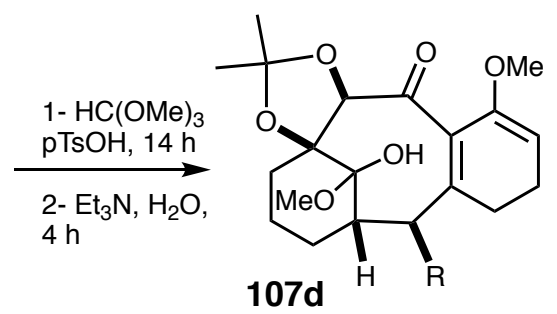

SCHEME 15 Ring expension by oxidative cleavage of the cyclobutenic double bond

One of the compounds (106d) bearing a phenyl group as R group gave nice crystals, which were suitable for X-Ray structure analysis (Figure 4). The highly substituted tetracyclic scaffold related to the taxane family was obtained in only 7 steps from 2-bromocyclohexen-2-one. When compound 106d was treated with methylorthoformiate in methanol in the presence of PPTS at room temperature it furnished derivative 107d. The three ketones were completely and selectively differentiated as an enolether, a hemiacetal and a remaining ketone function on the 8 membered ring.

$102 \mathrm{~g}$

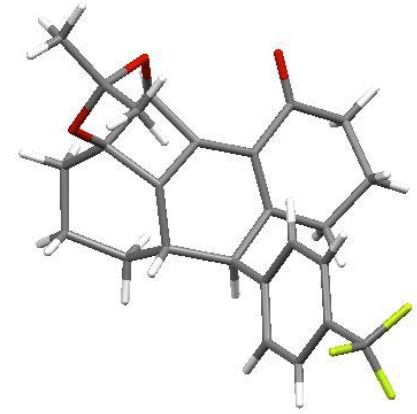

$106 d$

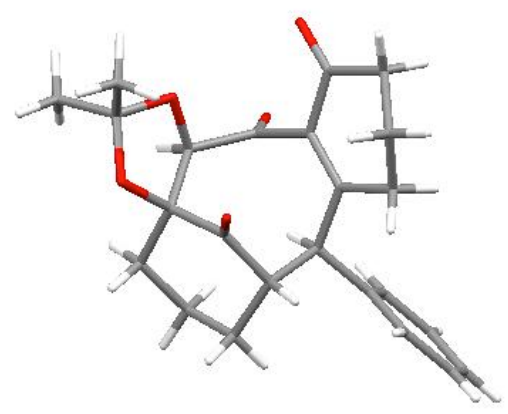

FIGURE 4 X-Ray crystal structures of compounds $102\left(\mathrm{R}=\mathrm{CF}_{3}\right)$ and $106(\mathrm{R}=\mathrm{Ph})$ 
An unusual reactivity was observed when the oxidative conditions that have been used for the synthesis of the taxane derivatives were applied to compound $108(\mathrm{R}=\mathrm{Ph})$. In this molecule, the less bulky methylene unit was used for the diol protection instead of the gem-dimethyl (Scheme 16). Surprisingly, in this case, the double bond of the $\alpha, \beta$-unsaturated ketone was cleaved and not the tight cyclobutenic double bond. It resulted in the formation of a substituted 10 membered ring $\mathbf{1 0 9}$ that can be find in the structure of brianthein A (Scheme 16), a natural product isolated from gorgonian braireum excavatum. No traces of product $\mathbf{1 1 0}$ were found. It is clear that steric effect also influence the selectivity that was achieved in the cleavage process.
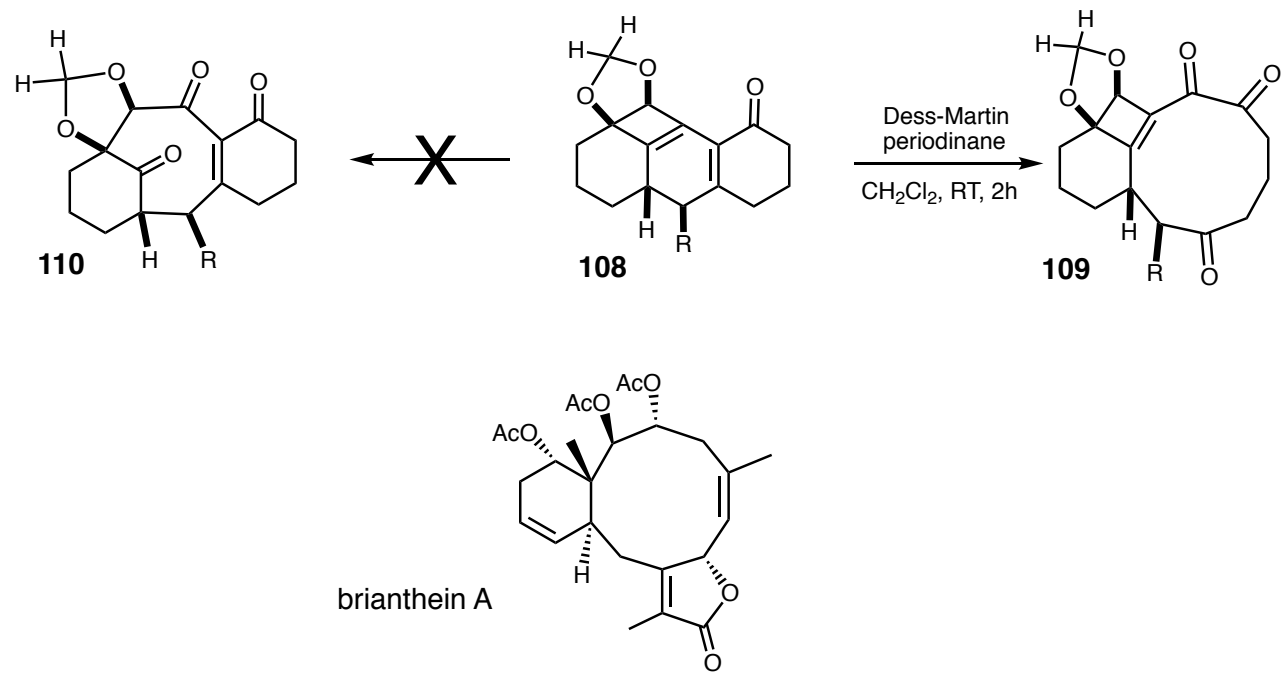

SCHEME 16 Synthesis of the tricyclic core structure of Brianthein A

\subsection{4-exo-dig in the synthesis of Original Polycyclic Structures Containing 3-, 4-, 5- and 6-Membered Rings}

In the course of the synthesis of complex polycyclic compounds, we were interested in the synthesis of derivatives containing two small strained rings in their structures, a cyclobutene (via the 4-exo-dig cyclocarbopalladation) and a cyclopropane (via a 3-exo-trig cyclocarbopalladation). To achieve this goal, we designed a starting compound 111 containing a substituent $\mathrm{R}^{1}$ on the double bond to avoid the $\beta$-hydride elimination that would generate a new double bond prone to trigger a $6 \pi$-electrocyclization. Consequently, this reaction should give access to unique scaffolds bearing 3-, 4-, 5- and 6-membered rings in their structures. As a first model, we choose to synthesized compound $111 a\left(\mathrm{R}^{1}=\mathrm{Me}\right)$ that was available from 2bromocyclohexen-2-one in 7 steps. 


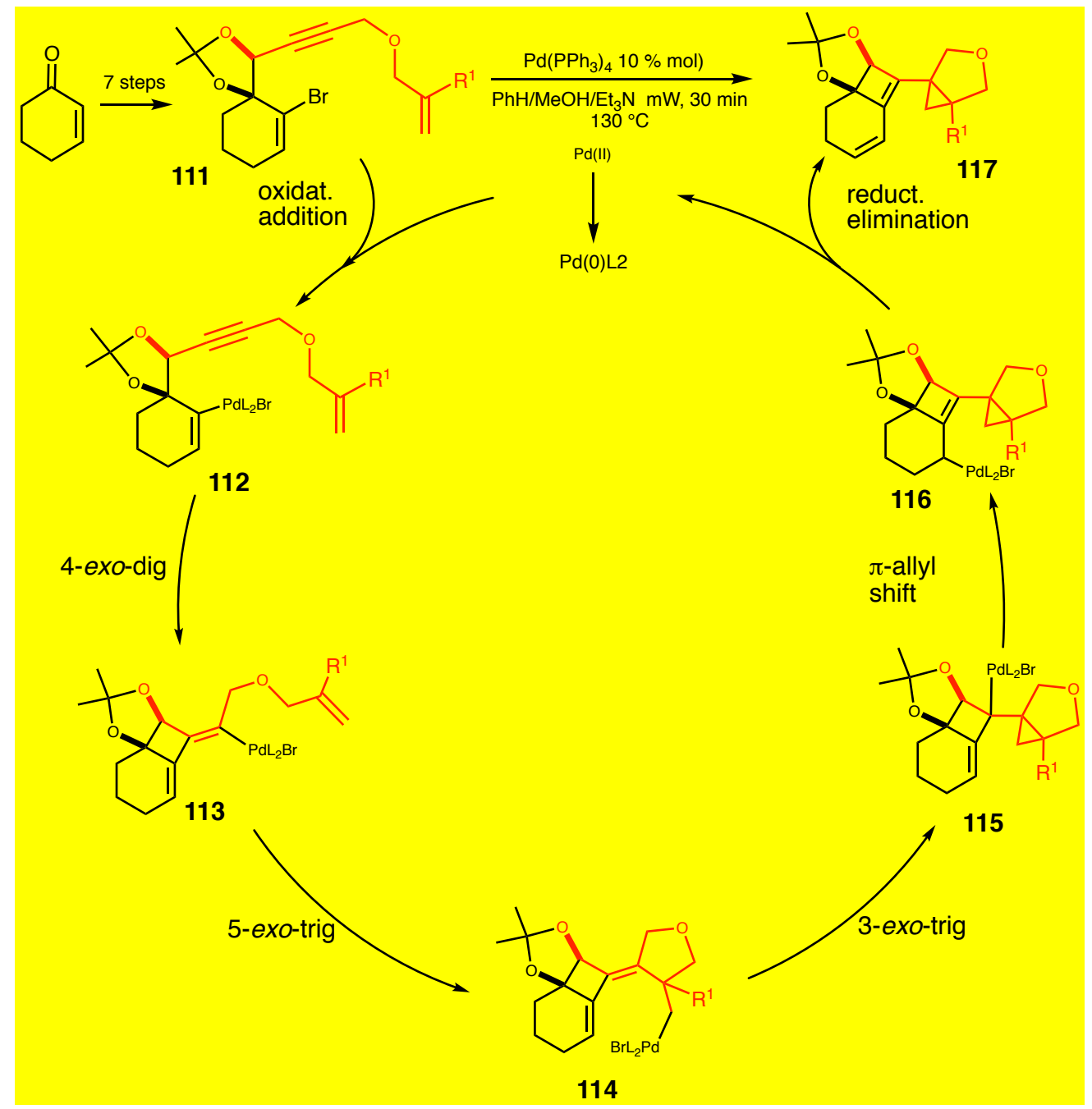

SCHEME 17 Catalytic cycle in the synthesis of compounds $\mathbf{1 1 7}$

After careful optimization of the reaction conditions, 111a was reacted under microwave irradiation with $\mathrm{Pd}\left(\mathrm{PPh}_{3}\right)_{4}(10 \% \mathrm{~mol})$ in a mixture of benzene/methanol/triethylamine in a ratio $6 / 2 / 1$ for $30 \mathrm{~min}$ at $100^{\circ} \mathrm{C}$ to give the corresponding desired compound $117 \mathrm{a}$ in $82 \%$ yield. The effect of methanol on the full process is still unclear but without $\mathrm{MeOH}$ as a co-solvent, the yield of the reaction dropped to only $45 \%$. The mechanism of the reaction is depicted in Scheme 17. After an oxidative insertion of the palladium on the vinylic bromide on $\mathbf{1 1 1}$ to produce 112, the 4-exo-dig cyclocarbopalladation gives the compound $\mathbf{1 1 3}$ bearing a four membered ring that immediately collapse to compound $\mathbf{1 1 4}$ through a 5-exo-trig reaction. This palladium intermediate now continues to evaluate through a 3-exo-trig carbocyclization that produces the organopalladium derivative 115. Follow a $\pi$-allyl palladium shift from the 4 membered ring to the 6 membered ring of $\mathbf{1 1 6}$ that eventually gives the final product $\mathbf{1 1 7}$ by a reductive $\beta$-hydride palladium elimination.

The cascade reaction was totally diastereoselective. This observation can be explained by the following proposition. The 5-exo-trig cyclocarbopalladation that occurred just after the 4-exodig cyclization, pre-organized the side chain ended by the double bond and controlled the fourcentered $\mathrm{C}-\mathrm{Pd} /$ alkene transition states 113A and 113B. In 113A there is only few interactions between the pseudo-axial methyl group and the proton in the $\alpha$-position of the oxygen of the dioxolane, therefore the formation $\mathbf{1 1 4 A}$ is favored. In the transition states $\mathbf{1 1 3 B}$ this interaction between the methyl group and the dioxolane is important and strongly disfavored the formation 
of 114B. The stereochemistry of the 3-exo-trig carbocyclization is now imposed by the structure of 114A to give 115A and eventually 117 (Scheme 18).

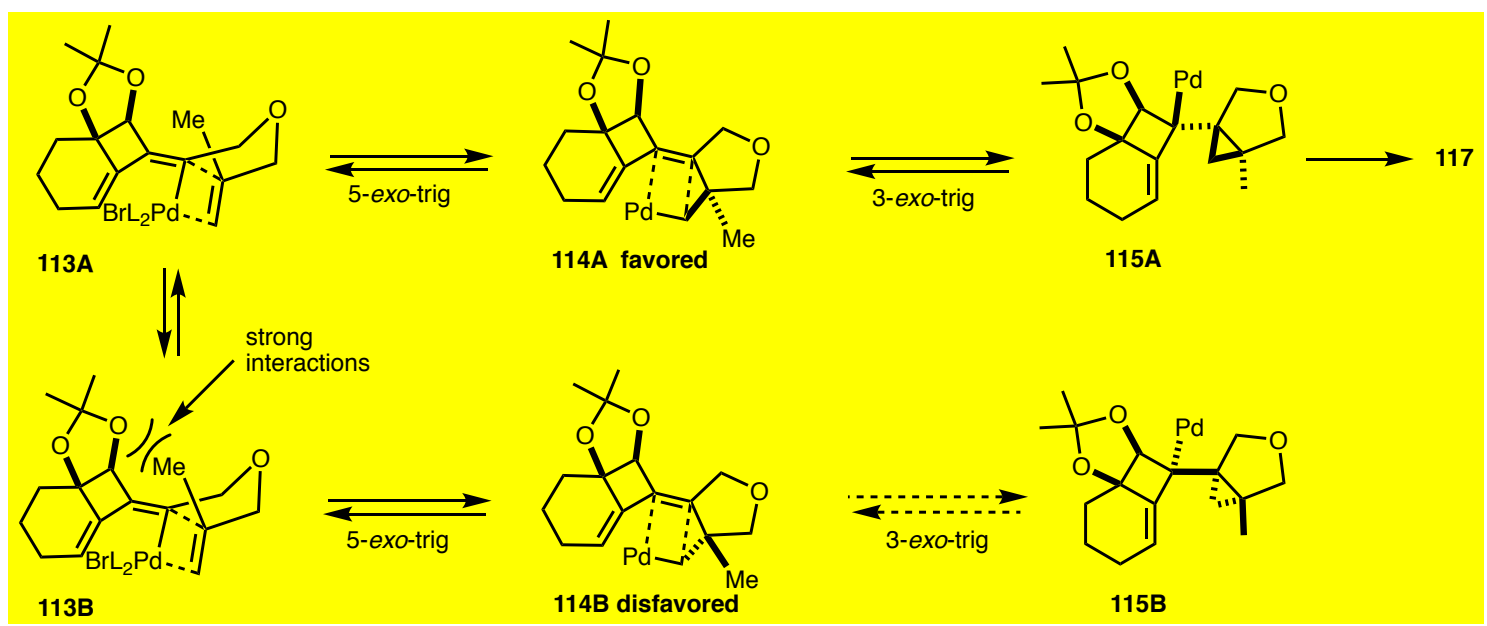

SCHEME 18 Diastereoselectivity of the cascade

Several polycyclic compounds of this type have been obtained. The reaction is general and usually the yields are good. Only when the tether contained sulfur or when a 7 membered ring was present in the starting product instead of a 6 membered ring the yield dropped considerably. On Figure 5 are represented the compounds 117a-j synthesized by this approach.<smiles>CC1(C)CC2=C3C4C=CCCC34C3(C)COCC3(C)C2O1</smiles>

$117 a 82 \%$<smiles>C[C@H]1C[NH2+]C[C@]12CC13CCC=CC1C3=C1CC(C)(C)OC12</smiles>

$117 b \quad 83 \%$<smiles>CC1(C)OC2C(=C3CCCC3)[C@]23CSC[C@]13C</smiles>

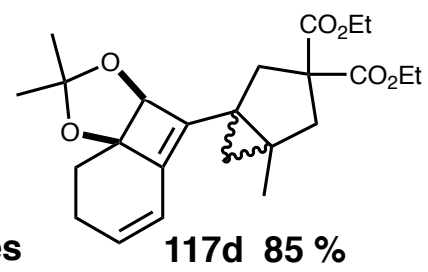

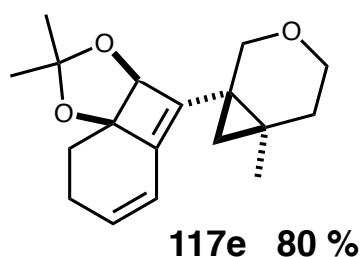

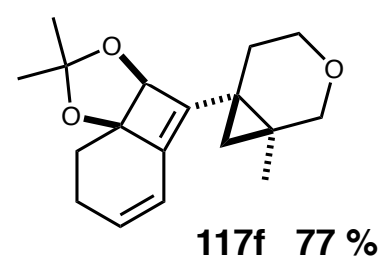

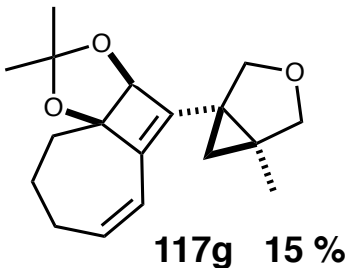<smiles>CC(=O)[C@]12COC[C@@]13C=CCCC14OC(C)(C)OC1C4=C3C2</smiles>

$117 \mathrm{~h} \quad 46 \%$

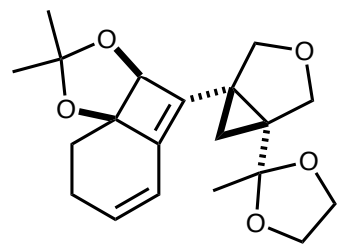

$117 i \quad 48 \%$

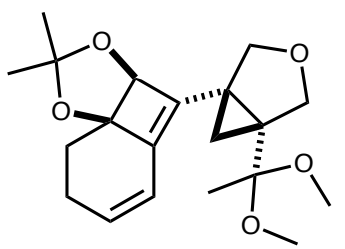

117j $50 \%$

FIGURE 5 New polycyclic scaffolds synthesized through a cascade cyclocarbopalladation

\section{The 4-exo-dig cyclocarbopalladation to the synthesis of fenestradienes and cyclooctatrienes}

\subsection{First generation of fenestradienes and cyclooctatrienes}


We have previously reported the straightforward preparation of 5-8-5 or 6-8-5 condensed polycycles that employs a $8 \pi$ electrocyclization reaction starting from simple alkenyl bromides and common palladium catalysts (cf part 2.2). ${ }^{13}$ Even if yields are modest, we were encouraged by these promising results and we investigated new methodologies further in hope of developing a new versatile and efficient route to this type of cyclooctatriene derivatives in higher yields.

In 2008, in order to synthesize stable 1,3,5-cyclooctatrienes $\mathbf{1 2 0}$, we have designed trienynes of type 118 able to undergo $8 \pi$-electrocyclization after Ni-catalyzed semi-hydrogenation of the triple bond (Scheme 19).${ }^{14}$ During our initial investigations, we were pleased to discover that a subsequent $6 \pi$ electrocyclization reaction took place at room temperature after the $8 \pi$ process providing in excellent yields a new class of fenestranes: the [4.6.4.6]fenestradienes 119. We also shown that it was possible to access cyclooctatrienes 120, with the same reaction conditions, only by slightly increasing the reaction temperature $\left(70{ }^{\circ} \mathrm{C}\right)$ or from 119 simply by microwaves heating at $110^{\circ} \mathrm{C}$.

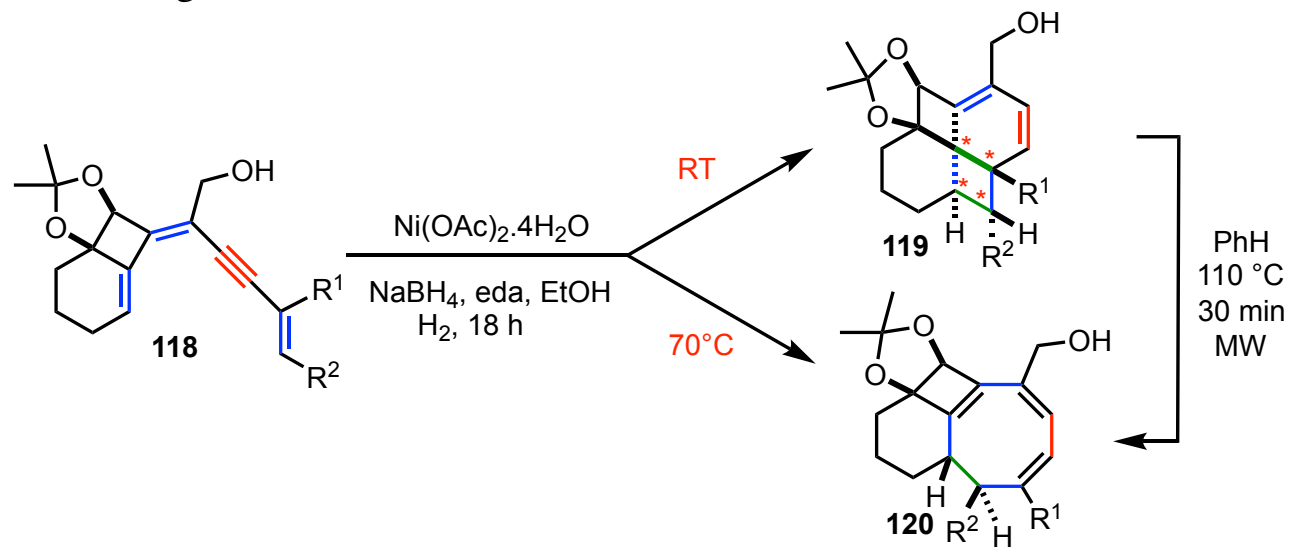

SCHEME 19 Ni-catalyzed semi-hydrogenation of the trienynes triple bond

The fenestranes are strained organic molecules containing a quaternary carbon shared by four rings. Due to their fascinating structure, several groups have examined these compounds extensively for more than 35 years, particularly from a theoretical standpoint. These studies focused mainly on exploring the deformation space between the tetrahedral and planar $\mathrm{C}(\mathrm{C})_{4}$ structures, as well as their stability, strain and reactivity. In 2013, we have published an update on fenestranes in synthesis. ${ }^{15}$ The first part recalls the definition and nomenclature of fenestranes followed by an account on the natural products with [m.n.p.q]fenestrane scaffolds, as well as their achieved syntheses. The [m.n.p]fenestranes are also considered, as they are common both in nature and in synthesis. A particular focus is on the experimentally determined bond angles around the central carbon and the comparison to theoretically predicted values. Several new syntheses of fenestranes have recently been advanced. ${ }^{16}$

In order to explain the formation of $\mathbf{1 1 9}$ and 120, we have proposed the following mechanism (Scheme 20). Partial reduction of the alkyne functionality in $\mathbf{1 1 8}$ generates tetraene 121, which can undergo a $8 \pi$-conrotatory electrocyclization to form cyclooctatrienes $\mathbf{1 2 0}$ or $\mathbf{1 2 2}$ depending on the direction of the rotation. Unlike 120 obtained at $70{ }^{\circ} \mathrm{C}$, intermediate 122 undergoes a $6 \pi$-disrotatory electrocyclization to provide $\mathbf{1 1 9}$ as the sole product isolated at room temperature. No traces of intermediates $\mathbf{1 2 1}$ or $\mathbf{1 2 2}$ were isolated during the process. The reaction was stereoselective and only one diastereomer of the [4.6.4.6]fenestradiene was obtained with the relative stereochemistry shown on Scheme 20 as determined by NOESY 
experiments. It is interesting to note that the stereochemistry of compound $\mathbf{1 2 0}$ is the opposite on compound 119 and that we never observed the formation of fenestrane $\mathbf{1 2 3}$.

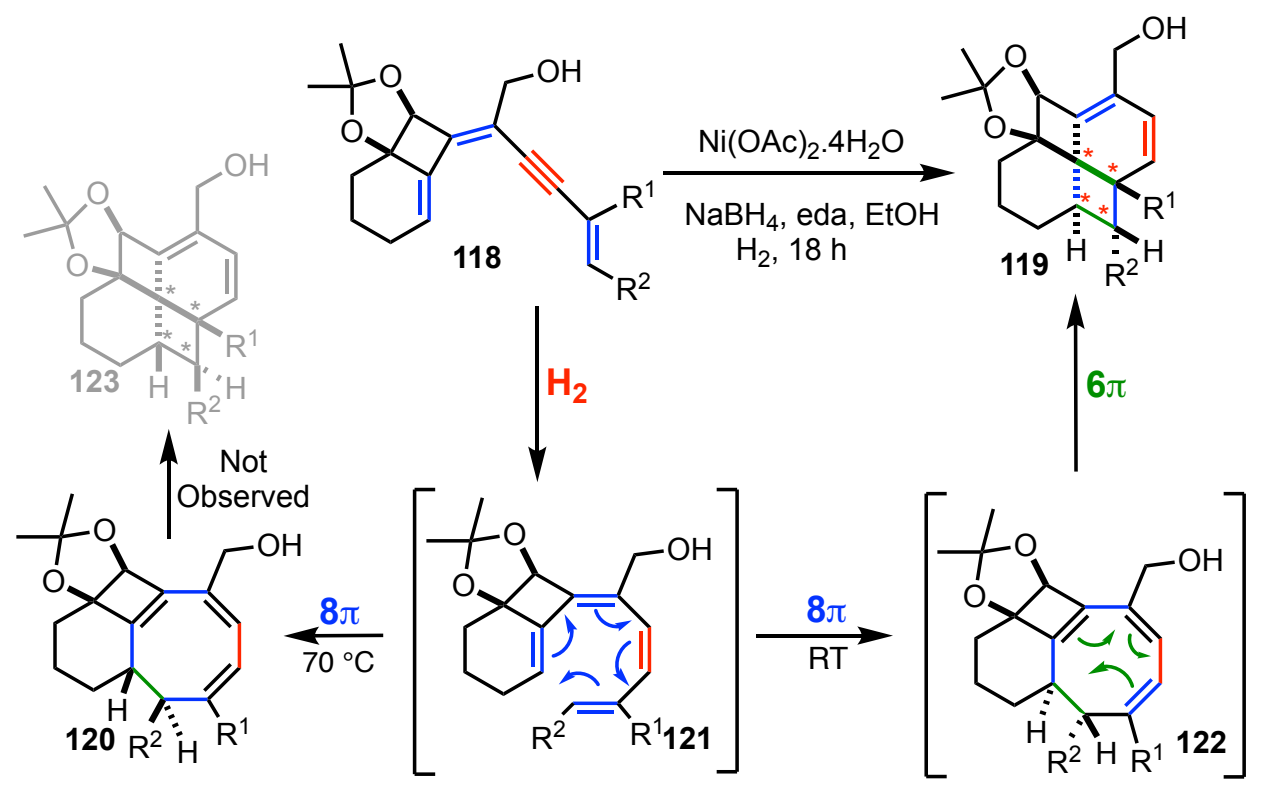

SCHEME 20 Proposed mechanism

DFT calculations have been done in order to explain these results (Scheme 21). The energy differences of the first transition structures control the diastereoselectivities in the cascade reactions. The six-membered ring TS toward the stereoisomer 122 is $0.9 \mathrm{kcal} \mathrm{mol}^{-1}$ lower in energy than toward 120. As a result, fenestrane 119 is the kinetic product and cyclooctatriene $\mathbf{1 2 0}$ the thermodynamically favored product, as cyclooctatriene $\mathbf{1 2 0}$ is the lowest-lying minima.

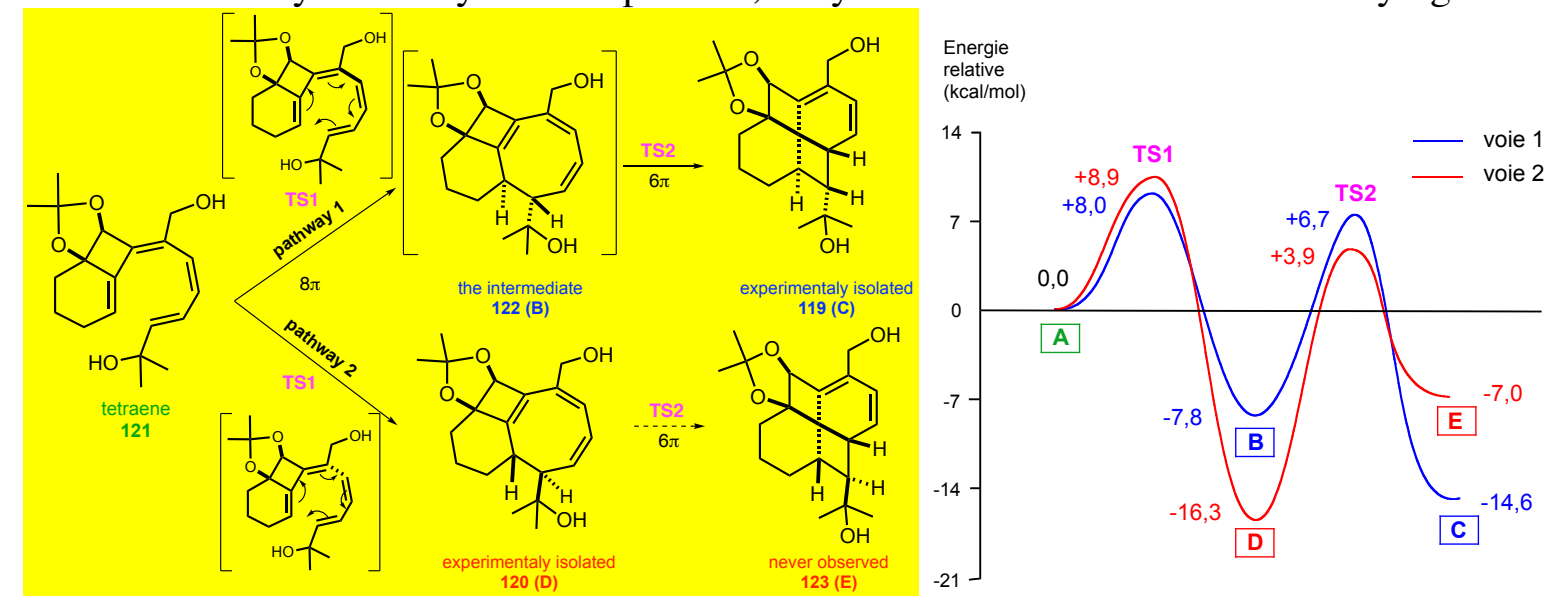

SCHEME 21 DFT calculation

The scope and limitations of this reaction were next investigated and some fenestranes 119a-e were isolated with yields up to $93 \%$ (Scheme 22). 


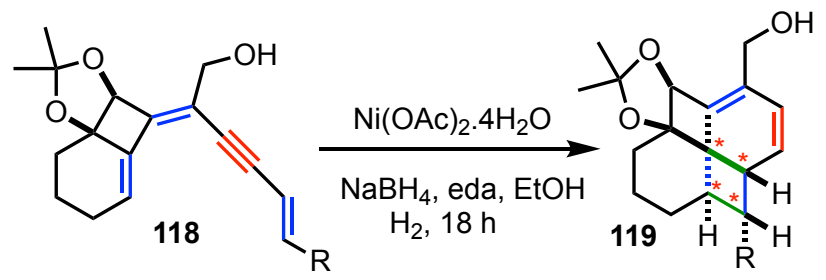

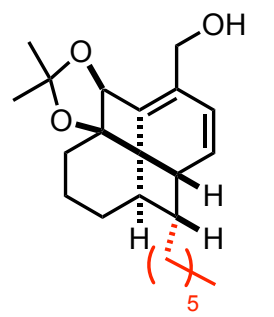

119a $90 \%$

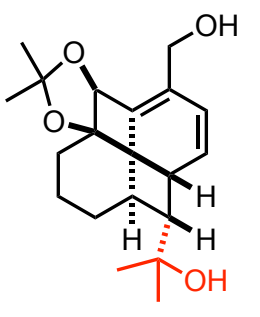

119b $88 \%$

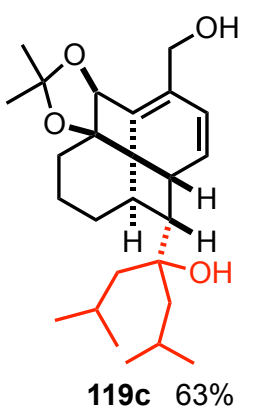

119 c $63 \%$

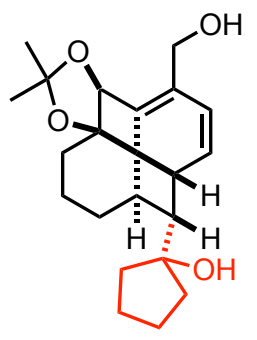

119d $93 \%$

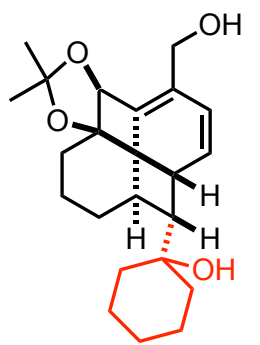

119 e $86 \%$

SCHEME 22 Scope of the reaction

When compounds of type 119 were stored at $-20^{\circ} \mathrm{C}$ under air for several hours, it rearranged slowly to give a new product that possesses all characteristic data corresponding to the [4.6.4.6]fenestrene $\mathbf{1 2 4}$ (Scheme 23). The transformation of 119 into 124 can be explained by a spontaneous oxidation of the highly strained [4.6.4.6]fenestradiene 119 with molecular oxygen. To confirm the oxidation sequence, 119 was submitted to one equivalent of $m$-CPBA in $\mathrm{CH}_{2} \mathrm{Cl}_{2}$ at $0{ }^{\circ} \mathrm{C}$, compounds $\mathbf{1 2 4}$ were isolated in yields up to $68 \%$. These experiments suggest that epoxide $\mathbf{1 2 3}$ is generated as a non-isolable intermediate, which leads to $\mathbf{1 2 4}$ by an $\mathrm{S}_{\mathrm{N}}{ }^{\prime}$ attack of the alcohol on the double bond opening the epoxide 123 as shown on Scheme 23. The stereochemistry observed for this rearrangement is completely controlled by the shape of the rings and occurred from the less hindered face of the molecule.
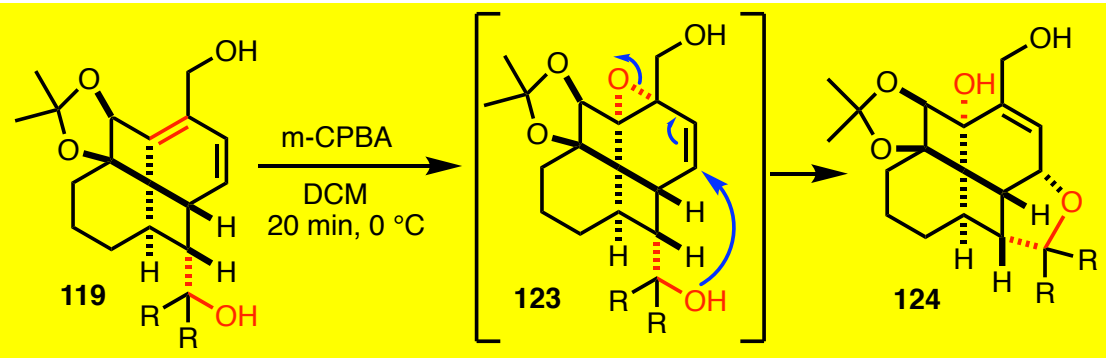

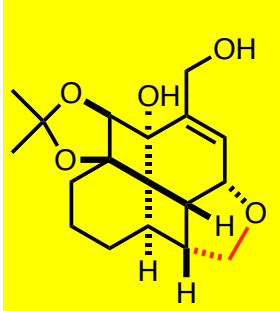

124a $35 \%$ (2 steps)

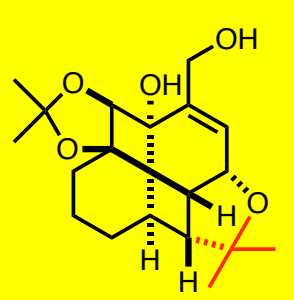

124b $63 \%$

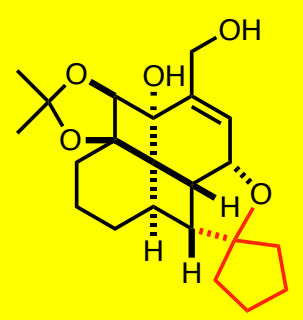

124c $62 \%$

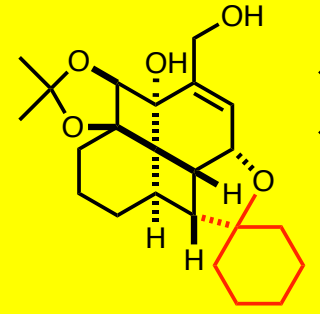

124d $68 \%$

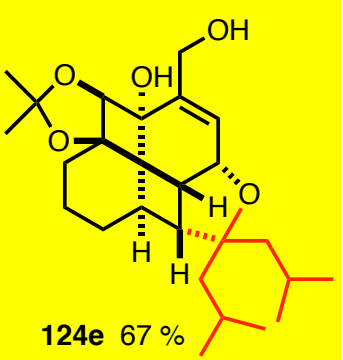

SCHEME 23 [4.6.4.6]fenestrenes formation 
Structural confirmation was obtained through X-ray crystallographic analysis of the 3,5-dinitrobenzoate derivative 125 (Scheme 24). This X-ray structure showed interesting features in the distortion of the central carbon atom that is dependent on the size and configuration of the fused rings. The [4.6.4.6]fenestrene $\mathbf{1 2 5}$ possess a central quaternary carbon that has a strong distortion. The two important orthogonal bond angles $\alpha$ and $\beta$ are respectively widened to $118^{\circ}$ and $124^{\circ}$.
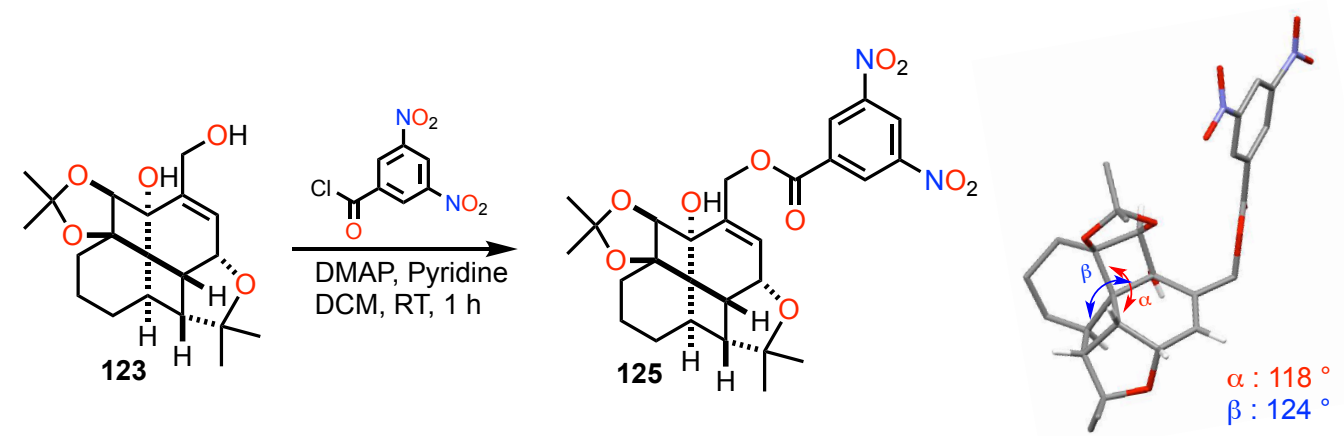

SCHEME 24 X-ray crystal structure of the 3,5-dinitrobenzoate derivative 125. The majority of $\mathrm{H}$ are omitted for clarity

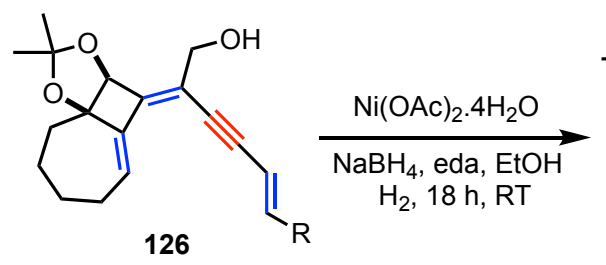

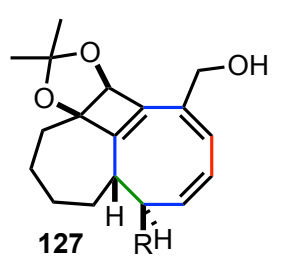

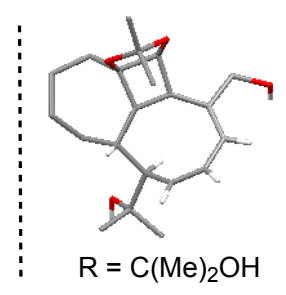<smiles>CC(C)(O)C1C=CC=C2C3OC(C)(C)C3OC2C12CCCCCC2</smiles><smiles>CC(C)CC(O)C1C=CC=C2C(CO)C3OC(C)(C)OC3C23CCCCC13CC(C)C</smiles>

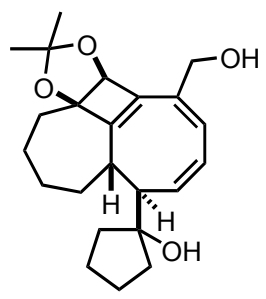

127 a $77 \%$

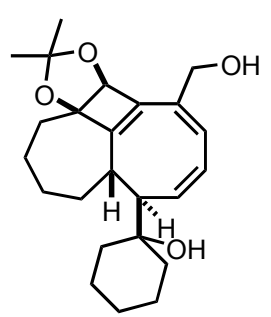

$127 d 81 \%$
$127 \mathrm{~b} 88 \%$

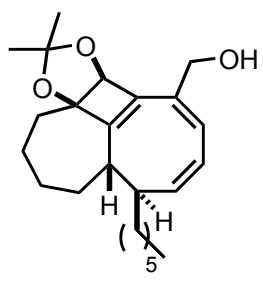

127e $63 \%$

$$
127 \mathrm{c} 81 \%
$$

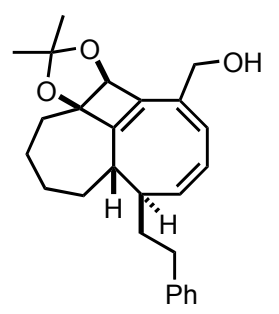

$127 f 76 \%$

SCHEME 25 Scope of the semi-hydrogenation of trienyne 126

Unlike trienynes 118 bearing a six-membered ring, which gave fenestradienes 119 at room temperature, stable cyclooctatrienes $\mathbf{1 2 7}$ were obtained when the seven-membered ring trienynes $\mathbf{1 2 6}$ were hydrogenated at room temperature (Scheme 25). The only products isolated in 63 to $88 \%$ yields were the stable 7-4-8 fused systems 127 and we never observed any 
fenestradienes. Reactions were again completely stereoselective as only one diastereomer is observed with opposite torquoselectivity compared to the formation of fenestradienes 119 .

DFT calculations have been done in order to explain the results (Scheme 26). The cyclooctatriene 127a is the kinetically as well as the thermodynamically favored product, in line with experiment.

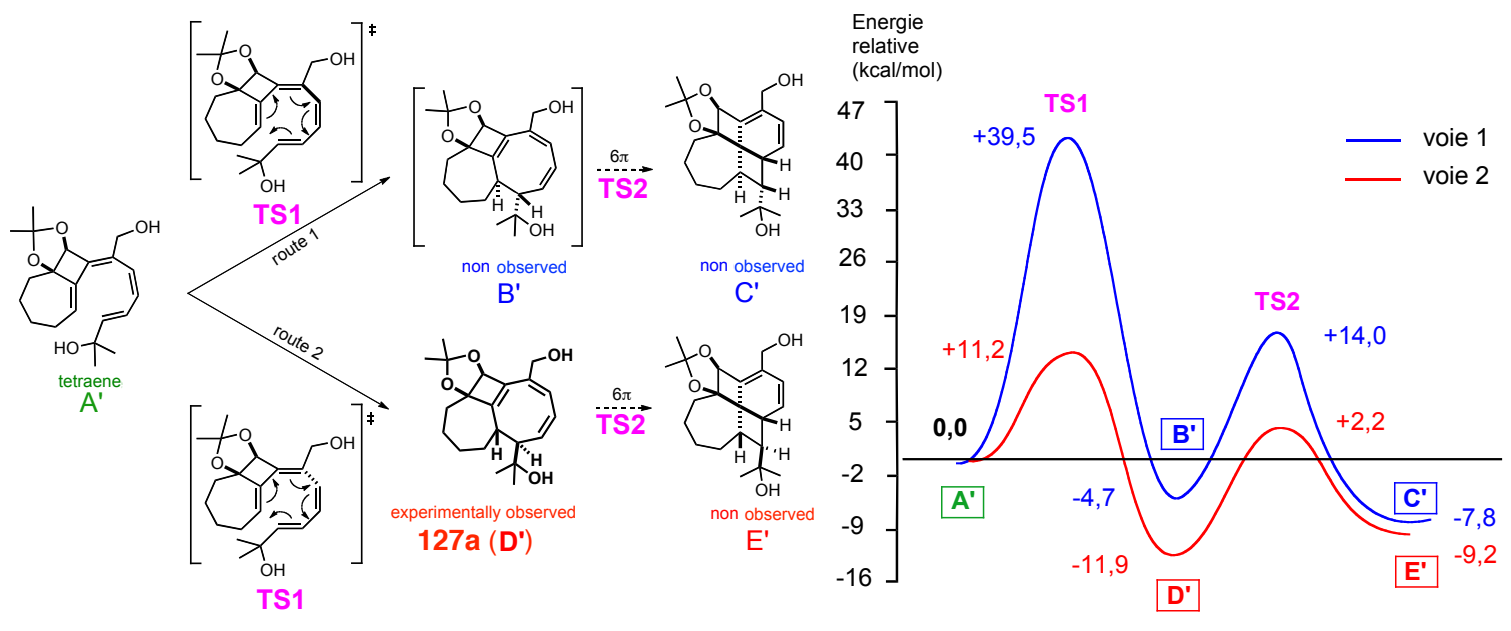

SCHEME 26 DFT calculations

Cyclooctatrienes and fenestranes previously reported were tested for their pro-apoptotic activities on two human cancer cell lines (THP-1, and SW620) (Figure 6). ${ }^{17}$ Among the 20 new compounds tested, two compounds (127b and 127e) presented specific activities on the colon carcinomas TRAIL-resistant metastatic cell SW 620 but a minor action on the monocytic leucemia THP1 cell line. Such differential pro-apoptotic activities, point out these two molecules as potent pharmacological tools to study TRAIL associated cellular mechanisms.

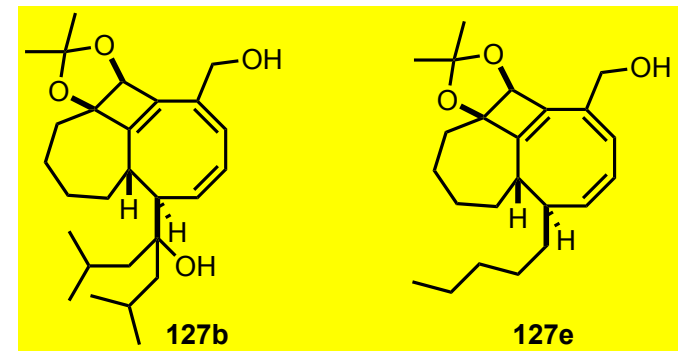

FIGURE 6 Pro-apoptotic activities considerations

\subsection{4-exo-dig cyclocarbopalladation followed by a Sonogashira coupling}

The previously described cascade to obtain cyclooctatrienes and fenestradienes uses trienynes derivatives (Scheme 27). This kind of compounds has been synthesized in three steps from alkenyl bromide 128. The first step is the cascade 4-exo-dig cyclocarbopalladation/Stille crosscoupling reaching 129 which undergoes a silyl deprotection and a Sonogashira cross-coupling. In spite of the high yield reached for the synthesis of trienynes 118, the toxicity of the stannane compounds used in this approach remains a major problem. Another issue brought by this type of cascade is the difficulty to completely eliminate the stannane residues from the isolated product. We were looking for a greener and faster route to form $\mathbf{1 1 8}$ with different functionalities, by means of a cascade 4-exo-dig cyclocarbopalladation/Sonagashira 
cross-coupling in order to access directly to trienynes 118 from 128, which would be even better in terms of step economy. These new approaches present major advantages: (i) the alkynes used are non-toxic; (ii) they are commercially available, that means an easier access to a large variety of alkynyl derivatives; (iii) it represents a rapid access to trienynes $\mathbf{1 1 8}$ and by the way fenestradienes 119 or cyclooctatrienes $\mathbf{1 2 0}$.

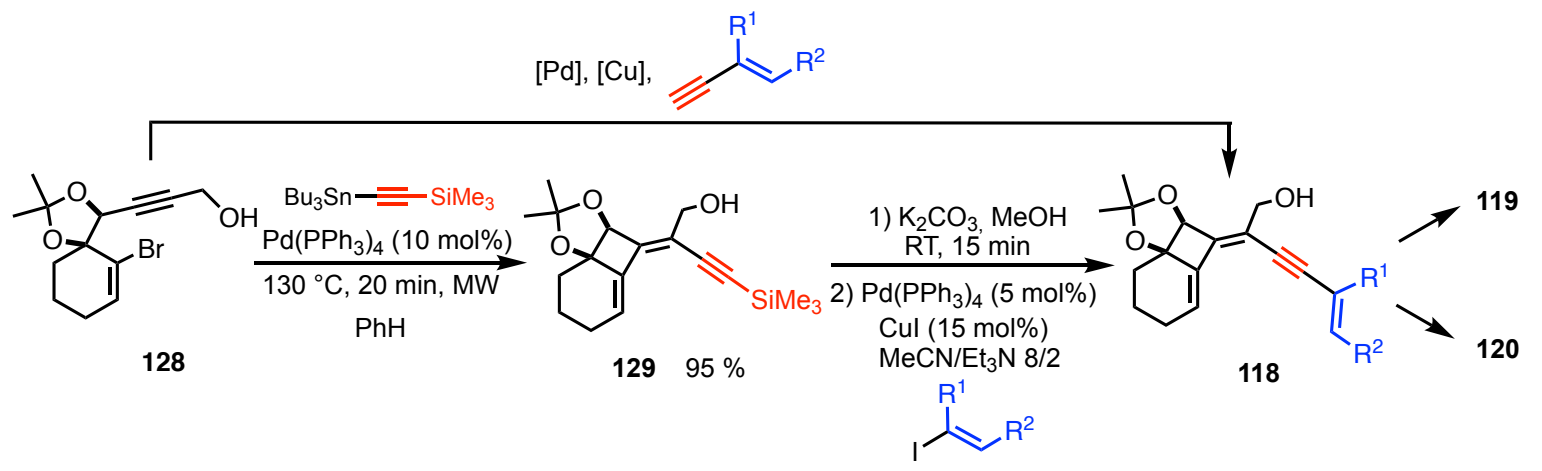

SCHEME 27 New strategies to access fenestradienes 119 and cyclooctatrienes $\mathbf{1 2 0}$

In order to assure a greater variety, the scope of a cascade 4-exo-dig cyclocarbopalladation/Sonogashira cross-coupling was explored. The alkyne used in the optimization study was trimethylsilyl acetylene, and the variation parameters were the palladium catalyst, the base and solvent (Table 2). The highest yield obtained with $\mathrm{Pd}\left(\mathrm{PPh}_{3}\right)_{4}$ as catalyst and $\mathrm{Et}_{3} \mathrm{~N}$ as solvent was $66 \%$ (entry 3). With such system, the conversion could not be improved even when the temperature was increased to $130{ }^{\circ} \mathrm{C}$. Other catalysts were screened: $\mathrm{Pd}\left(\mathrm{PPh}_{3}\right)_{2} \mathrm{Cl}_{2}$ never allowed a complete conversion (entries 5 to 11) whereas $\mathrm{Pd}(\mathrm{OAc})_{2}$ did. Combined with triphenylphosphine, palladium acetate in diisopropylamine as a solvent and starting material 128, $91 \%$ of the desired product 129 was isolated (entry 13). These optimized conditions were used to extend the method through different examples.

TABLE 2<smiles>CC1(C)OC(C#CCO)C2(CCCC=C2Br)O1</smiles>

128

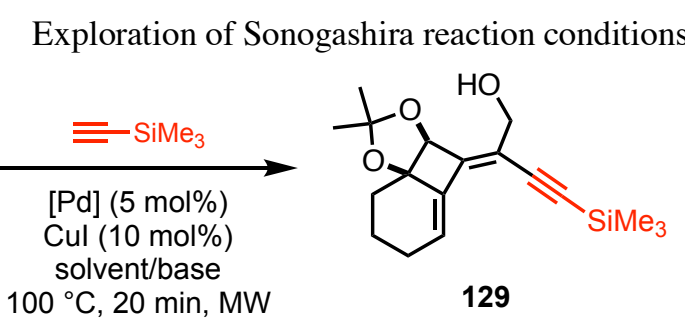




\begin{tabular}{|c|c|c|c|}
\hline Entry & {$[\mathrm{Pd}]$} & Base/Solvent & Yield (\%) 129 (128) \\
\hline 1 & $\mathrm{Pd}\left(\mathrm{PPh}_{3}\right)_{4}$ & $i-\mathrm{Pr}_{2} \mathrm{NH} / \mathrm{PhH}: 1 / 2$ & $34(56)$ \\
\hline 2 & $\mathrm{Pd}\left(\mathrm{PPh}_{3}\right)_{4}$ & $\mathrm{Et}_{3} \mathrm{~N} / \mathrm{PhH}: 1 / 2$ & $49(27)$ \\
\hline 3 & $\mathrm{Pd}\left(\mathrm{PPh}_{3}\right)_{4}$ & $\mathrm{Et}_{3} \mathrm{~N}^{\mathrm{a})}$ & $66(13)$ \\
\hline 4 & $\mathrm{Pd}\left(\mathrm{PPh}_{3}\right)_{4}$ & $i-\operatorname{Pr}_{2} \mathrm{NEt}^{\mathrm{a})}$ & $13(49)$ \\
\hline 5 & $\mathrm{Pd}\left(\mathrm{PPh}_{3}\right)_{2} \mathrm{Cl}_{2}$ & $i-\mathrm{Pr}_{2} \mathrm{NH} / \mathrm{PhH}: 1 / 2$ & $45(36)$ \\
\hline 6 & $\mathrm{Pd}\left(\mathrm{PPh}_{3}\right)_{2} \mathrm{Cl}_{2}$ & $\mathrm{Et}_{3} \mathrm{~N} / \mathrm{PhH}: 1 / 2$ & $42(35)$ \\
\hline 7 & $\mathrm{Pd}\left(\mathrm{PPh}_{3}\right)_{2} \mathrm{Cl}_{2}$ & $i-\mathrm{Pr}_{2} \mathrm{NH} / \mathrm{THF}: 1 / 2$ & $32(28)$ \\
\hline 8 & $\mathrm{Pd}\left(\mathrm{PPh}_{3}\right)_{2} \mathrm{Cl}_{2}$ & $i$ - $\operatorname{Pr}_{2} \mathrm{NEt} / \mathrm{PhH}: 1 / 2$ & $13(68)$ \\
\hline 9 & $\mathrm{Pd}\left(\mathrm{PPh}_{3}\right)_{2} \mathrm{Cl}_{2}$ & $i-\operatorname{Pr}_{2} \mathrm{NH}^{\mathrm{a})}$ & $71(14)$ \\
\hline 10 & $\mathrm{Pd}\left(\mathrm{PPh}_{3}\right)_{2} \mathrm{Cl}_{2}$ & $\mathrm{Et}_{3} \mathrm{~N}^{\mathrm{a})}$ & $20(56)$ \\
\hline 11 & $\mathrm{Pd}\left(\mathrm{PPh}_{3}\right)_{2} \mathrm{Cl}_{2}$ & Pyrrolidine $^{\text {a) }}$ & degradation \\
\hline 12 & $\mathrm{Pd}(\mathrm{OAc})_{2} / \mathrm{PPh}_{3}: 1 / 2$ & $\mathrm{Et}_{3} \mathrm{~N}^{\mathrm{a})}$ & $32(58)$ \\
\hline 13 & $\mathrm{Pd}(\mathrm{OAc})_{2} / \mathrm{PPh}_{3}: 1 / 2$ & $i-\operatorname{Pr}_{2} \mathrm{NH}^{\mathrm{a})}$ & 91 \\
\hline
\end{tabular}

a) Solvent as base

The cascade reaction with aromatic and aliphatic alkynes afforded the corresponding dienynes 129a-m in high yields (Scheme 28).<smiles></smiles>

128
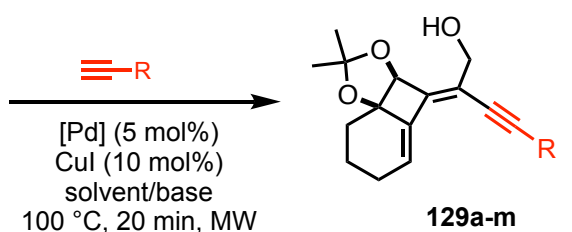

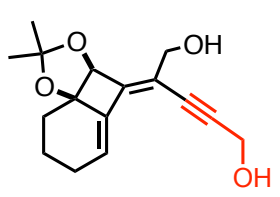

129a $74 \%(60 \mathrm{~min})$

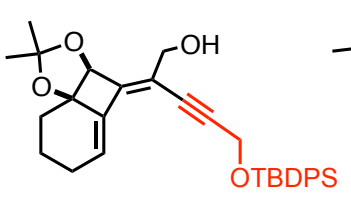

129b $80 \%$

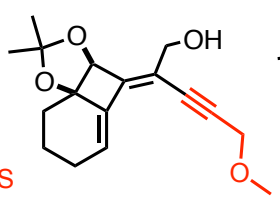

129c $70 \%$

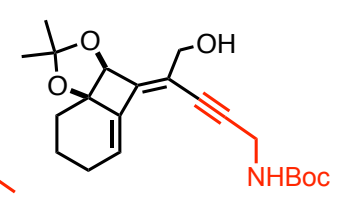

129d $93 \%$ (60 min)

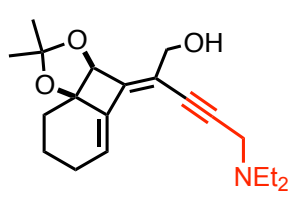

129e $69 \%(60 \mathrm{~min})$<smiles>CC#CC(CO)=C1C2=CCCCC23OC(C)(C)OC13</smiles><smiles>CC1(C)OC2/C(=C(/C#CCC[OH+])CO)C3=CCCCC32O1</smiles>

129g $91 \%$

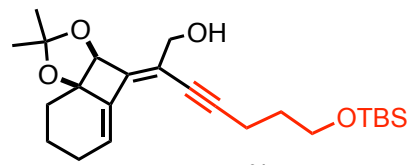

129h $94 \%$

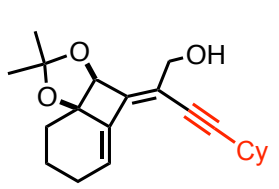

129i $68 \%$<smiles>CC1(C)C=C2CCCCC(O1)C2=C(C#CCCl)CO</smiles>

129j $85 \%$<smiles>CC1(C)OC2CCCC(=C(C#CCCc3ccccc3)CO)C2O1</smiles>

129k $81 \%$<smiles>CC1(C)OC2C(=C(O)C#Cc3ccccc3)C3=CCCCC3OC21</smiles>

129I $84 \%$

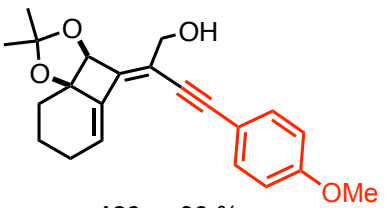

$129 \mathrm{~m} 88 \%$

SCHEME 28 Scope of the cascade 4-exo-dig cyclocarbopalladation/Sonogashira cross-coupling

After demonstrating the scope offered by the starting material 128 with various alkyne derivatives, the 4-exo-dig/Sonogashira cascade was next examined on enynes, alkynyl imine and oxime (Scheme 29). Trienynes of type $\mathbf{1 3 0}$ were available with this process in good yields (64-83\%). This represents a faster access to fenestradienes. Only a one-pot operation is 
required instead of three steps and the use of stannanes is no more necessary. Some new azatrienynes were also obtained from an alkynyl imine and oxime with good yields (64 - $70 \%)$.

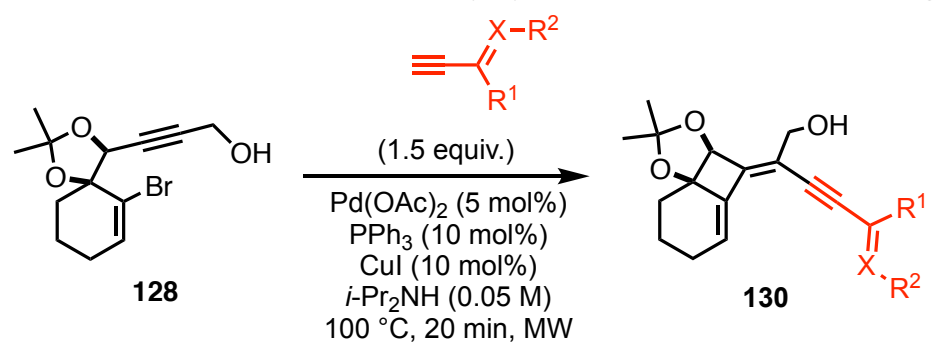

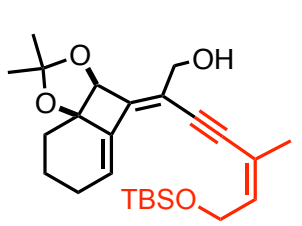

130a $79 \%$

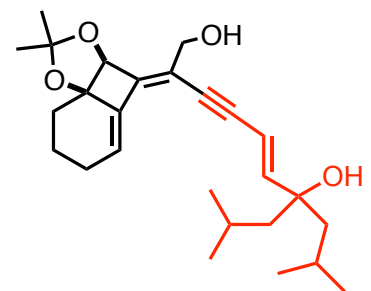

130b $83 \%(60 \mathrm{~min})$

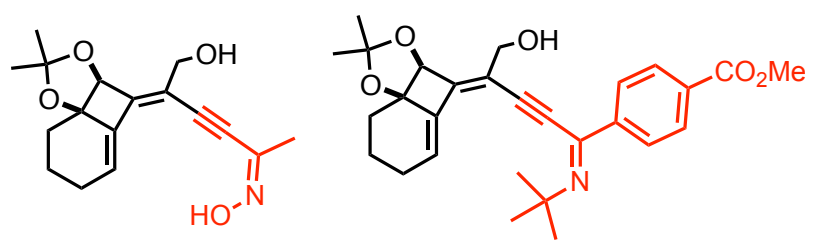

130c $64 \%\left(40 \mathrm{~min}, 130{ }^{\circ} \mathrm{C}\right) \quad 130 \mathrm{~d} 70 \%\left(40 \mathrm{~min}, 130{ }^{\circ} \mathrm{C}\right)$

SCHEME 29 Trienynes and azatrienynes synthesis

\subsection{The second generation of fenestradienes and cyclooctatrienes}

Thereafter, in 2013, following this work, we have reported a palladium-catalyzed one-step procedure that provides facile access to substituted fenestradienes $\mathbf{1 3 1}$ directly from alkenylbromides 128 (Scheme 30). ${ }^{18}$ This process was developed in order to overcome the problems of the use of sensitive nickel(0) catalyst, hydrogen and stannane, and the polymerization problems with some trienynes $\mathbf{1 1 8}$ if not subjected to appropriate care.

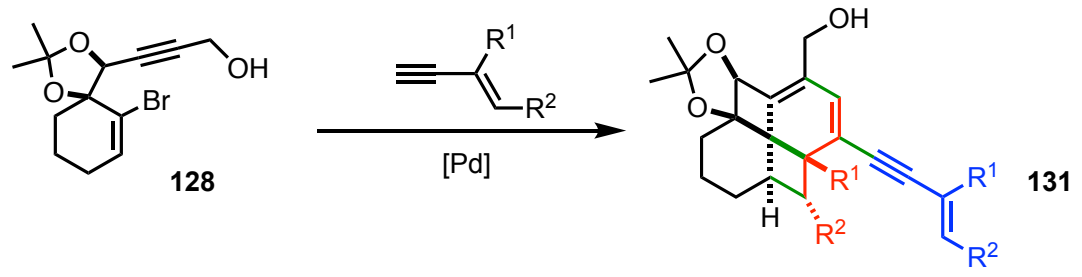

SCHEME 30 2nd generation of fenestradienes

Our approach was inspired by Trost et coll. works concerning the selective synthesis of headto-tail enynes in the presence of $\mathrm{Pd}(\mathrm{OAc})_{2}$ and tris(2,6-dimethoxyphenyl)phosphine (TDMPP). ${ }^{19}$ Gevorgyan et coll. have developed as well the head-to-head palladium-catalyzed dimerization of aryl acetylenes, which is catalyzed under analogous conditions. ${ }^{20}$ The high regio- and stereoselectivities of these reactions have been explained by the strong steric influences of the ester group $\mathrm{R}^{2}$ and specific agostic interactions between the ortho proton of the aromatic ring and the palladium, respectively (Scheme 31).

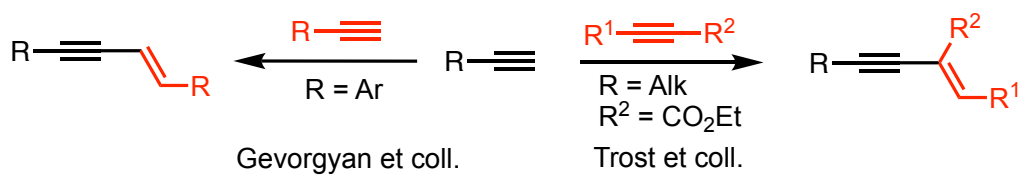

SCHEME 31 Trienynes and azatrienynes synthesis 
According to Trost and Gevorgyan works, we thought that the initial Sonogashira type reaction of the alkenylbromides $\mathbf{1 2 8}$ should easily generate $\mathbf{1 3 2}$ following our recent results. This trienyne 132 could be subjected to a regioselective alkynylation of a disubstituted triple bond producing the tetraene $\mathbf{1 3 3}$ which undergoes a $8 \pi$ and a $6 \pi$ electrocyclizations giving 131 (Scheme 32).

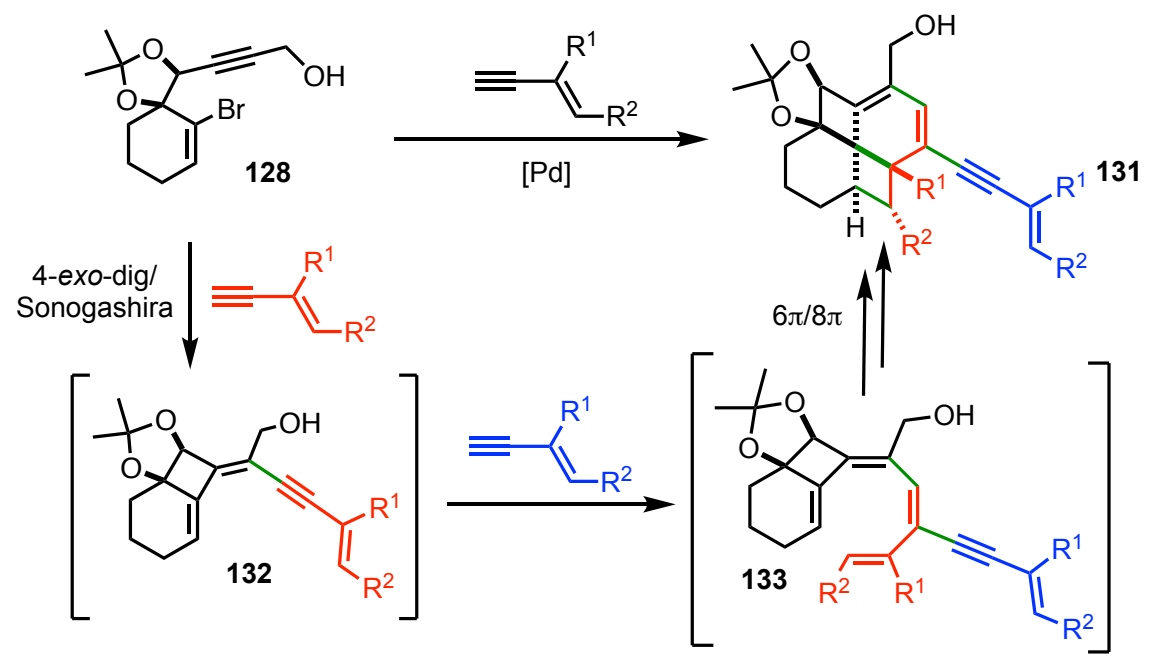

SCHEME 32 New strategies to access the second generation of fenestradienes 131

Drawing on this analysis, we have described the preparation of new types of fenestradienes 131 based on a straightforward, fully controlled introduction of an enyne moiety on a non-activated disubstituted triple bond in a one-pot operation from the alkenylbromides $\mathbf{1 2 8}$ (Scheme 33).<smiles>CC1(C)OC(C#CCO)C2(CCCC=C2Br)O1</smiles>

128

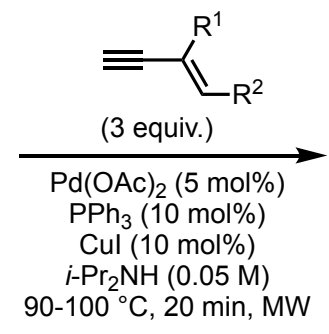

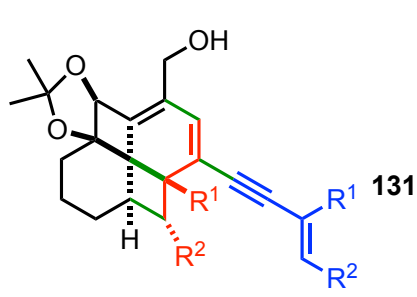

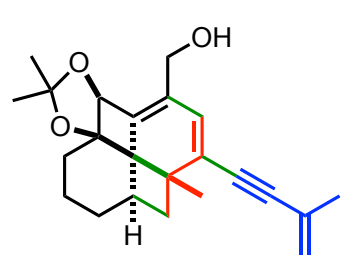

131a $73 \%$

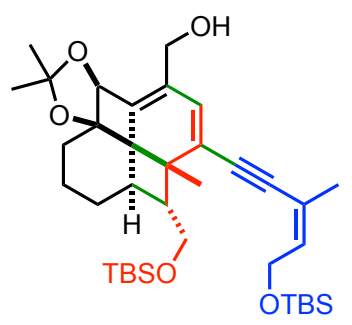

131e $40 \%$

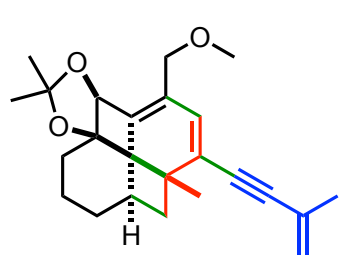

131b $51 \%$

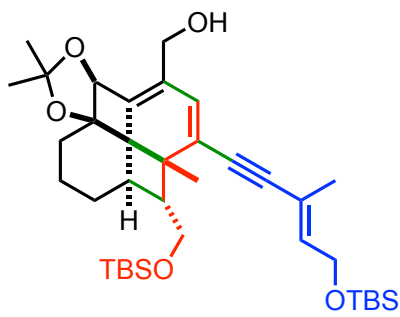

$131 f 72 \%$

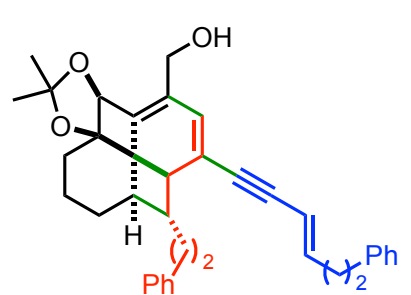

131c $46 \%$ (30 $\mathrm{min})$

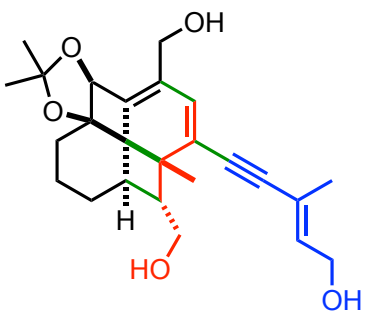

131g $73 \%$

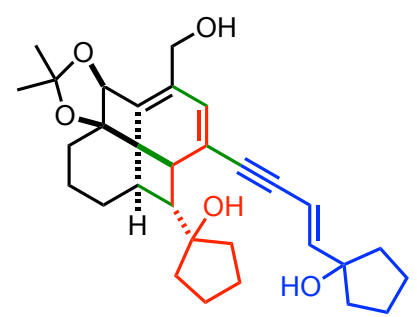

131d $59 \%$

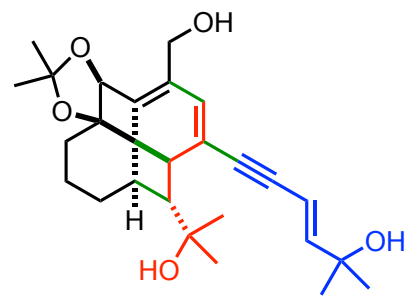

131h $36 \%$ (30 min)

SCHEME 33 Scope of cascade 
All the highly substituted fenestradienes of this new family are reasonably stable at room temperature and do not oxidize and cyclize, as is the case for the first generation products obtained from the P-2 Ni reduction giving fenestrenes 124. They represent the first examples of fenestradienes possessing a conjugated trienyne and incorporate differentiated functionality for further elaboration.

The reaction is stereoselective and only one diastereomer of the [4.6.4.6]fenestradiene was obtained in each case as determined by NOESY experiments. The structures of the [4.6.4.6]fenestradienes 131d were confirmed through NMR and MS studies. Structural confirmation was obtained through X-ray crystallographic analysis of the 3,5-dinitrobenzoate derivative 134 (Scheme 34). This X-ray structure shows interesting features in the significant distortion of the central quaternary carbon atom that is attributable to the size and configuration of the fused rings. The two important orthogonal bonds angles $\alpha$ and $\beta$ are widened to $126^{\circ}$ and $122^{\circ}$, respectively.

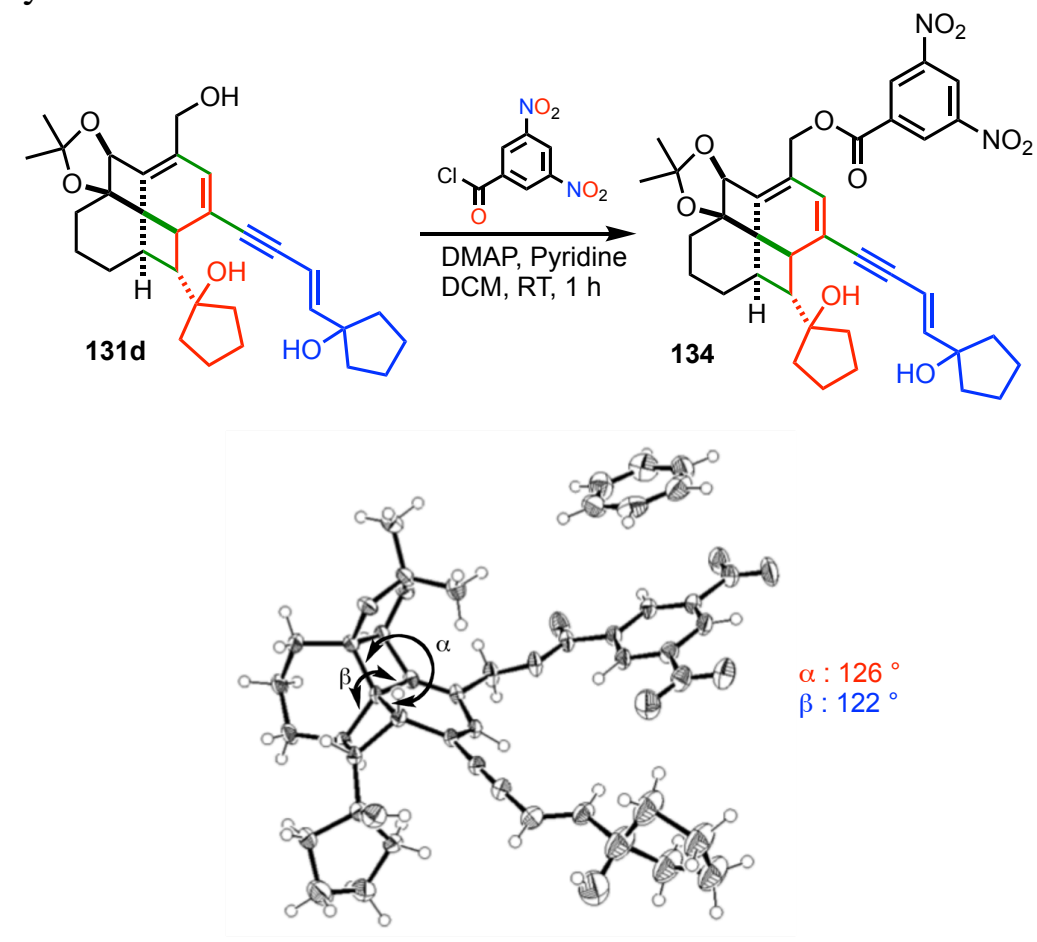

SCHEME 34 X-ray crystal analysis of the 3,5-dinitrobenzoate derivative 134

It is interesting to note that when the reaction of compound 128 was conducted at $130{ }^{\circ} \mathrm{C}$ in the presence of 3 equivalents of the enyne, palladium acetate, $\mathrm{PPh}_{3}$ and copper iodide, the cyclooctatriene 135a was cleanly obtained in very good yield (98\%) without any trace of the corresponding fenestradiene (Scheme 35). As anticipated by our previous observations, the torquoselectivity of this reaction was opposite to the one observed in the formation of the fenestradiene. Undoubtedly, the cyclooctatriene $\mathbf{1 3 5}$ represents the thermodynamically more stable product in this reaction. In order to confirm this hypothesis, the fenestradiene 131a was heated under microwave irradiation at $130{ }^{\circ} \mathrm{C}$ for $30 \mathrm{~min}$ affording 135a in $26 \%$ yield. This low yield can be explained by the unstability of the fenestradiene $135 \mathrm{a}$ at $130^{\circ} \mathrm{C}$. This behavior is general for all other fenestradienes submitted to similar reaction conditions. 


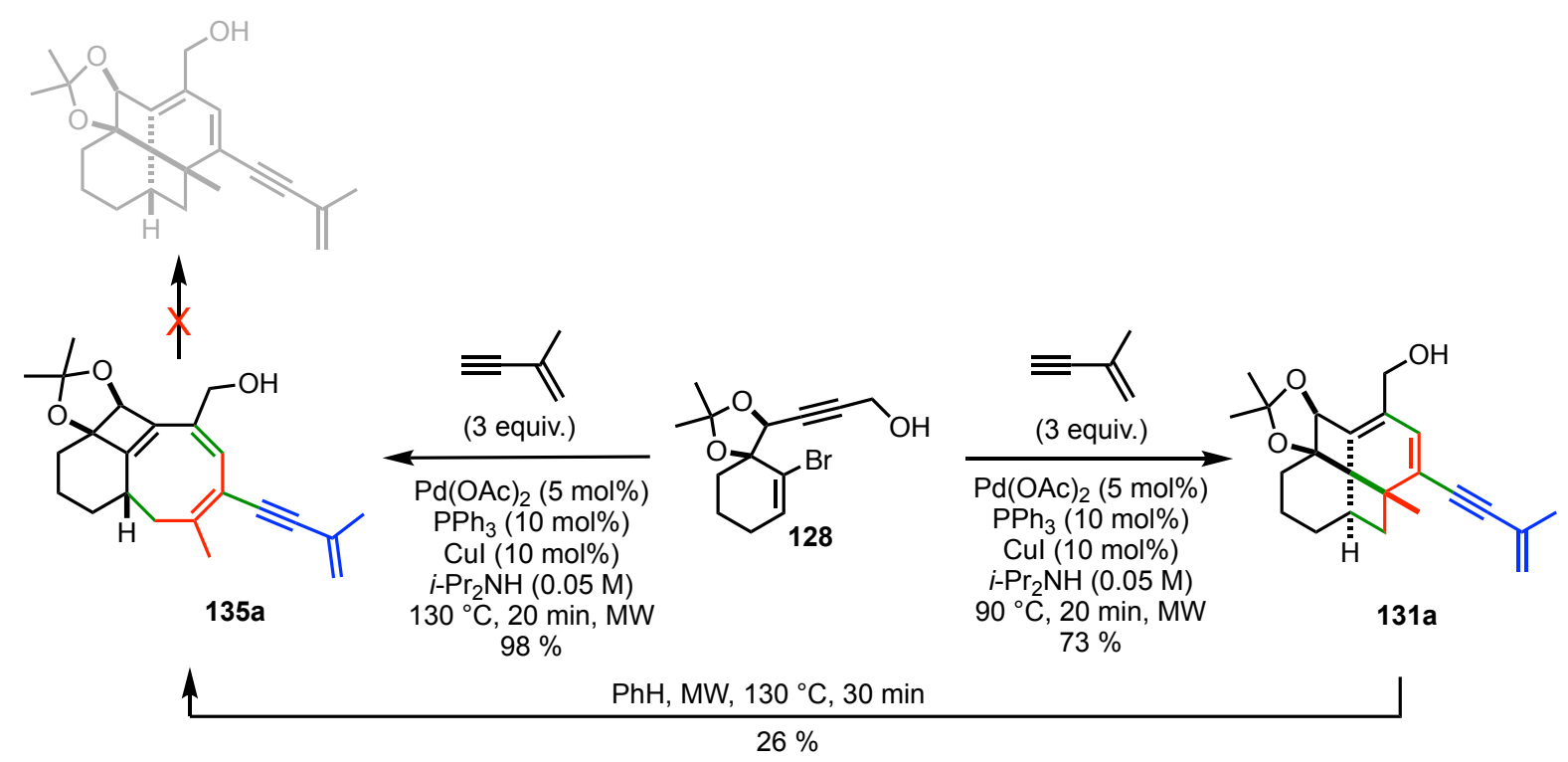

SCHEME 35 Thermodynamic/kinetic control of the reaction.

The reaction was applied on $\mathbf{1 2 8}$ with different enyne substrates (Scheme 36). The yields of this cascade reaction are generally very high if one consider the complexity of the process. For example with enyne $\mathrm{R}^{1}=\mathrm{CH}_{3}$ and $\mathrm{R}^{2}=\mathrm{H}$ a quantitative yield was obtained for compound 135a. In only one case $\left(\mathrm{R}^{1}=\mathrm{CH}_{3}, \mathrm{R}_{2}=\mathrm{CH}_{2} \mathrm{OTBS}\right)$, a disappointing yield of $16 \%$ (135h) was obtained while this one raised to $80 \%(\mathbf{1 3 5 g})$ when the free allylic alcohol was used.<smiles>CC1(C)OC(C#CCO)C2(CCCC=C2Br)O1</smiles>

128<smiles>C=C(C)C#CC1=C(C)CC2CCCC34CC2=C(C1)C3OC(C)(C)O4</smiles>

135a $98 \%$

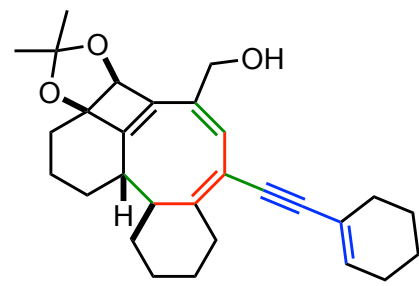

$135 f 77 \%$

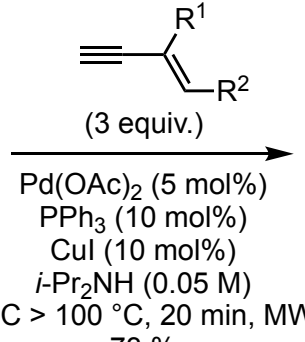
$73 \%$

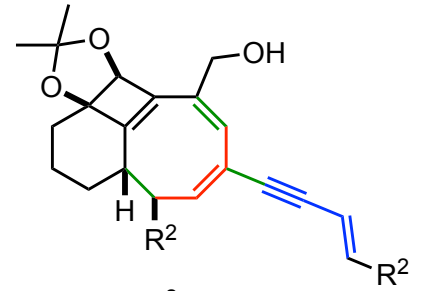

135b $\mathrm{R}^{2}=\mathrm{CH}_{2} \mathrm{CH}_{2} \mathrm{Ph} 59 \%$ 135c $\mathrm{R}^{2}=\left(\mathrm{CH}_{2}\right)_{5} \mathrm{CH}_{3} 72 \%$ 135d $R^{2}=\mathrm{Ph} 68 \%$

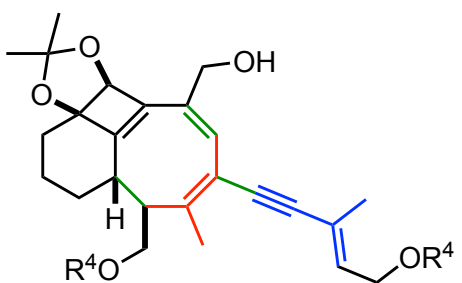

$135 \mathrm{~g} \mathrm{R} \mathrm{R}^{4}=\mathrm{H} 80 \%$ 135h R $\mathrm{R}^{4}=$ TBS $16 \%$

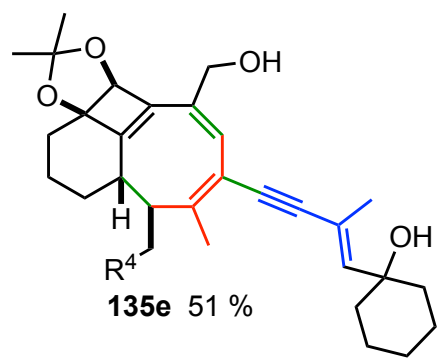<smiles></smiles>

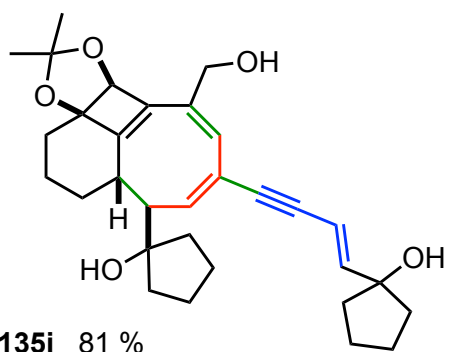

SCHEME 36 Synthesis of $6,4,8$ polycycles 
The reactivity of the seven membered ring 136 were also satisfying and the corresponding tricyclic products 7-4-8 137a-h were synthesized with good yields between 32 and $89 \%$ again considering the complexity of the process (scheme 37 ). The formation of the trienynes issued from a single addition of the enyne moieties were also observed in non-negligible amount rising as a sole product in $95 \%$ yield when $\mathrm{R}^{1}=\mathrm{Me}$ and $\mathrm{R}^{2}=\mathrm{CH}_{2} \mathrm{OTBS}$.

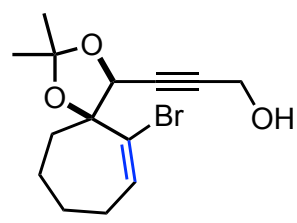

136

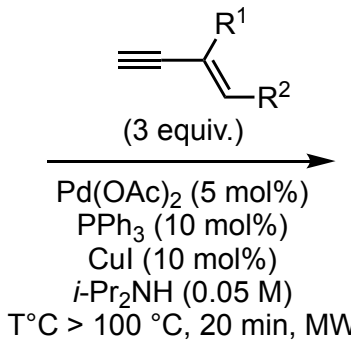

$73 \%$

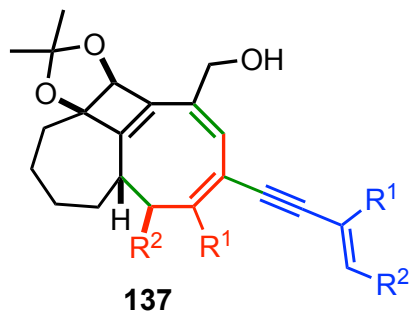

137

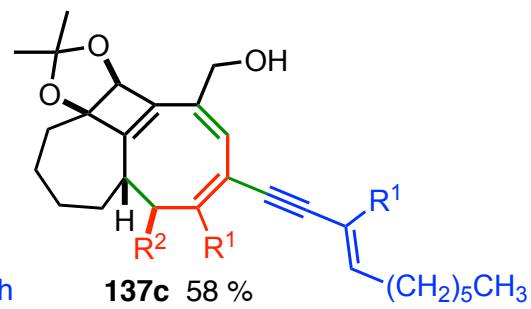

137a $86 \%$

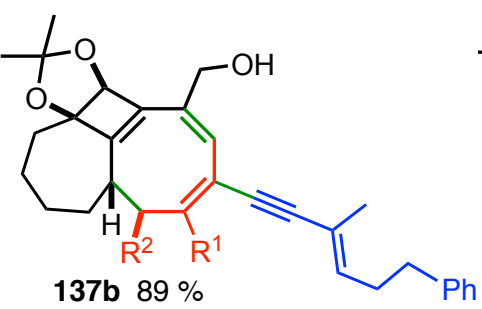

$137 \mathrm{c} 58 \%$

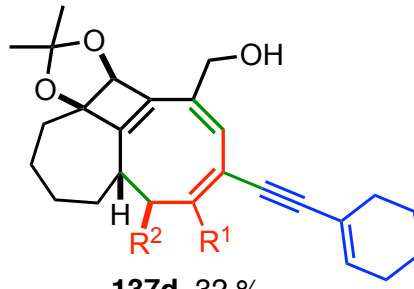

$137 d 32 \%$
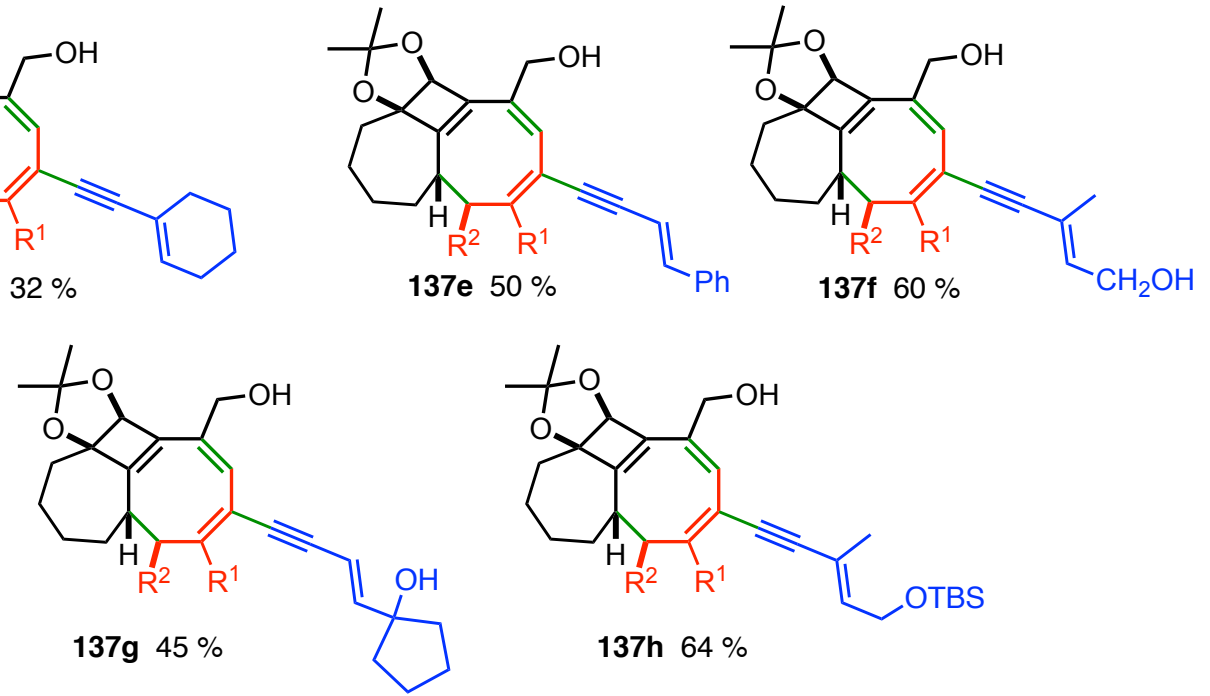

137h $64 \%$

SCHEME 37 Synthesis of cyclooctatrienes 137

\subsection{Conclusion}

During this work on fenestradienes and cyclooctatrienes, we have greatly improved the way of the preparation of these compounds. In the first generation, a four steps process was necessary to obtain fenestradienes 119 and cyclooctatrenes 120 with the use of hydrogen, tin under very delicate experimental conditions, particularly the fragility of the P2-Ni(0). Due to the high sensitity of the trienyne intermediates, it was important to find a new way that exclude the formation of this trienyne. Therefore the second approach, for the synthesis of the second generation of fenestradiene $\mathbf{1 3 1}$ and cyclooctatrenes 135, elegantly solved this problem. Only one step in a one-pot procedure was used to produce these unusual molecules that had no 
precedent in the literature. More interesting was the better stability toward manipulation of the second generation versus the first one.

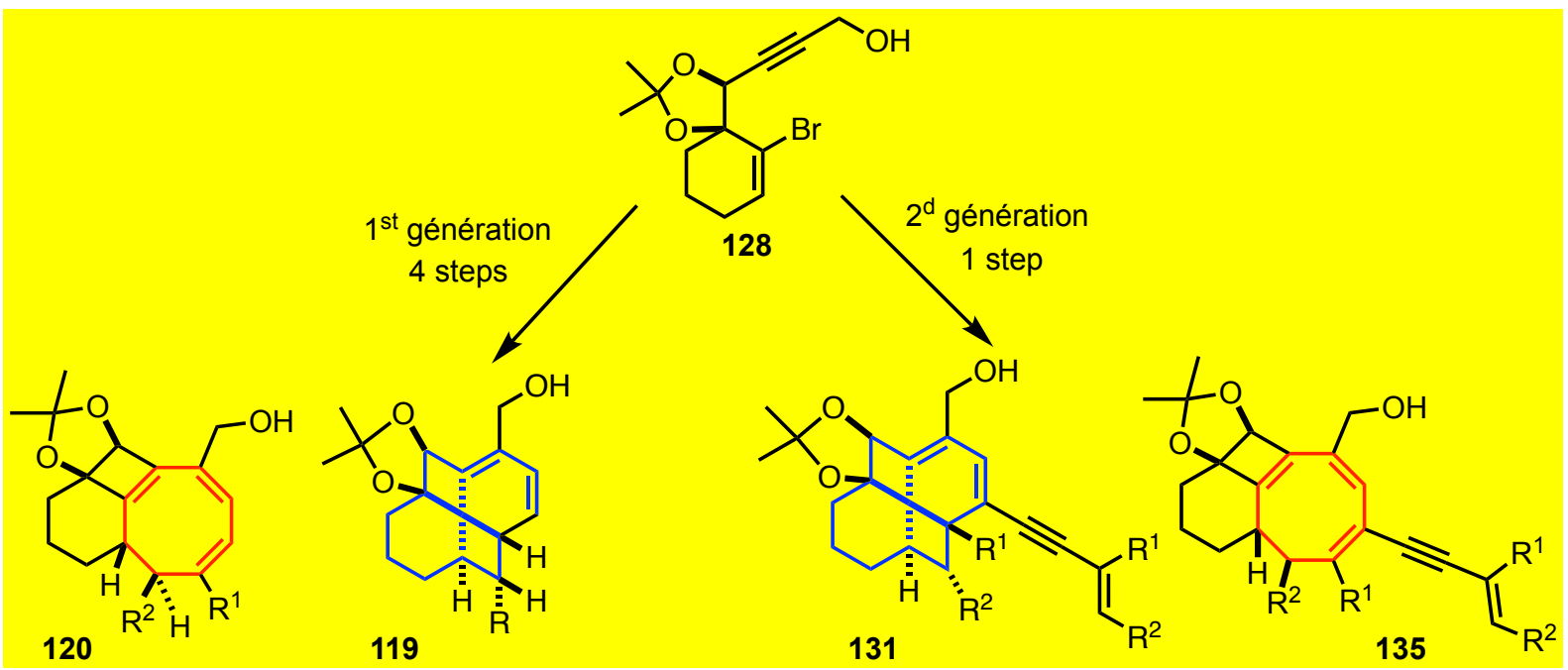

SCHEME 38 First and second generation of fenestradienes and cyclooctatrienes

\section{The 4-exo-dig cyclocarbopalladation in the synthesis of cyclooctatetraenes}

Our next challenge was to introduce four double bonds in eight-membered rings. The obtained structure is a cyclooctatetraene (COT). This motif is hardly represented in Nature, and Caulerpin, a bis-indole alkaloid isolated from algae of the genus Caulerpa, is the only representative. ${ }^{21}$ Nevertheless, COTs display important properties, especially as ligands in the field of metal-catalyzed processes ${ }^{22}$ or in the field of materials. ${ }^{23}$ The development of metal mediated syntheses to access highly substituted COTs has been investigated and when we started our investigation in the field, the challenge was the synthesis of fully substituted, unsymmetrical COTs with structural complexity.

Therefore, in 2016, we reported an efficient palladium-catalyzed cascade reaction for the synthesis of the first examples of octasubstituted unsymmetrical COTs and in 2018, an extension of our process (Scheme 39). ${ }^{24}$
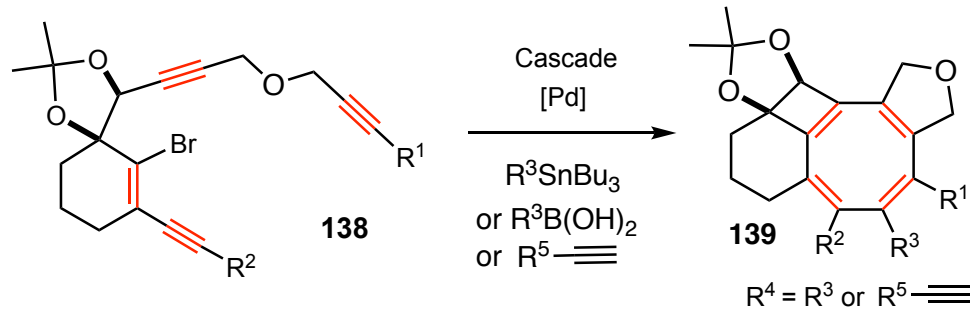

SCHEME 39 Palladium-catalyzed cascade reaction for the synthesis of COTs

\subsection{Stille cross coupling}

In an initial experiment, classical conditions for palladium catalysis were applied simply using $\mathrm{Pd}(\mathrm{OAc})_{2}, \mathrm{PPh}_{3}$ as the ligand and vinyltributylstannane as the simplest tin trapping reagent of the final organopalladium species (Scheme 40). The reaction was conducted under microwave irradiation at $100{ }^{\circ} \mathrm{C}$ in benzene. After full conversion of the starting compound 138a, the COT 
139aa was isolated in $44 \%$ yield. During this process, the side product 140a was also formed. A $2 / 1$ ratio (as determined by ${ }^{1} \mathrm{H}-\mathrm{NMR}$ ) between 139aa and $140 \mathrm{a}$ was observed in the crude reaction mixture indicating a possible competitive pathway during the reaction.

The palladium acetate/triphenylphosphine system provides an excellent conversion but the 2/1 ratio between 139aa and 140a was unsatisfactory. Except for triphenylphosphine, the monodentate ligands triphenylphosphite, tricyclohexylphosphine, tri(ortho-tolyl)phosphine, and tri(2-furyl)phosphine led to low conversion and low selectivity. The use of a bidentate phosphine (such as dppm, dppe, dppp, XantPhos) increased the selectivity but a poor conversion was observed. Next we turned our attention to the bulkier electron-rich dialkylbiaryl phosphines (such as Buchwald type ligands : SPhos, MePhos, DavePhos). SPhos and DavePhos provided the best balance between conversion (up to $100 \%$ with DavePhos) and selectivity $([139 \mathbf{a a} / \mathbf{1 4 0 a}=6 / 1]$ and $[\mathbf{1 3 9} \mathbf{a a} / \mathbf{1 4 0} \mathbf{a}=4 / 1])$. With these systems in hand, the effect of different solvents on the conversion and ratio was tested (DMF, Dioxane, THF, MeCN). Eventually, the use of $\mathrm{Pd}(\mathrm{OAc})_{2}$ with DavePhos in acetonitrile under microwave irradiation proved to be the conditions of choice to obtain 139aa $(53 \%$,) in a 8/1 ratio relative to $140 a$.

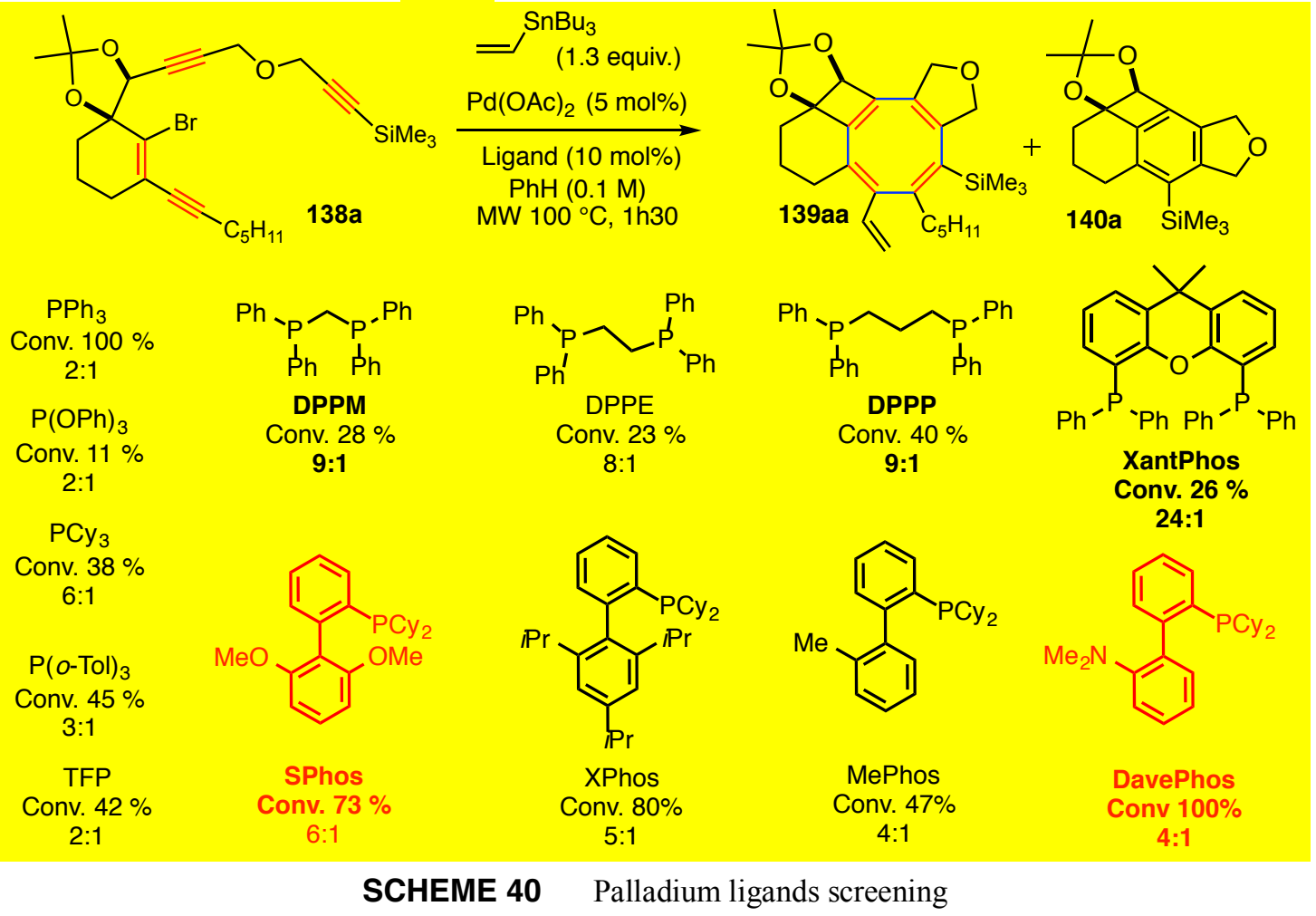

NMR data and other analytical analyses were consistent with the presence of the COT core in these products, and a structural confirmation was obtained by an X-ray crystallographic analysis (Figure 7). The COT framework adopts a boat-like geometry, which minimizes the steric congestion between the dimethyldioxolane, the dihydrofuran moiety and the trimethylsilyl group, and avoids the antiaromaticity that would result from planarity. The rigidity conferred by cyclobutene ring actually precludes the inversion of the COT. Moreover, this X-ray crystal analysis allowed us to determine the location of the four double bonds. It indicates a complete shift of all unsaturations of the starting material during the reaction. The lengths of the single bonds are around $1.47 \AA$, whereas the double bonds are around $1.34 \AA$ (Figure 7). By comparison, in a non-substituted COT, the single bonds are longer $(1.54 \AA)$ while the double bonds are identical in length. 

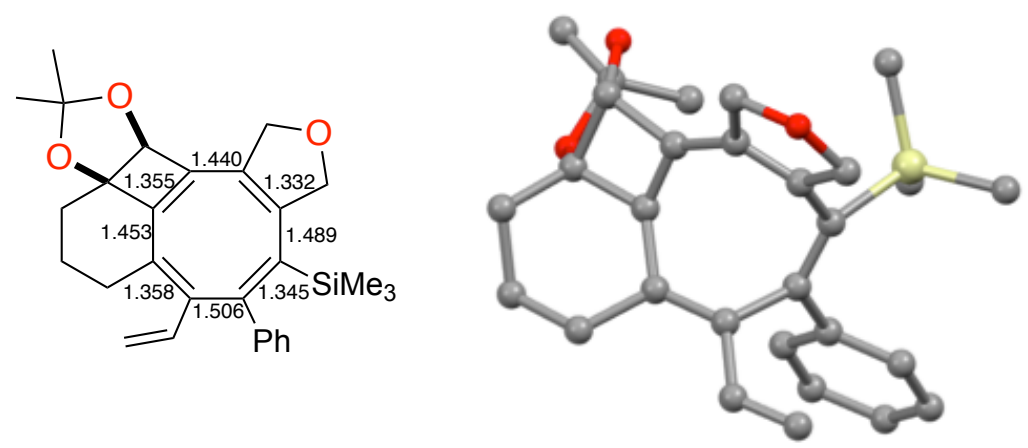

FIGURE $7 \quad \mathrm{X}$-ray crystal analysis of the COT and its bonds length.

The scope and limitations of this reaction were next investigated. The starting compounds of type 138 were prepared and tested under the optimized reaction conditions with various vinyl, allyl, alkenyl and heteroaromatic stannanes $\left(\mathrm{R}^{3} \mathrm{SnBu}_{3}, \mathrm{Pd}(\mathrm{OAc})_{2}(5 \mathrm{~mol} \%)\right.$, DavePhos (10 mol\%), MeCN, MW, $100{ }^{\circ} \mathrm{C}$ ). The side product 140 were actually found in almost all reaction mixtures, yet they proved separable and their yields did not exceed $15 \%$. Isolated yields for the desired compounds 139 range from 18 to 53\% (Scheme 41), which can be considered as good considering the five steps reaction, forming four new $\mathrm{C}-\mathrm{C}$ bonds. 


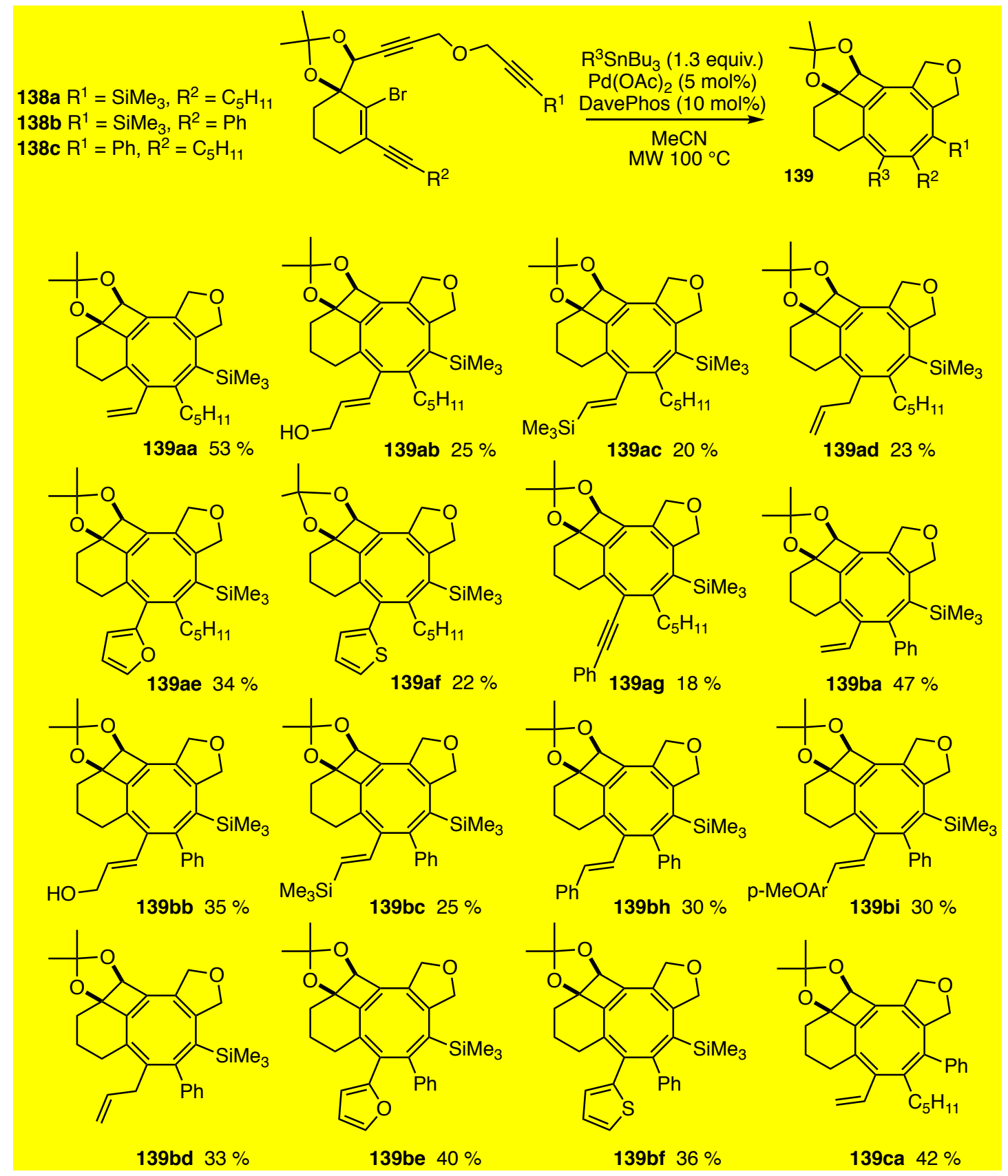

SCHEME 41 Scope of the reaction

Nevertheless, the toxicity of the stannane compounds and their difficulty in purifying residual tin from the products remain a major concern. We were looking for a greener route to form $\mathbf{1 3 9}$ with alternative functionalities by means of a cascade ending with a different type of crosscoupling reaction.

\subsection{Suzuki-Miyaura cross coupling}

In addition to the toxicity of stannane reagents, the introduction of aryl group on the structure was not possible with Stille cross-coupling conditions; therefore a new sequence using SuzukiMiyaura cross-coupling reaction conditions was explored. Different parameters were again tested: the palladium catalyst, the ligand, the base and the solvent mixture (Table 3 ). The base 
first has been varied since it plays an important role in the mechanism of a Suzuki-Miyaura cross-coupling. ${ }^{[5]}$ In the presence of $\mathrm{Na}_{2} \mathrm{CO}_{3}$ or $\mathrm{K}_{3} \mathrm{PO}_{4}$, the reaction was not complete even after $2 \mathrm{~h}$. With $\mathrm{Cs}_{2} \mathrm{CO}_{3}$, the reaction was complete but the yield was modest, around $30 \%$ (entry 1 ). $\mathrm{NaOH}$ leads to the best yield (53\%, entry 2 ) and we observed that adding more water was not suitable for the reaction ( $27 \%$, entry 3 ). Then the influence of the palladium source was evaluated, and $\mathrm{Pd}\left(\mathrm{PPh}_{3}\right)_{4}$ was used without better result (46\%, entry 4). The use of DavePhos, as ligand dramatically decreased the yield of the reaction (14\%, entry 5). THF was replaced by 1,4-dioxane or MeTHF, and did not show a better result (44 and $34 \%$, entries 6-7). Eventually, the use of $\mathrm{Pd}(\mathrm{OAc})_{2} / \mathrm{PPh}_{3}$ with $\mathrm{NaOH}$ in a mixture of THF and water under microwave irradiation proved to be the conditions of choice to obtain $139 \mathbf{d j}$ in good yield.

TABLE 3 Suzuki-Miyaura reaction conditions

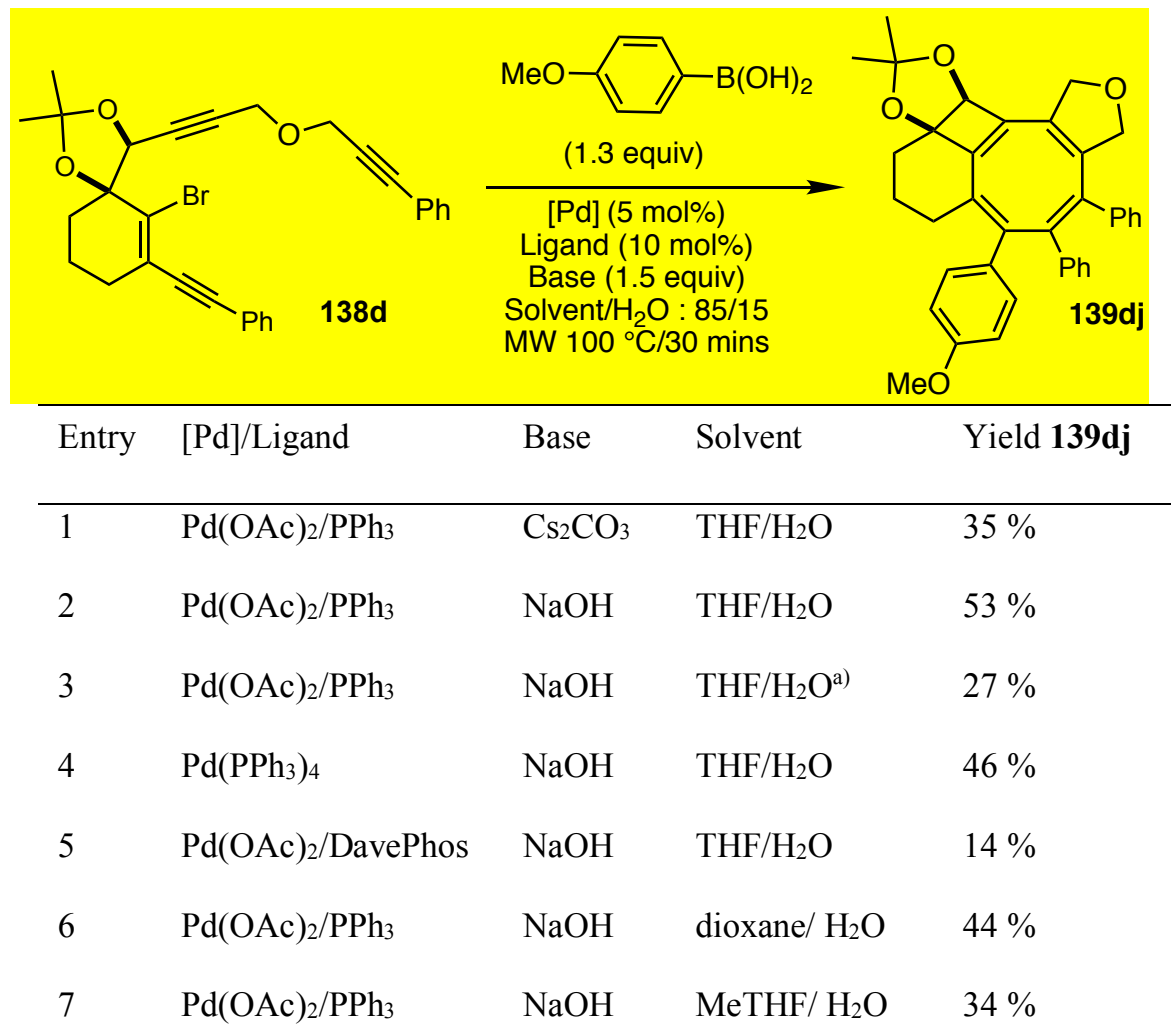

Reaction conditions: [Pd] (5 mol\%), Ligand (10 mol\%), base (1.5 equiv.) and 4-methoxyphenylboronic acid (1.3 equiv), solvent

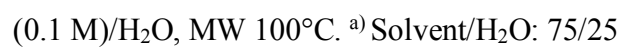

The scope and limitations of these optimized conditions were next investigated. The starting compound 138d was used with various aryl boronic acids. The isolated yields for compounds 139dj-dn range from 15 to $53 \%$ (Scheme 42 ). The presence of a donating group in metaposition of the aryl boronic acid hindered the reaction. This was also the case with an electron withdrawing group in the para position. The side product 140d were actually found in all reaction mixtures, yet they proved separable and their yields ranged between $15 \%$ to $43 \%$. 


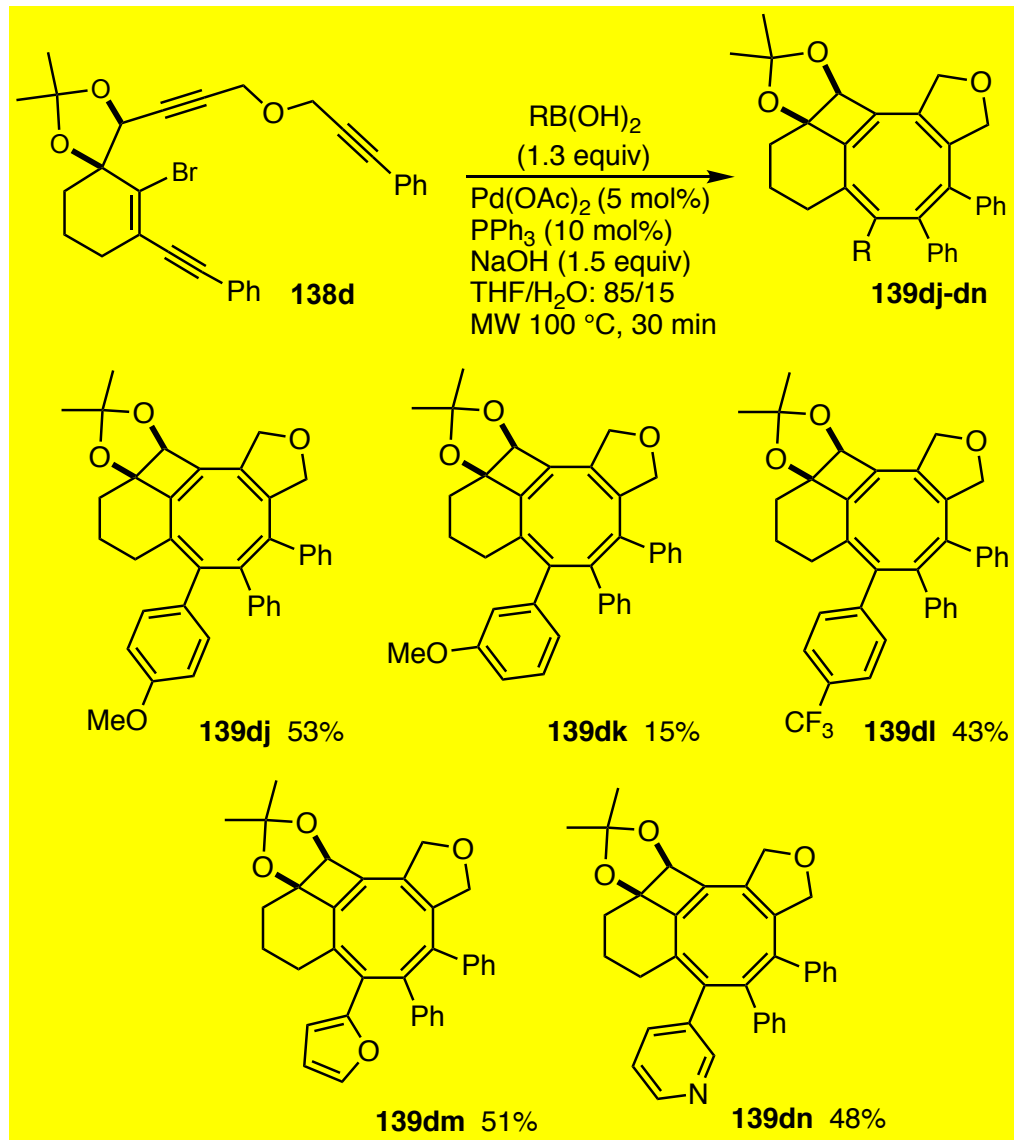

SCHEME 42 Scope of the reaction

\subsection{Sonogashira cross coupling}

During our scope explorations, Stille cross-coupling reaction afforded COTs with low yields when alkynyl stannane were used. That why we investigated a new sequence and we decided to end the cascade reaction with a Sonogashira cross-coupling. This study was carried out with alkenyl bromide 138d. In a preliminary experiment, classical conditions for the palladium catalysis were applied using $\mathrm{Pd}(\mathrm{OAc})_{2}, \mathrm{PPh}_{3}, \mathrm{CuI}$ and trimethylsilyl acetylene as the trapping reagent of the final organopalladium species (Table 4). The reaction was conducted under microwave irradiation at $100{ }^{\circ} \mathrm{C}$ in diisopropylamine. After full conversion of the starting compound 138d, COT 139do was isolated in 58\% yield. During this process, two side products were also formed: the same type of aromatic compound 140d and one another COT 139d. We then decided to optimize the reaction conditions to increase the selectivity towards 139do. The reaction parameters examined were the palladium catalyst, the ligand, the copper and the base. Side products 140d and 139d were observed in almost all reaction mixtures, yet they proved separable and their yield did not exceed $10-15 \%$ for both compounds. Compare to the initial reaction conditions (entry 1), the use of DavePhos, the best ligand used during the previous study, did not give good results, only $32 \%$ of COT 139do was isolated (entry 2). $\mathrm{PdCl}_{2}\left(\mathrm{PPh}_{3}\right)_{2}$ (entry 3) and $\mathrm{Pd}\left(\mathrm{PPh}_{3}\right)_{4}$ (entry 4) gave almost the same result. The reaction was not complete after $30 \mathrm{~min}$ with the use of diisopropylethylamine while it was the case with diisopropylamine (entry 5). With triethylamine, the reaction worked as well as in diisopropylamine (58\%, entry 6). The copper source was also taken into account, and the use of $\mathrm{CuCN}$ showed identical result 
compared to $\mathrm{CuI}$ (entry 7). The presence of a copper source was also essential to enhance the rate of the reaction (entry 1 and 8). Eventually, the use of $\mathrm{Pd}(\mathrm{OAc})_{2} / \mathrm{PPh}_{3}$ with $\mathrm{CuI}$ in diisopropylamine or triethylamine under microwave irradiation proved to be the best conditions to obtain 139do in good yield.

TABLE 4 Screening of the catalytic systems

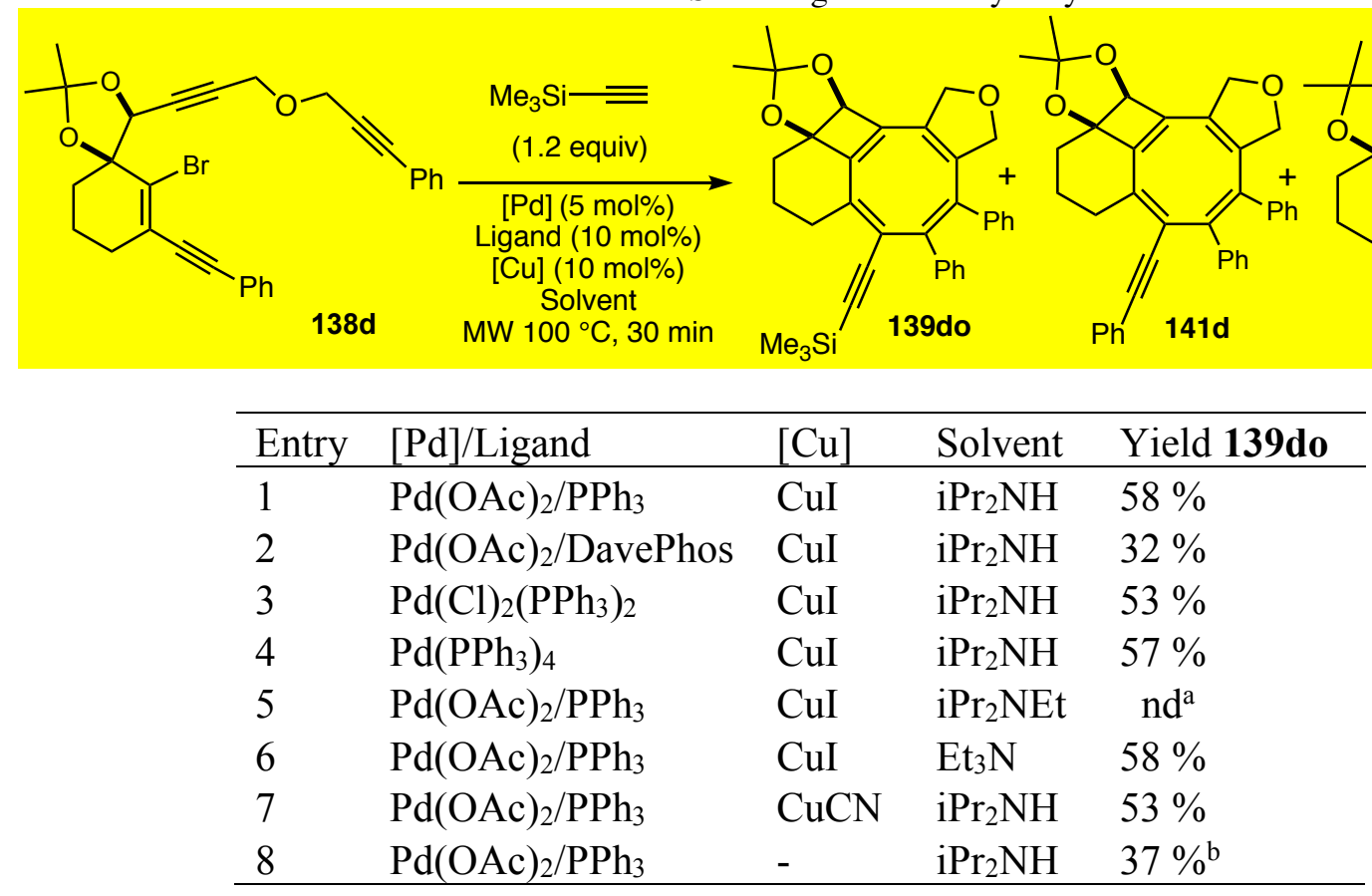

a) not determined, mostly starting material 138d.b) $24 \%$ of $\mathbf{1 3 8 d}$ is recovered.

The scope and limitations of this reaction were next investigated. The starting compound 138d was tested under the optimized reaction conditions with various vinyl, silyl, aryl, alkyl acetylene. COTs was isolated in yields ranging from 50 to $71 \%$ and compared to Stille or Suzuki cross-coupling, undoubtedly Sonogashira cross coupling gave our best yields (Scheme 43). 


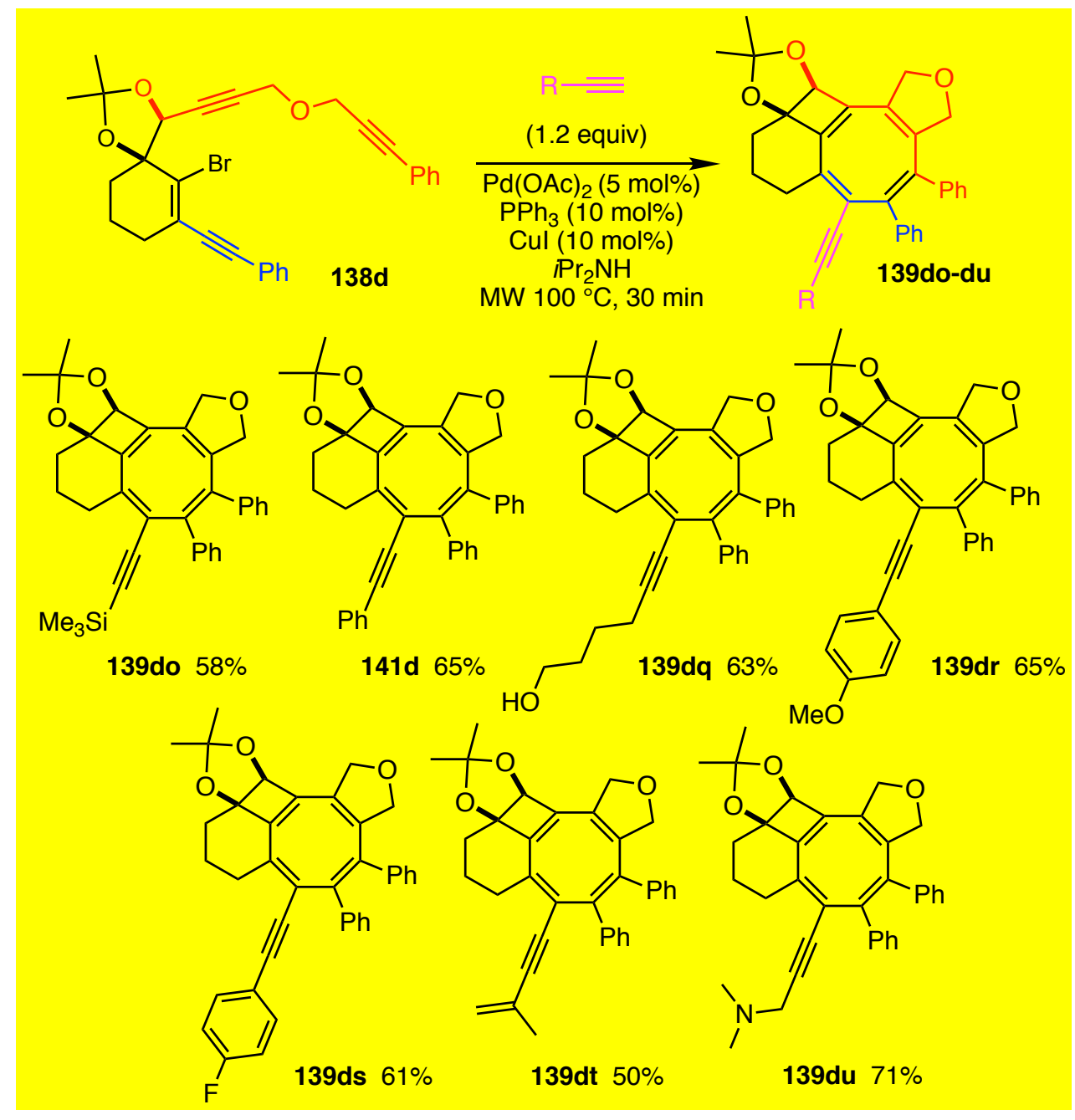

SCHEME 43 Scope of the reaction

\subsection{Mechanisms of the COTs and side product formation}

Three type of products 139, 140 and 141 were observed during this process depending on the reaction conditions. We propose the following mechanism to account for the experimental results (Scheme 44). 


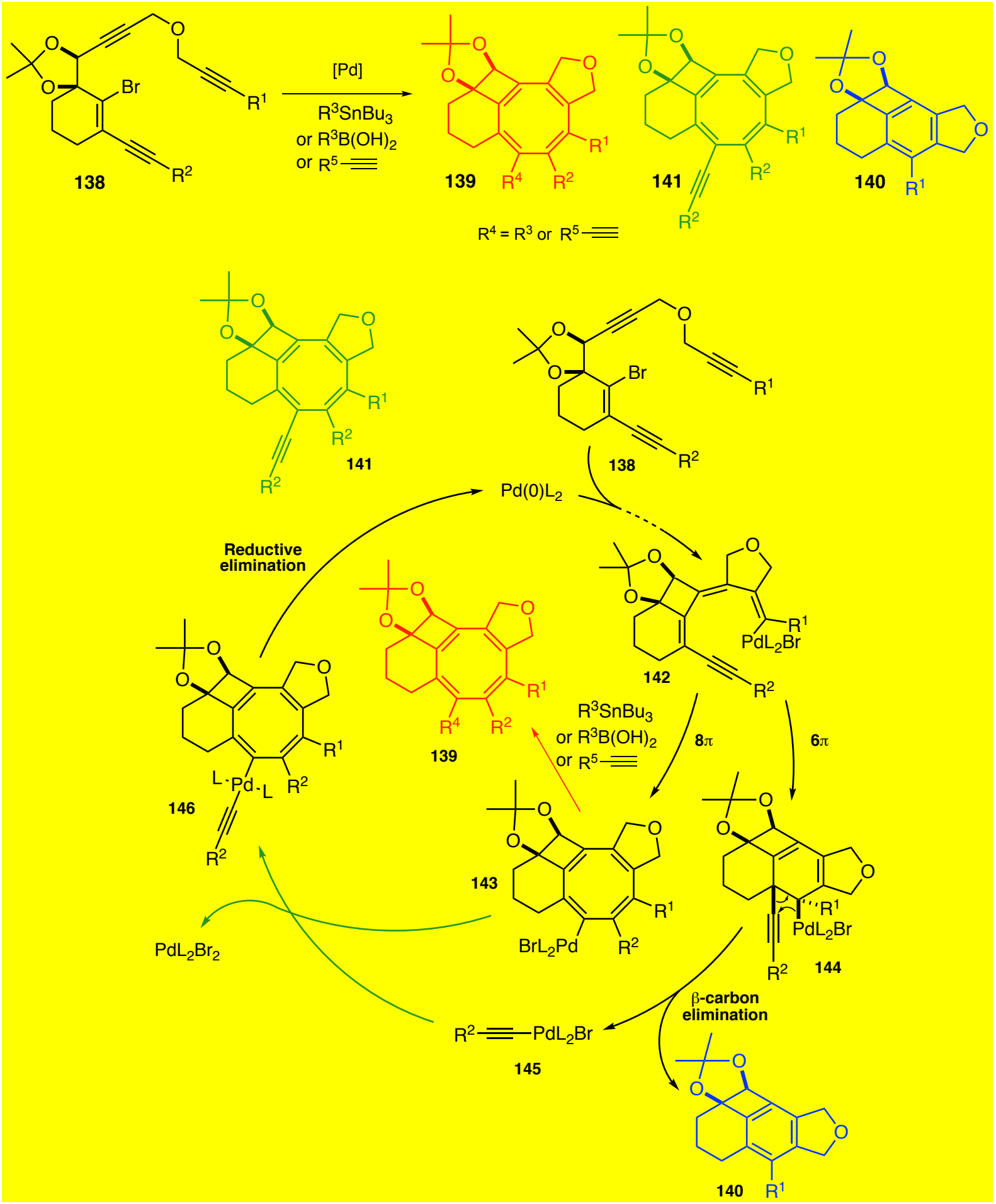

SCHEME $44 \quad$ Proposed mechanism

After oxidative addition of the active palladium species into the $\mathrm{C}-\mathrm{Br}$ bond of $\mathbf{1 3 8}$, a 4-exo-dig and a 5-exo-dig cyclocarbopalladations give intermediate 142. A $8 \pi$-electrocyclization and a $1,3 \pi$-allyl palladium shift takes place to provide $\mathbf{1 4 3}$ followed by a cross coupling reaction leading to the final COT 139.

Complex 142 is supposed to be a common intermediate towards 139 and the side product 140 . To go to 140, it undergoes a $6 \pi$-electrocyclization to give intermediate 144 . This complex 
finally undergoes a $\beta$-carbon elimination giving compound $\mathbf{1 4 0}$ and the alkynyl palladium species 145.

A transmetallation between the two-organopalladium species 143 and 145 gives intermediate 146, that after reductive elimination produces the new COT 141. The presence of the COT 141 also supports the proposed mechanism and confirms the formation of $\mathbf{1 4 0}$ occurring through a unique process of $\beta$-carbon elimination.

It is interesting to note that when Stille or Suzuki cross-coupling reaction conditions are used, compound 141 was not observed while it was not the case with the Sonogashira cross-coupling. That means that the transmetallation of a stannane or a boronic acid is faster than a transmetallation of an alkynyl palladium specie.

\subsection{Conclusion}

In conclusion, we have proposed three routes for the formation of fully substituted cyclooctatetraenes: cyclocarbopalladations followed by an $8 \pi$-electrocyclization and ended either by Stille, Sonogashira or Suzuki-Miaura cross-couplings. These approaches present the advantage of extending the structural diversity of fully substituted unsymmetrical COT. The reaction proceeds in a one-pot operation, where three new rings and four bonds are formed.

\section{General Conclusion}

We have shown that the 4-exo-dig cyclocarbopalladation reaction is a fantastic tools for producing complexity in short and very efficient ways from very simple starting material. The preparations of many unusual polycyclic molecules described above are all the consequences of several impressive cascade reactions trigger by this unique 4-exo-dig reaction. Four membered ring, strained aromatic derivatives, taxane scaffolds, cyclooctatrienes, cycloctatetraenes, fenestradienes and fenestrenes were all obtained, many in very high yields and with always high stereoselectivities by this "magic reaction ». We have been able to understand the mechanistic aspect of all the routes which have been used to afford these products. We probably didn't explore all the power of the 4-exo-dig reaction and a lot of efforts are still necessary to discover new application of this tool.

\section{References}

1. For reviews on palladium cascade reactions see: (a) de Meijere A.; Meyer, F. E. Angew. Chem., Int. Ed. Engl. 1994, 33, 2379-2411. (b) Bräse, S.; de Meijere, A. In Metal-Catalysed Cross Coupling Reaction; Stang, P. J., Diederich, F., Eds.; Wiley-VCH: Weiheim, Germany, 1997. (c) Grigg, R.; Major, J. P.; Martin, F. M.; Whittake M. Tetrahedron Lett. 1999, 40, 7709-7712.

2. (a) Mizoroki, T.; Mori, K.; Ozaki, A. Bull.Chem. Soc.Jpn. 1971, 44, 581; (b) Heck, R. F.; Nolley, J. P. J. Org. Chem. 1972, 37, 2320; (c) Burns, B.; Grigg, R.; Sridharan, V.; Worakun, T. etrahedron Lett. 1988, 29, 4325; (d) von Zezschwitz, P.; Petry, F.; de Meijere, A. Chem. Eur. J. 2001, 7, 4035; (e) de Meijere, A.; Meyer, F. E. Angew. Chem., Int. Ed. 1994, 33, 2379; (f) Malacria, M. Chem. Rev. 1996, 96, 289; (g) Yu, H.; Richey, R. N.; Carson, M. W.; Coghlan, M. J. Org. Lett. 2006, 8, 1685.

3. (a) Wender, P. A.; Miller, B. L. Org. Synth. Theory Appl. 1993, 2, 27. (b) Bertz, S. H.; Sommer, 
T. J. Org. Synth. Theory Appl. 1993, 2, 67. (c) Malacria, M. Chem. Rev. 1996, 96, 289-306. (d) Ang, K. H.; Bräse, S.; Steinig, A. G.; Meyer, F. E.; Llebaria, A.; Voigt, K.; de Meijere A. Tetrahedron 1996, 52, 11503-11528. (e) Henniges, H.; Meyer, F. E.; Schick, U.; Funke, F.; Parsons, P. J.; de Meijere, A. Tetrahedron 1996, 52, 11545-11578.

4. (a) Burns, B.; Grigg, R.; Sridharan, V.; Worakun, T. Tetrahedron Lett. 1988, 29, 4325; (b) Burns, B.; Grigg, R.; Ratananukul, P.; Sridharan, V.; Stevenson, P.; Sukirthalingam, S.; Worakun, T. Tetrahedron Lett. 1988, 29, 5565- ; (c) Burns, B.; Grigg, R.; Sridharan, V.; Stevenson, P. Tetrahedron Lett. 1989, 30, 1135-

5. (a) Zhang, Y.; Negishi, E. J. Am. Chem. Soc. 1989, 111, 3454; (b) Negishi, E.; Noda, Y.; Lamaty, F.; Vawter, E. Tetrahedron Lett. 1990, 31, 4393

6. Suffert, J.; Salem, B.; Klotz, P. J. Am. Chem. Soc. 2001, 123, 12107-12108

7. Salem, B.; P. Klotz, P.; J. Suffert, J. Org. Lett., 2003, 5, 845-848

8. Salem, B.; P. Klotz, P.; J. Suffert Synthesis 2004, 2, 298-307; Bour, C.; Blond, G.; Salem, B.; Suffert, J. Tetrahedron 2006, 62, 10567-10581

9. Bour, C. ; Suffert, J. Eur. J. Org. Chem. 2006, 1390-1395

10. Lauer, U.; Anke, T.; W. S. Sheldrick, W. S. J. Antibiot. 1989, 42, 875

11. (a) Nozoe, S.; Morisaki, M.; Tsuda, K.; Iitaka, Y.; Takahashi, N.; Tamura, S.; Ishibashi, K.; Shirasaka, M. J. Am. Chem. Soc. 1965, 87, 4968; (b) Erguang, L.; Clark, A. M.; Rotella, D. P.; Hufford, C. D. J. Nat. Prod. 1995, 58, 74-81.

12. Lautens, M.; Smith, N. D.; Ostrovsky, D. J. Org. Chem. 1997, 62, 8970 - 8971

13. Salem, B.; P. Klotz, P.; J. Suffert, Angew. Chem. Int. Ed. 2004, 43, 2826 -2829

14. (a) Hulot, C.; Blond, G.; Suffert, J. J. Am. Chem. Soc. 2008, 130, 5046 - 5047. (b) Hulot, C.; Amiri, S.; Blond, G.; Schreiner, P. R.; Suffert, J. J. Am. Chem. Soc. 2009, 131, 13387-13398.

15. Boudhar, A.; Charpenay, M.; Blond, G.; Suffert, J. Tetrahedron 2013, 52, 12786-12798.

16. Das, D.; Chakraborty, T. K. Tetrahedron Lett 2016, 57, 3665-3677.

17. Hulot, C.; Peluso, J.; Blond, G.; Muller, C. D.; Suffert, J. Bioorg. Med. Chem. Lett. 2010, 20, 6836-6839.

18. Charpenay, M.; Boudhar, A.; Hulot, C.; Blond, G.; Suffert, J. Tetrahedron 2013, 69 (36), 7568 7591.

19. Trost, B. M.; Gunzner, J. L.; Yasukata, T. Tetrahedron Lett. 2001, 42, 3775-3778.

20. Rubina, M.; Gevorgyan, V. J. Am. Chem. Soc. 2001, 123, 11107-11108.

21. Avalcante-Silva, L. H. A.; Correia, A. C. de C.; Sousa, J. C. F.; Barbosa-Filho, J. M.; Santos, B. V. de O.; de Miranda, G. E. C.; Alexandre-Moreira, M. S.; Cavalcante, F. de A. Nat. Prod. Res. 2016, 30, 2605-2610.

22. Hirano, M.; Komine, N.; Arata, E.; Gridneva, T.; Hatori, A.; Kaizawa, N.; Kamakura, K.; Kuramochi, A.; Kurita, S.; Machida, S.; Okada, H.; Sawasaki, A.; Uchino, T. Tetrahedron Lett. 2019, 60, 150924.

23. Urieta-Mora, J.; Krug, M.; Alex, W.; Perles, J.; Fernández, I.; Molina-Ontoria, A.; Guldi, D. M.; Martín, N. J. Am. Chem. Soc. 2020, 142, 4162-4172.

24. (a) Blouin, S.; Gandon, V.; Blond, G.; Suffert, J. Angew. Chem., Int. Ed. 2016, 55 (25), 72087211. b) Blouin, S.; Pertschi, R.; Schoenfelder, A.; Suffert, J.; Blond, G. Adv. Synth. Cat. 2018, $360,2166-2171$. 